Portland State University

PDXScholar

Winter 3-13-2019

\title{
Racial Disparities in a State Based Workers' Compensation System
}

Caroline Kristine Smith

Portland State University

Follow this and additional works at: https://pdxscholar.library.pdx.edu/open_access_etds

Part of the Public Health Commons, and the Sociology Commons Let us know how access to this document benefits you.

\section{Recommended Citation}

Smith, Caroline Kristine, "Racial Disparities in a State Based Workers' Compensation System" (2019). Dissertations and Theses. Paper 4831.

https://doi.org/10.15760/etd.6707

This Dissertation is brought to you for free and open access. It has been accepted for inclusion in Dissertations and Theses by an authorized administrator of PDXScholar. Please contact us if we can make this document more accessible: pdxscholar@pdx.edu. 
Racial Disparities in a State Based Workers' Compensation System

by

Caroline Kristine Smith

A dissertation submitted in partial fulfillment of the requirements for the degree of

\author{
Doctor of Philosophy \\ in \\ Sociology
}

Dissertation Committee: Matthew Carlson, Chair Hyeyoung Woo

Alex Stepick

Carlos Crespo

Portland State University 2019 


\begin{abstract}
Racial, ethnic, and linguistic minority workers suffer higher rates of work-related injuries and illnesses in the United States compared to their White counterparts. Explanations for these higher rates include potential socioeconomic causes (education, income, and wealth) and occupational segregation into more dangerous occupations. What is less studied are the post-injury sequelae for minority workers, which is their experiences in the workers' compensation system, as well as their health and return to paid employment. What is known comes primarily from qualitative literature, which includes themes of racial discrimination (from employers, health care providers, and workers' compensation employees), a lack of information on how to navigate the workers' compensation system, and linguistically inappropriate communication with those whose first language is not the majority language. In addition, qualitative studies have found differences in the treatment of minority workers, delays in receiving partial wage payments, and worse health outcomes. Most studies examining minority workers in the workers' compensation system have not provided a theoretical framework from which to test hypotheses as to why differences exist in a social insurance system based on race, ethnicity, and language. The purpose of this dissertation was to test the role of racial discrimination in creating worse post-injury workers' compensation outcomes for minorities, compared to English speaking Whites. This dissertation utilized fundamental cause theory to frame the hypotheses and analyses in a cross-sectional investigation of differences in workers' compensation system outcomes, using both administrative data from the workers' compensation agency, as well as survey responses from a sample of 488 injured workers
\end{abstract}


in Washington State. The survey, conducted by Washington State University Social and Economic Science Research Center (SESRC), provided many variables not available in the WC administrative data including measures of perceived racial discrimination to test the hypotheses that racial discrimination is a fundamental cause of worse workers' compensation outcomes for minorities. Fundamental cause theory suggests that there are basic or fundamental reasons for health disparities that are not caused by mechanisms linking the fundamental cause with a health outcome; in fact, these mechanisms can and do change, but the relationship between the primary cause and the health disparity outcome will remain. In addition, a fundamental cause affects multiple outcomes via multiple mechanisms. Access to resources such as income, wealth, prestige, knowledge, and beneficial social connections can reduce the impact of a disease once it occurs. The analytic chapters in this dissertation are organized first, to address racial discrimination in health care provider outcomes; second, to address racial discrimination in workers' compensation agency outcomes; and third, to address the role of pre-injury racial discrimination in post-injury return to work outcomes. Racial discrimination was tested in this dissertation as the fundamental cause of health-care provider disparities in timeliness of follow-up care, adequacy of care, and patient satisfaction. Racial discrimination was tested in the workers' compensation agency as the fundamental cause of administrative delays and difficulties: delays in diagnostic approval and wage replacement payments, as well as language appropriate communication, and higher counts of independent medical exams. Racial discrimination was also tested as the fundamental cause of poor return-towork outcomes (feeling a worker returned to work too early and overall general health). 
Workplace support, as a possible resource (social connection), was tested as a mediator in the relationship between racial discrimination and workplace outcomes. Due to the survey nature of the study design, replicate weights were calculated based upon information available in both the surveyed and not-surveyed population to account for non-response bias, and all analyses were bootstrapped using Stata survey software. The results support the role of racial discrimination as a fundamental cause of outcomes for hypotheses in the workers' compensation agency with clear differences in delays for diagnostic services, a higher number of independent medical exams, as well as linguistically inappropriate communication for language minorities. Racial discrimination (prior to injury) was found to be significant in overall general health for minority workers, and for feeling they had returned to work too early. Workplace support (a potential social resource), was found to mitigate the role of racial discrimination in the workplace return-to-work outcomes. This study is an initial effort to examine racial discrimination as a fundamental cause of disparities in occupational health after an injury. As the majority of adults will spend one-fifth to one-third of their lives in paid employment, the ability to heal and return to full and active employment after a workrelated injury is critical to ones' self-worth, as well as to the economic stability of individuals, families, and societies. If racial, ethnic, and language minorities suffer worse outcomes in their post-injury sequelae, these results will have long-lasting implications in any quest for a more equitable society. 


\section{Dedication}

I dedicate this work to my grandmother, Kimiko Sugiyama Terao, and my mother, Clara Kazuko Smith. 


\section{Acknowledgments}

I would like to first acknowledge my Chair, Matt Carlson. Thank you for not giving up on me and encouraging me along the way. To the rest of my committee, Hyeyoung Woo, Alex Stepick, and Carlos Crespo, thank you for all that I have learned in classes from you, and for helping me to make this dissertation better; I am indebted to you for your professional wisdom and personal encouragement along the way. I would also like to acknowledge Moni Blazej Neradilek and Nayak Polissar for their statistical assistance. To the amazing grammarian Rose Ernst, thank you for getting me across this finish line.

To my amazing coworkers past and present SHARPsters, the passion you have for protecting workers from injuries, illnesses, and fatal incidents energizes me and makes coming to work a privilege. You fight uphill battles, so I thank you for all that you do. I want to acknowledge a few specific co-workers. Naomi Anderson, David Bonauto, and Sara Wuellner: you have been supportive, helpful, and have seen me through many difficulties on this journey. Thank you for your understanding, support, encouragement, and sympathetic ears when I needed them.

I am forever indebted to my mentor, Barbara A. Silverstein, and to her husband, the equally remarkable Michael Silverstein. Without the encouragement from the Silverstein's, I would not be writing this today. Thank you, Barbara, for your absolute trust that I was smarter than I felt, and that I could learn faster and be more than I thought I could. You have instilled in me not only a passion for my vocation but a belief that I can make things better for those less fortunate. 
To my two best friends, Tara Brink and Kristine Moore, thank you for getting me out into the world, for helping me take my mind off work, school, and life stressors — and for always having my back.

I would like to acknowledge my parents, Fred and Clara Smith. Thanks, dad, for teaching me at a young age to read, write, and memorize all of the state capitals through your fantastic games. Mom, you are the best, strongest, and most amazing mom ever. To my uncle Masao: thank you for being you, and for teaching me to be me. To my brothers, Tom, Pat, and Mark, to my sister-in-law, Robin, to my uncles, Albert, Sam, Jim, and Jack, to my aunts, Ida, Margarita, Paula, and Joanne-you have all played such an important role in my life and have helped to grow the person who finished this dissertation. Thank you. 


\section{Table of Contents}

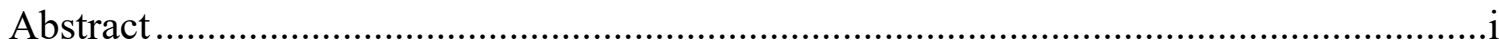

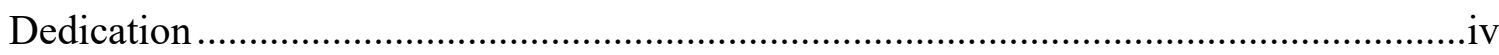

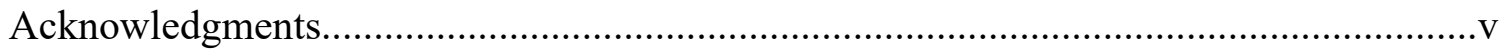

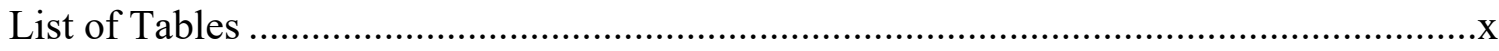

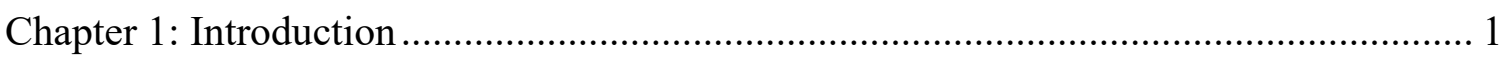

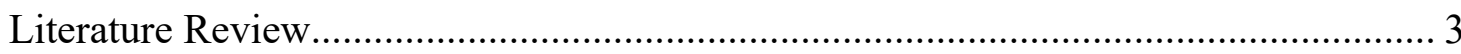

Health-Care Providers................................................................................. 3

The Workers' Compensation Agency ............................................................ 5

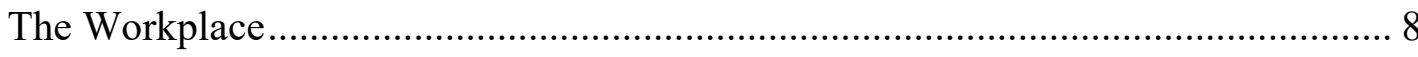

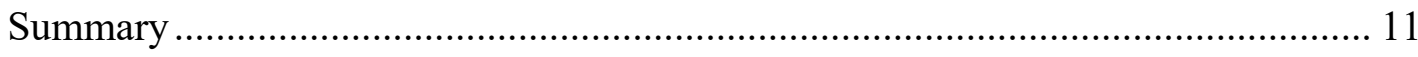

Theoretical Framework: Fundamental Cause ........................................................ 12

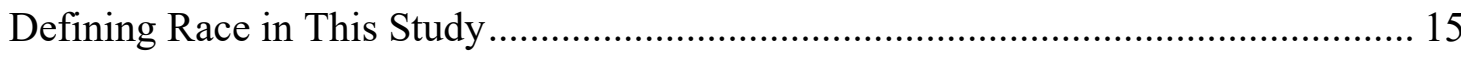

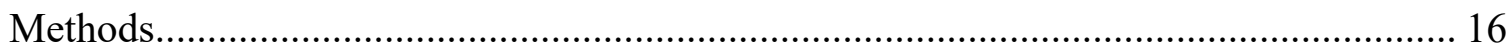

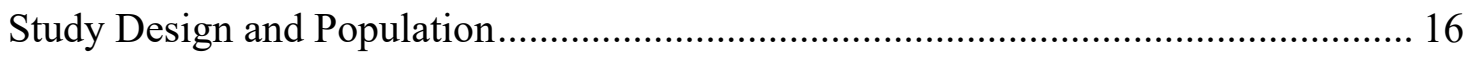

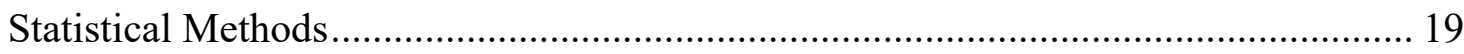

Race and Racial Discrimination Measures .............................................................. 20

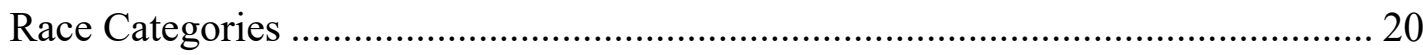

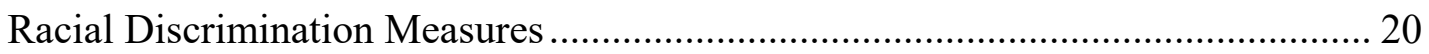

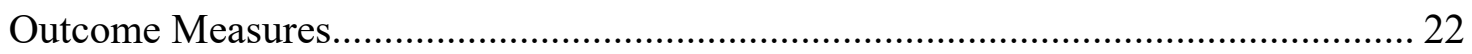

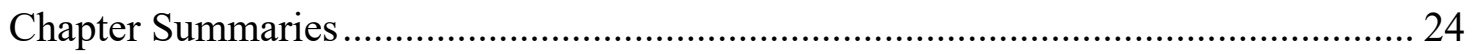

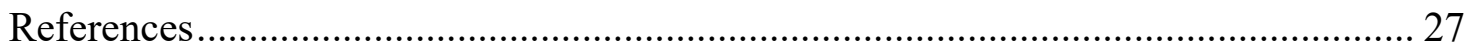

Chapter 2: Health Services in Workers' Compensation: Is Provider Racial Discrimination a Key Factor in Racial Inequalities in Occupational Injury Outcomes?......................... 34

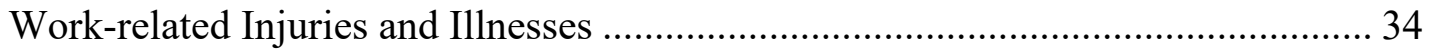

Health Care for Work-Related Injuries and Illnesses ......................................... 34

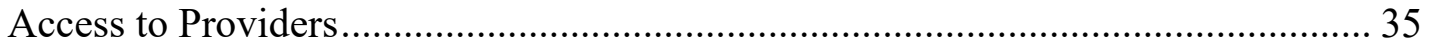

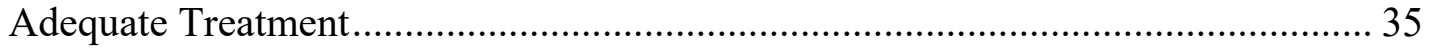

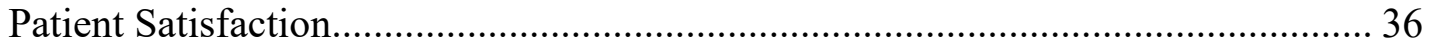

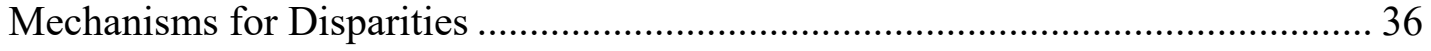

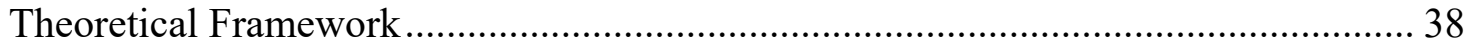

Fundamental Cause and Work-Related Injuries and Illnesses............................... 39

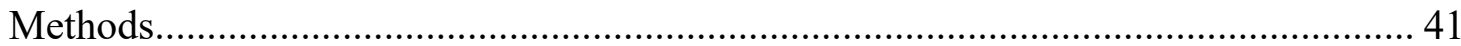


Data Sources: Workers' Compensation Claims Data ............................................ 41

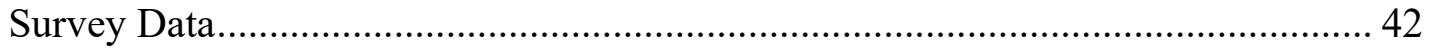

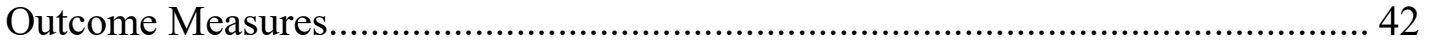

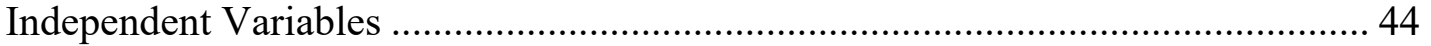

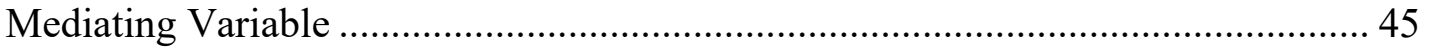

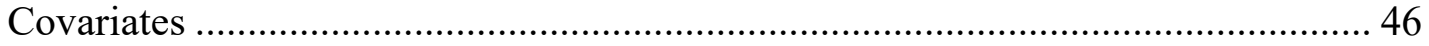

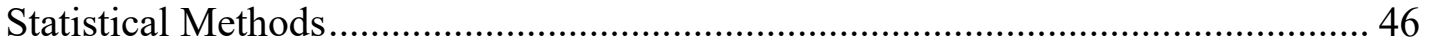

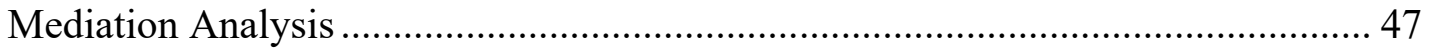

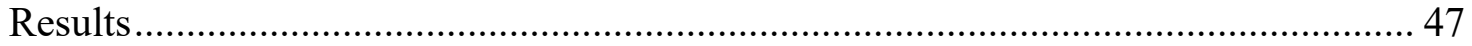

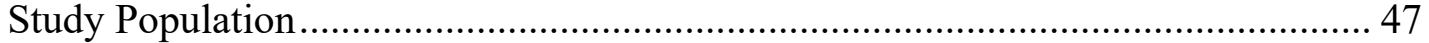

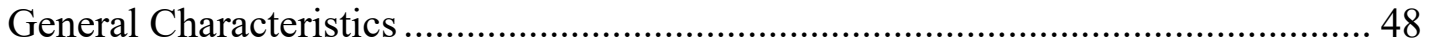

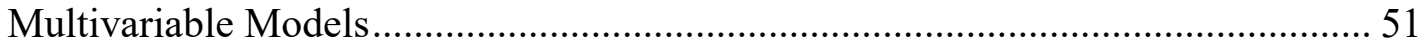

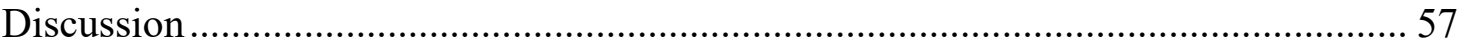

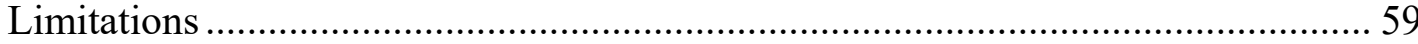

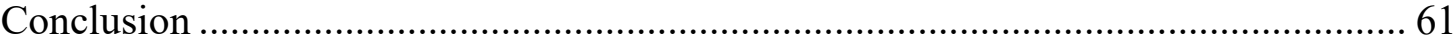

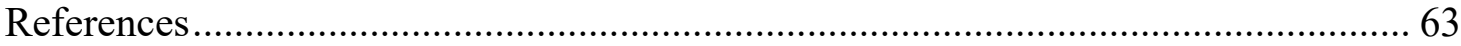

Chapter 3: The Role of Workers' Compensation Policies and Procedures in Racial Inequalities in Work-Related Injury Outcomes ........................................................... 68

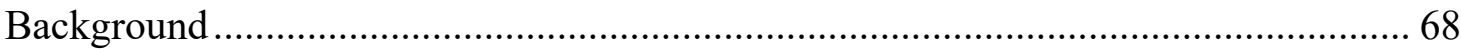

Workers' Compensation: A Brief Primer .................................................................... 69

Administrative Barriers in Workers' Compensation .............................................. 71

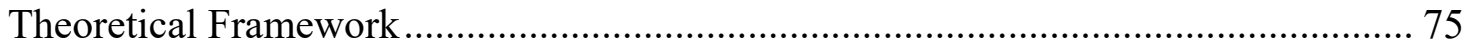

Objectives and Hypotheses of the Study …............................................................. 76

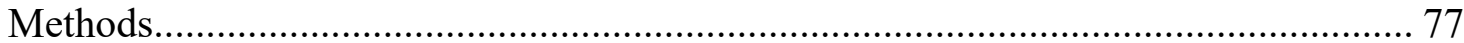

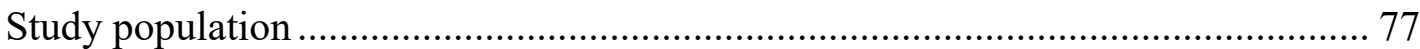

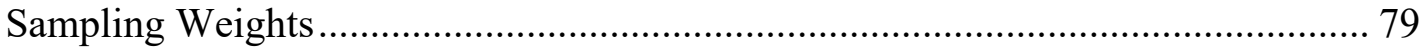

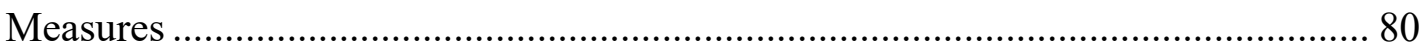

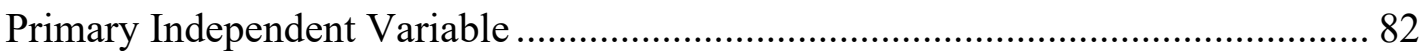

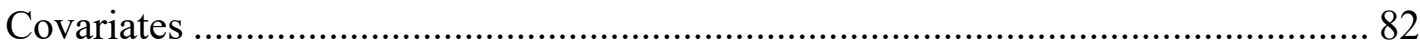

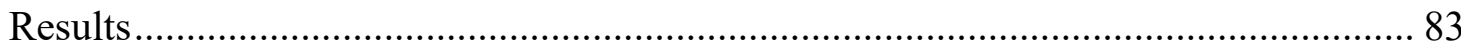

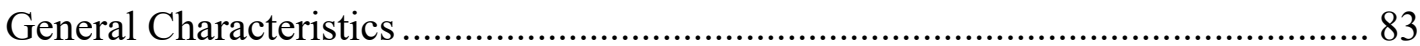

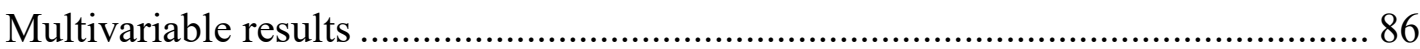

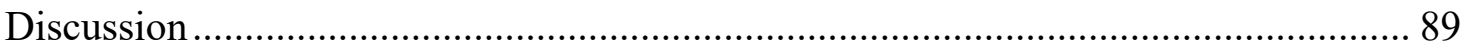


References

Chapter 4: Pre-injury Racial Discrimination at Work, and Its Association with Post-Injury Return to Work for Minorities: Does Workplace Support Mediate Racial Discrimination?

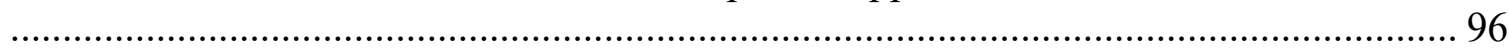

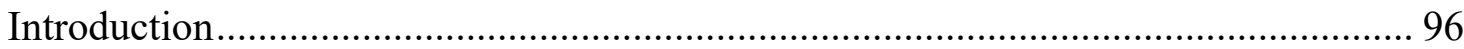

Racial Discrimination and Workplace Injuries...................................................... 97

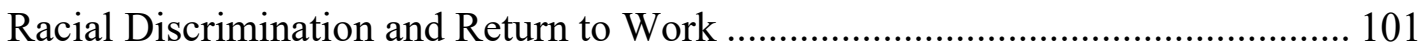

Workplace Discrimination, Injury, and Supervisor Support .................................. 102

Conceptual Framework and Hypotheses ............................................................... 104

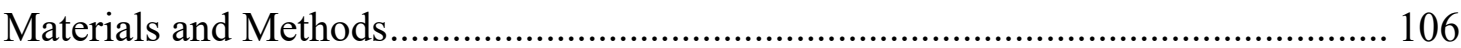

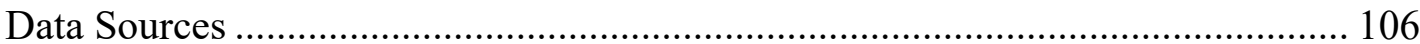

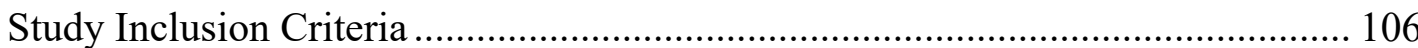

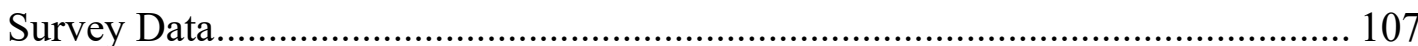

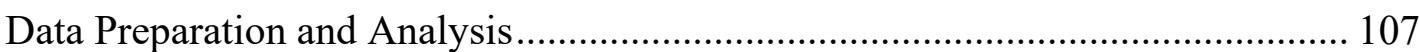

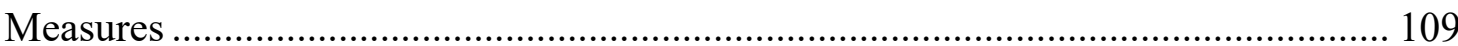

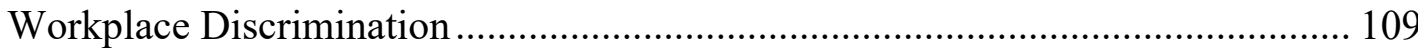

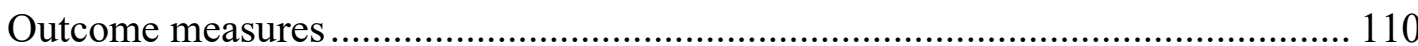

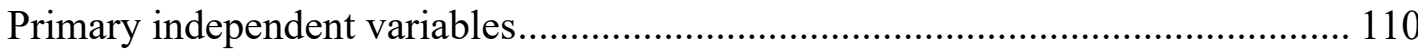

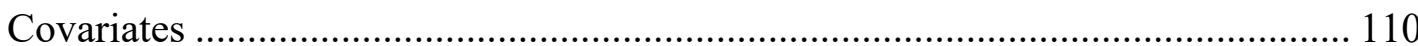

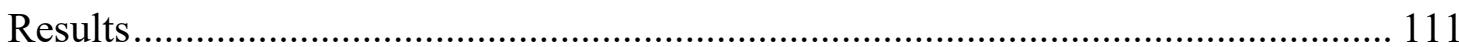

Return to Work and Workplace Discrimination..................................................... 113

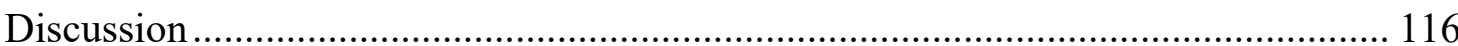

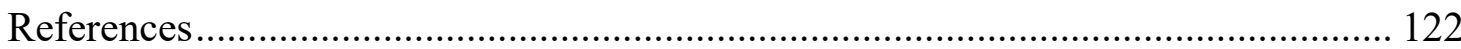

Chapter 5: Summary of Findings, Limitations, and Directions for Future Research ..... 128

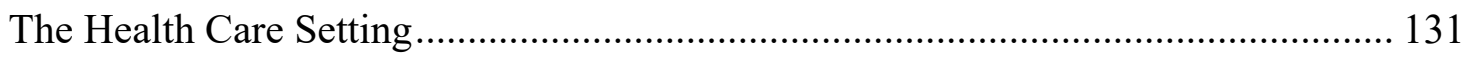

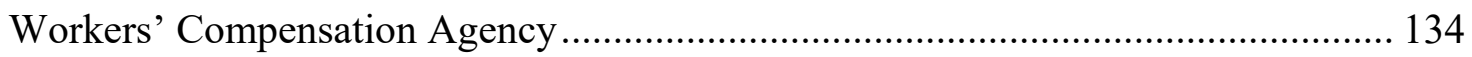

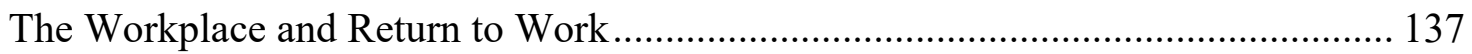

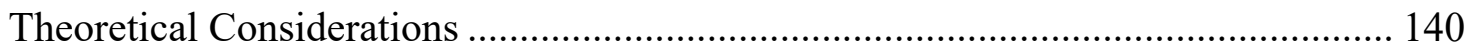

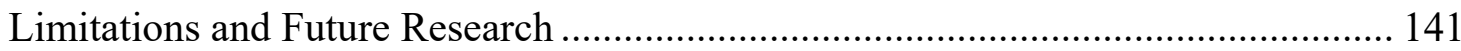

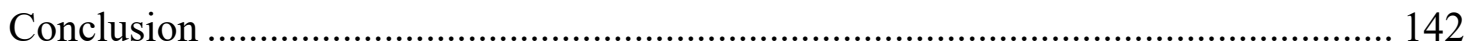

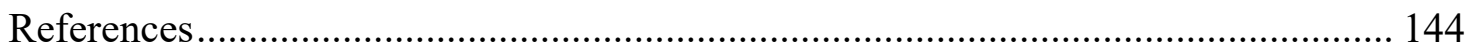




\section{List of Tables}

Chapter 1 Tables

Table 1 Self-Reported Race, Ethnicity, and Language and

Final Categories for Analyses................................................. 18

Chapter 2 Tables

Table 1 Adequate Care Case Definitions..........................................43

Table 2 Survey Respondent Characteristics by Race, Ethnicity, and Language Status...48 Table 3 Timeliness of Care for Minorities, Effects of Racial Discrimination from Health

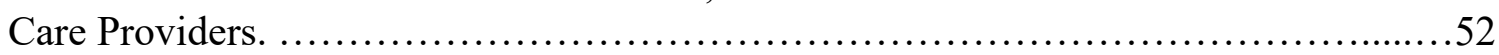

Table 4 Adequacy of care for injured workers, and mediation of flexible resources......53

Table 5 Mediation Analysis of Inadequate Care and Household Income and

Education...................................................................54

Table 6 Patient Satisfaction by Minority Status, and Effects of Racial Discrimination from Health-Care Providers.................................................55

Table 7 Mediation of Perceived Racial Discrimination on Patient Satisfaction and HæadtRrovider Inquiring About Work Duties or Household Income....................56

Chapter 3 Tables

Table 1 Descriptive Characteristics by Racial Group Status........................83

Table 2 Associations by Racial Group Status and Administrative Outcomes..............85

Table 3 Multivariable Regression Analyses for Administrative Barriers...............87

Table 4 Logistic Regression Model for More Than Two Administrative Barriers in Workers' Compensation................................................... 88

$\underline{\text { Chapter } 4 \text { Tables }}$

Table 1 Descriptive Characteristics of the Surveyed Population by Race, Ethnicity and

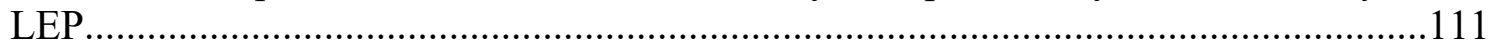

Table 2 Outcomes by Racialized Group Status..................................113

Table 3 Associations with Work Discrimination and Return-to-Work (RTW)

Support............................................................114

Table 4 Mediation of Association Between Return to Work (RTW) too Early and Workplace Discrimination, via RTW Support................................115 


\section{Chapter 1: Introduction}

Work-related injuries and illnesses are estimated to be the eighth leading cause of death among working adults (estimates from 49,000 to 60,000 per year) (Hilgert, 2012), yet it receives far less attention and funding than lower-ranked causes of death among working-age adults, such as kidney disease and suicides (Kochanek, Murphy, Xu, \& Arias, 2017). While scholarly literature (Angelon-Gaetz, Richardson, \& Wing, 2010; Robinson, 1984; Seabury, Terp, \& Boden, 2017) has documented workers of color and limited English proficient (LEP) workers facing higher risks for injury than non-Latino Whites (hereafter referred to as Whites), much less is known about their treatment for these injuries.

Work-related injuries and illnesses in the United States are generally covered by a workers' compensation (WC) state or federal program. ${ }^{1}$ While WC programs differ by types of injuries covered, partial wage replacement percentages, and reporting requirements, there are four major stakeholders ${ }^{2}$ required to work together in order to treat an injured worker and return them to active, paid work. These entities are healthcare providers, WC agency staff, the workplace, and the injured worker themselves. These four stakeholders comprise the workers' compensation system. All four actors must understand their role in the recovery and return-to-work (RTW) process in order to

\footnotetext{
${ }^{1}$ State and federal WC systems cover all employees unless a company is large enough to self-insure. Only the State of Texas does not require a company to have some sort of workers' compensation insurance.

${ }^{2}$ This is a generalization that applies to Washington State as a sole source of WC insurance. Most states have a minimum of five major stakeholders (WC agency that oversees claims, private insurance companies who adjudicate and pay claims, and then the employer, health-care provider and injured worker). In reality there are also third party administrators acting as a go-between for employers and insurance, lawyers are frequently involved from all parties as well as WC Boards who oversee disagreements. The stakeholders listed here, however, are the necessary actors in a WC claim.
} 
ensure timely, adequate, and speedy care after an injury or illness. Unfortunately, for workers of color and LEP workers, there are reported problems in all aspects of the WC system (MacEachen, Kosny, Ferrier, \& Chambers, 2010).

Many potential mechanisms have been identified as the source of inequitable care for minorities in the WC system. These mechanisms include inadequately trained healthcare professionals (Premji, 2014a; Safran, Cohen, Caplan, Ohuabunwa, \& PharagoodWade, 2005); impersonal WC agency employees (Elizabeth Kilgour, Agnieszka Kosny, Donna McKenzie, \& Alex Collie, 2014); confusing, arduous rules and paperwork demands (A. Kosny et al., 2012; MacEachen et al., 2010); and workplace discrimination (Shannon, Rospenda, Richman, \& Minich, 2009). More distal mechanisms have also been identified, such as low-socioeconomic status (Lipscomb, Loomis, McDonald, Argue, \& Wing, 2006) — which puts minorities in riskier jobs in the first place - and a worker's individual characteristics such as race, ethnicity and LEP status. What is less likely to be suggested as a cause of inequality in WC outcomes is forms of racial discrimination. Racial discrimination is institutionalized, pervasive, and affects many aspects of people's lives, such as education, housing, occupational attainment, income, and wealth, all of which affect life chances and health (Braveman \& Gottlieb, 2014); this critical factor, however, has not been adequately addressed in studies investigating inequality in occupational injuries and illnesses.

The purpose of this study is to investigate the role of racial discrimination as a fundamental cause of inequitable outcomes for minority workers in a state-run workers' compensation system. This study uses fundamental cause theory (FCT) as the framework 
to investigate health-care providers, the WC agency, and the workplace, using a unique set of survey and administrative data from a group of injured workers in Washington State. While injuries occur in the workplace, this dissertation begins with the health-care provider, as they are the primary instigator of a workers' compensation claim, and then follows the worker through their interactions with the workers' compensation agency, culminating in finally in returning to work. I explore associations between workers and their employer in return-to-work outcomes. The remainder of this chapter summarizes the current literature on injured minority workers in the WC system, presents this study's theoretical framework, overarching methods, and briefly describes all subsequent chapters.

\section{Literature Review}

\section{Health-Care Providers}

Disparities in health-care services (access, timeliness, and quality) by race and ethnicity are still significant issues in the United States (AHRQ, 2015; Cooke, Nallamothu, Kahn, Birkmeyer, \& Iwashyna, 2011; Johnston \& Bao, 2011; Press, Carrasquillo, Sciacca, \& Giardina, 2008). Disparities in work-related health-care services by race, ethnicity, and language have also been documented, with minorities more likely to suffer worse health outcomes compared to Whites (Chibnall, Tait, Andresen, \& Hadler, 2006; Tait, Chibnall, Andresen, \& Hadler, 2004). Access to appropriate healthcare is critical in ensuring maximal recovery from work-related injuries and illnesses, though few general practice physicians are well-versed in occupationally related disorders and diseases, and many lack a thorough understanding of the WC system and 
requirements for a return to work (Duncan, 2003; Safran et al., 2005). In Washington State, health-care providers $(\mathrm{HCP})$ are responsible for initiating the paperwork to file a workers' compensation claim. ${ }^{3}$ Health-care providers are critical actors in the smooth and timely function of the WC system: initiating, treating, and communicating with all other parties involved. Unfortunately, prior studies describe some significant issues with health-care providers and their treatment of minorities which may delay or worsen the recovery process, yet stop short of investigating causes for racial differences in treatment.

For immigrants and LEP workers, Kosny et al. (2012) identified a lack of language-concordant health-care providers to be a major issue. Language-concordant providers proved difficult to find, and led many immigrants and/or LEP workers to receive care at hospital emergency rooms where interpreters were rarely available (A. Kosny et al., 2012). A study of hotel room cleaners in Las Vegas (85\% of whom were immigrants), Premji and Krause (2010) found that Latinos were much less likely to find satisfaction with their health care for work-related injuries and illnesses (WRII).

Rudolph, Dervin, Cheadle, Maizlish, and Wickizer (2002) also found patient satisfaction to differ by race and LEP status in their study of 800 workers' compensation claimants in California: they found that when compared to English speakers and Whites, satisfaction with the doctor-patient relationship was significantly lower for Spanish speakers, African-Americans, Asians and others (Rudolph, Dervin, Cheadle, Maizlish, \& Wickizer, 2002). Patient satisfaction is a common and important indicator of quality of care and has

\footnotetext{
${ }^{3}$ Both employers and employees can file a workers' compensation claim in Washington State, but a healthcare provider seeing the injured worker is required in order to begin adjudication of a claim.
} 
been linked to better clinical and return-to-work outcomes (Dasinger, Krause, Thompson, Brand, \& Rudolph, 2001; Skolasky, Albert, Vaccaro, \& Riley, 2009).

Health-care provider actions may be a significant mechanism in creating inequitable health-care services. In the general health-care literature, health-care provider bias has been found to be associated with delayed or inadequate care for minority patients (Institute of Medicine, 2003; Johnson, Saha, Arbelaez, Beach, \& Cooper, 2004; van Ryn et al., 2011). For work-related-injury health care, the literature reflects similar biases that may affect minorities in seeking treatment (Elizabeth Kilgour et al., 2014; Agnieszka Kosny, MacEachen, Ferrier, \& Chambers, 2011), yet no study has explicitly tested bias or perceived racial discrimination as a cause of disparities in workers' compensation health care.

Most workers are confused about the process for filing a WC claim and how to seek appropriate medical care for these injuries and therefore rely on professionals to help them navigate the system (Azaroff, Levenstein, \& Wegman, 2004). Instances of perceived racial discrimination most likely increase barriers for injured workers of color and LEP workers in entering and navigating the health-care system for work-related injuries, which is why it is critical that health-care providers fulfill their mission of providing equitable service to all injured workers.

\section{The Workers' Compensation Agency}

Workers' compensation is the oldest social insurance system in the United States; though different in all states, various territories, and for federal programs, WC is 
designed to provide no-fault ${ }^{4}$ medical care and some proportion of wage replacement for people injured on the job. For many injured workers who are without other forms of health insurance, $\mathrm{WC}$ is the only system that will cover their work-related injuries and illnesses, making the system critical for the most vulnerable in lower-wage, high-hazard occupations. The qualitative literature regarding WC agencies is very consistent and suggests that interpersonal and institutional racial discrimination may be key factors in inequalities by racial group status. These issues of racial discrimination include being treated by WC staff with hostility, and suspicion (Beardwood, Kirsh, \& Clark, 2005); inadequate or delayed services and late wage replacement benefits (Gravel et al., 2010; Scherzer, Rugulies, \& Krause, 2005). In addition, the increasing use of independent medical exams (IMEs) used by $\mathrm{WC}$ agencies to hasten the claim process, adds to $\mathrm{WC}$ agency staff suspicion and contempt, as many IME physicians label workers who do not recover quickly as "malingering" or having "secondary gain syndrome. ${ }^{5}$ Both these labels negatively impact workers; Lippel defines IMEs as potentially anti-therapeutic in that they may create a mental injury on top of existing physical injuries (Lippel, 1999). To date, there are no studies examining racial, ethnic, or linguistic bias in the frequency of IMEs; however, there appear to be a host of systemic, institutionalized issues within

\footnotetext{
${ }^{4}$ In workers' compensation systems, "no-fault" means that neither the worker or the employer are held responsible for an injury or illness; the system will pay for the health care and time loss of the injured worker. This also means that neither party can be sued to cover costs for the injury or illness.

${ }^{5}$ Malingering refers to the perception that an injured worker is exaggerating symptoms or severity of injury to prolong treatment or time off work. Secondary gain refers to benefits psychological or material, that an injured worker perceives they are getting from their injury. This would lead to a worker not wanting to recover.
} 
various $\mathrm{WC}$ agencies that create inequitable outcomes for minorities, especially those who are LEP workers.

MacEachen et al. (2010) refer to the administrative barriers found in workers' compensation processes as "mundane," in that an individual instance of a late payment, case managers not returning a phone call, delayed letters for adjudication, or misplaced paperwork, are in themselves minor incidents. MacEachen and other scholars have found that these "mundane" issues are too often combined within one claim and when added up, create a "toxic dose" of problems that have serious consequences for injured workers (MacEachen, 2000; MacEachen et al., 2010). The extant literature confirms these assessments by identifying systemic issues within WC agencies that have consequences for injured workers (Bonauto et al., 2010; Dembe, 2001a; E. Kilgour, A. Kosny, D. McKenzie, \& A. Collie, 2014; Kirsh \& McKee, 2003; Lippel, 2007). There is some limited evidence that these mundane processes may occur differentially for language minorities compared to dominant-language-speaking workers. For instance, Gleeson notes in her detailed ethnographic work with immigrants in the southwest United States that many injured LEP workers seek attorneys to assist with WC claims, and attorneys generally take a portion (10-15\% on average) of monies paid to these injured workers, depriving LEP workers of a significant portion of an already small wage replacement check (Gleeson, 2016). The hiring of legal assistance in order to get the same service as an English proficient worker is an example of a structurally discriminatory reality in WC systems that negatively influences a specific group of injured workers. In addition, Premji Lippel and Messing (2008), note in their review of appeal decisions from the court of 
appeals in Montreal, Québec (Commission des lésions professionnelles (C.L.P.)) that piecework in the garment industry (comprised of many LEP workers) is structured to encourage working as quickly as possible, regardless of physical risk. When injured LEP workers filed claims, they were frequently denied and when not denied, the system of adjudication was not set up to recognize the piecework style of work. Therefore, injured workers returned to hourly wage jobs classified as light duty, which were not paid at the same rate as those for healthy pieceworkers (Premji, Lippel, \& Messing, 2008). These piecework and nonstandard work styles are increasingly prevalent in low-wage and highhazard occupations which are predominantly filled by immigrants (Flynn et al., 2015). The literature to date indicates structural and interpersonal racial discrimination within workers' compensation agencies that have yet to be explicitly explored and tested.

\section{The Workplace}

Occupational segregation. Historical segregation and inequalities in occupations, education, wealth, and labor-market participation have resulted in a twotiered occupational system in the United States, what Edna Bonacich referred to as a "split labor market" in her work comparing African Americans and Whites (Bonacich, 1972). Occupational segregation by racial group status continues to be a significant issue and one of the stronger explanations for racial disparities in work-related injury rates (BLS, 2017b; Chung-Bridges et al., 2008).

Racial occupational segregation and work-related injury. Historical trends in workplace injury risk by racial/ethnic group status do not exist in national surveillance data. The main source of workplace injury statistics come from the Bureau of Labor 
Statistics (BLS); these data were not coded for occupation or race/ethnicity until the mid1990s (BLS, 2017a), and even now, race/ethnicity in these data are missing approximately $40 \%$ of the time (BLS, 2017c). Evidence of occupational racial segregation and subsequent increase in injuries, however, can be found in high-profile, catastrophic incidents such as acute silicosis at Gauley Bridge, West Virginia during the Great Depression and J. William Lloyd's classic study of long-term mortality among steelworkers. ${ }^{6}$ Both of the above classic cases found Black workers in the most hazardous conditions (and with highest exposure and premature mortality), even though they were the minority of employees. Workers inside the Gauley Bridge tunnel, exposed to almost pure silica, were overwhelmingly Black, even though they were less than $20 \%$ of the population in the surrounding community (Cherniack, 1986). In epidemiological studies of steelworkers, J. William Lloyd found that Black workers were more likely than White workers to work on top of coke ovens ${ }^{7}$ where they were exposed to much higher rates of known carcinogenic compounds (Lloyd, 1971).

While socioeconomic conditions have improved for many workers over time, minorities are still disproportionally represented in high-hazard occupations (BLS, 2017b). Even when controlling for levels of education, a common labor market indicator

\footnotetext{
${ }^{6}$ Gauley Bridge, West Virginia was the site of one of the worst industrial incidents in American history. Union Carbide chose to dig through a mountain of (almost) pure silica using dry drilling techniques, even though wet drilling was considered much safer. Approximately 700 workers died between 1930 and 1935 . The local population was $80 \%$ White, but the workers chosen to dig inside the tunnel (site of most silica exposure) were $80 \%$ Black (Murray, 2003; Cherniack, 1986). In a series of papers documenting steelworker respiratory cancers compared to coke plant workers respiratory cancers, Lloyd found that $74 \%$ of the workers who worked on the top of coke ovens (extremely high heat and highest exposure to coke oven fumes) were Black. This task also produced the largest numbers of lung cancer in Gauley Bridge. ${ }^{7}$ Coke ovens are where coke is produced. Coke is a vital component in iron and steel production. For more information about this process and the carcinogens released into the air, see Graham \& Holtgrave (1990).
} 
of higher paid, safer jobs, workers of color and LEP workers are still more likely to suffer higher rates of WRII than Whites (Seabury et al., 2017).

Workplace racial discrimination. Workplace racial discrimination appears to affect workers of color and LEP workers in hiring (Bertrand \& Mullainathan, 2004; Quillian, Pager, Hexel, \& Midtbøen, 2017), promotions (Maume, 1999; Wingfield, 2009), and occupational segregation into lower-paying jobs (Alonso-Villar, Del Rio, \& Gradin, 2012; Browne, Hewitt, Tigges, \& Green, 2001). Perceived racial discrimination is also associated with the risk of work-related injuries and illnesses (Shannon et al., 2009). In a national telephone survey, Shannon et al. found that Blacks and Hispanics were 8-10 times more likely to suffer discrimination at work, and those who suffered discrimination at work were twice as likely to suffer a work-related injury or illness (Shannon et al., 2009). Racial discrimination at work has also been associated with higher rates of mental health illnesses (Bhui et al., 2005; Premji, Messing, \& Lippel, 2008; Roberts, Swanson, \& Murphy, 2004), similar to studies of the long-term unemployed (Bartley, Ferrie, \& Montgomery, 2006). Mental-health issues, such as depression, impede physical recovery. Being away from work for an extended period of time also affects an injured worker's economic stability, social relationships, and sense of self-worth. While race and LEP status and subsequent racial discrimination have been associated with higher rates of work-related injuries, no studies have, to my knowledge, investigated the role of discrimination at work and subsequent return to work for minorities. 


\section{Summary}

The literature summarized above has identified some common systemic and individual-level biases among the three largest stakeholders in the WC system- - healthcare providers, the WC agency, and the workplace - that lead to inequitable health outcomes for the fourth actor: injured workers. Unfortunately, most studies to date have not used a theoretical framework that would account for both individual and institutional discrimination patterns by racial, ethnic, and LEP status. Many past studies have listed differences in SES as the primary mechanism through which minority workers are exposed to higher-hazard, lower-paying jobs (Bambra, 2011; Lipscomb et al., 2006). There is, however, extensive literature comparing occupational attainment for minorities versus Whites; when controlling for education and income, minority workers are still more likely to work in high-hazard, low-wage occupations (Alonso-Villar et al., 2012). In addition, minorities have worse health outcomes compared to Whites when controlling for socioeconomic status (SES) (P. A. Braveman, Cubbin, Egerter, Williams, \& Pamuk, 2010; Farmer \& Ferraro, 2005; Williams, Mohammed, Leavell, \& Collins, 2010). Therefore, simply controlling for differences in SES does not adequately account for differences in work-related rates of injury, nor does it account for differences in workers' compensation outcomes by racial, ethnic, and LEP status. The type of injury a worker has suffered may also explain part of the variance in outcomes that have been found in the literature, yet most studies controlling for specific injury types lack detailed information regarding injury, diagnoses, treatments, and health outcomes. We lack comprehensive studies that investigate WRII among the three primary institutions in the WC system 
(health-care providers, WC agency, and the workplace), while controlling for potential differences related to the injury (e.g., injury type) and explicitly investigating outcomes for minorities. To date, racial status has been primarily used as a control mechanism in the investigation of WC claims and health outcomes for injured workers. Even when inequalities are found, these studies lack a theoretical perspective that would explain these results.

The three analytic chapters included in this dissertation address these gaps in the literature by investigating how minorities navigate major aspects the WC system (the health-care, workers' compensation agency, and the workplace) and hypothesizing that racial discrimination is a basic or primary cause of inequalities in workers' compensation systems by utilizing fundamental cause theory as the overarching conceptual framework.

\section{Theoretical Framework: Fundamental Cause}

Fundamental cause theory (FCT), developed by Link and Phelan (1995), states that there are enduring social conditions that perpetuate inequalities in health, regardless

of the specific mechanisms which link them to health disparities. According to Link and Phelan (1995), four basic criteria indicate a potential fundamental cause. First is that a fundamental cause affects multiple health outcomes. Second, a fundamental cause influences multiple health outcomes via multiple mechanisms. Third, avoiding or ameliorating the association between a fundamental cause and health inequality involves the use of flexible resources, such as power, social connections, and money. Fourth, the association between the fundamental cause and health outcome is persistent, even if identified mechanisms linking them are eliminated (Link \& Phelan, 1995). 
In a more recent article, Phelan and Link (2015) propose that racism is a fundamental cause of health inequalities and test this using Feagin's concept of systemic racism (Feagin, 2000; Feagin \& Bennefield, 2014), as a framework to review past studies on race and health. Feagin's concept of systemic racism states that racism (starting as an economic tool during slavery) has been interwoven into all major institutions and social practices, thus reproducing socioeconomic disadvantage for minority populations. In their analysis of the extant literature, Phelan and Link find ample evidence that continued racism, via multiple mechanisms, is both a strong factor in determining racial differences in socioeconomic status (SES) - already purported as a fundamental cause (Lutfey \& Freese, 2005; Phelan, Link, \& Tehranifar, 2010) —and as an fundamental cause of health disparities, independent of SES (Phelan \& Link, 2015).

Using FCT as this dissertation's theoretical framework allows for the specific investigation of the effects of race and perceived racial discrimination, on WC system outcomes for injured workers. By examining effects by race or racial discrimination, this study can test both independent and interactional effects of racial discrimination and SES as significant causal mechanisms in the $\mathrm{WC}$ system process. While this dissertation cannot test all tenets of FCT, it does test the primacy of race or racial discrimination, via multiple mechanisms, in work-related injury outcomes, as well as identify potential flexible resources that may alter or negate disparities in outcomes within a state-based workers' compensation system.

Based upon the literature cited above, the existing research, while not extensive, does suggest that race may be an overlooked fundamental cause of disparities in workers' 
compensation system outcomes, and suggests that fundamental cause theory is the most appropriate for this study. In health-care services, for example, differential diagnoses and subsequent disability determinations in Tait et al. (2006) survey of workers' compensation claimants with low back injuries, found that even when controlling for SES, as well as injury and disability ratings, the determination for disability was higher for Whites than for African Americans. Tait et al. suggest a social justice problem in the determination of disability but stop short of suggesting racial discrimination is the causal factor (Tait et al., 2006).

In the workers' compensation agency literature, language barriers, and being treated with disrespect and suspicion appear as significant issues for injured workers, with some indication that racial discrimination plays a significant role in the selective utilization of administrative procedures (Dembe, 2001b; Nevitt, Daniell, \& Rosenstock, 1994). While Premji (2014b) has developed a conceptual model to address inequalities for language minorities in workers' compensation systems, this model does account for (a) the racialization of linguistic minorities (Massey, 2009; Rosa \& Flores, 2017), and (b) phenotypical racial minorities. Fundamental cause theory can address both of these issues and is therefore better suited for this study.

This dissertation investigates post-injury outcomes in health services, the workers' compensation agency, and workplace interactions in return-to-work processes. Even though a work-related injury is suffered at work, the conceptual framework for these analyses starts with the health-care provider, as they are the primary instigator of a workers' compensation claim. Next, this dissertation follows the worker through their 
interactions with the workers' compensation agency and finally in returning to work; I explore associations between workers and their employer in return-to-work outcomes.

Each of these studies utilizes fundamental cause theory to position the role of racial discrimination as the primary cause of inequalities found in each of these three aspects of the WC system. Fundamental cause in health services (Chapter 2) is investigated primarily in how provider racial discrimination may affect health-care outcomes via mechanisms of delays and quality of care. In the WC agency (Chapter 3), fundamental cause is utilized to test the role of racial discrimination in two ways, first via mechanisms of workers' compensation adjudicator delays, and second, through policies and procedures that more negatively affect minorities. In the third set of analyses (Chapter 4), this dissertation studies the role of workplace discrimination as a cause for injured workers feeling they returned to work too early, and also tests the mediating role of return-to-work support from employers. In each study, mechanisms are tested across multiple outcomes while controlling for the flexible resources of education and income.

\section{Defining Race in This Study}

This study also borrows from prior literature in public health, sociology, and anthropology in combining standard definitions of race, ethnicity, and LEP status into one "race" group (Davis \& Moore, 2014; Grosfoguel, 2004; Rosa, 2016; Williams et al., 2010). Race is a socially constructed category that changes over time and shifts groups of people from one category to another. This study operationalizes race as a racial designation, used in the United States as a label to determine in-group and out-group status, citizenship, rights, and ultimately life chances. Racialized grouping includes 
traditional phenotypic characteristics and language spoken, because language is a key construct by which people create and reinforce stereotypes of "otherness", intelligence, and competence (Davis \& Moore, 2014; Rosa, 2016; Williams et al., 2010).

\section{Methods}

\section{Study Design and Population}

This study utilizes a unique set of cross-sectional data from a statewide survey of injured workers along with their workers' compensation claim administrative records for time loss injuries from 2008-2013. The Washington State workers' compensation system is a sole-source, state-fund insurance program. This means that unlike most other states, Washington data come from one source, rather than a myriad of private insurance companies. Data from the Washington workers' compensation fund contain all medical and billing records associated with every accepted injury and illness for every firm in the state with at least one employee and are not large enough to self-insure. For those few companies who are large enough to self-insure, the Washington WC agency still has counts and descriptions of all injuries and illnesses, as well as final costs for claims that include partial wage replacement. Other than Washington State, only Ohio has similarly detailed and comprehensive records (Dunning et al., 2010). The survey data contains detailed information regarding perceived racial discrimination, general health status, post-injury workplace outcomes, and additional socio-economic information, all of which are not available through the workers' compensation administrative data. The Washington State WC agency data, coupled with survey responses, provide a unique opportunity to study racial inequalities in WC system outcomes. 
Inclusion criteria for this study included claim eligibility type (compensable claims $^{8}$ ), industry/occupation limits (construction; food service and accommodation; and janitorial services), specific injury types (three musculoskeletal disorders: rotator cuff syndrome, carpal tunnel syndrome, and low-back pain), and three traumatic injuries (burns that required hospitalization, amputations, and hand and/or wrist fractures). The limitation for claim eligibility type was chosen to focus only on the more serious injuries, as temporary total disability claims (compensable) require time away from normal work. Industry/occupation limits were selected to partially control for the effects of SES on occupational attainment, and the limits by injury type were chosen to control for differential treatments that could account for differences by race/ethnicity and language. In controlling for these three important factors, I can more directly test the hypotheses that racial discrimination (regardless of occupation and injury) will be fundamental to the outcomes associated with health-care providers, the WC agency, and the workplace return-to-work.

The survey sample included 1,350 White workers' compensation claims and 2,170 non-White workers' claims. A total of 550 injured workers were interviewed and $488(88.7 \%)$ of these provided complete responses to the survey, thus limiting this study

\footnotetext{
${ }^{8}$ Compensable claims refer to those accepted WC claims that are categorized as either being temporary total disability (more than three days of time loss), kept on salary (employer continues to pay wages for worker off work with an injury), total permanent disability (injured worker unable to work for wages anymore), fatality, or loss of earning power (employee injured in a way that precludes them from returning to work in the same pay level job they had before the injury). Compensable claims make up approximately $30 \%$ of all accepted claims in the Washington State SF WC system, and are considered more severe than medical only claims (where a worker experience no or minimal missed work and was ineligible for wage replacement) (Labor and Industries, 2015).
} 
to 488 subjects. Based on the total possible responses, this study had an overall response rate of $25 \%$ using the American Association of Public Opinion Research (AAPOR) guidelines (AAPOR, 2015). The survey of injured workers asked a host of questions about the workers' compensation process, their satisfaction with health-care services provided, as well hazards faced, discrimination faced at work, and support from their employer in returning to work. Surveys were conducted in the worker's native language. Due to small numbers for specific self-reported race, ethnicity, and linguistic minority status, subjects were grouped together to create three mutually exclusive race categories, resulting in a sample of 224 White English speakers, 97 non-White English speakers, and 162 non-White LEP speakers. Table 1 presents the self-reported race and English language proficiency from the self-report survey data.

Table 1

Self-Reported Race, Ethnicity, and Language and Final Categories for Analyses

\begin{tabular}{|c|c|c|c|}
\hline Racial/ethnic group & $\begin{array}{l}\text { Speak or read } \\
\text { English well or } \\
\text { very well }\end{array}$ & $\begin{array}{l}\text { Speak or } \\
\text { read English } \\
\text { poorly or } \\
\text { very poorly }\end{array}$ & Total \\
\hline White & 222 & $8 *$ & 230 \\
\hline Black/African American & 11 & 2 & 13 \\
\hline Asian or Pacific Islander & 9 & 2 & 11 \\
\hline American Indian or Alaska Native & 10 & 0 & 10 \\
\hline Latino or Hispanic & 66 & 158 & 224 \\
\hline Total & 318 & 170 & 488 \\
\hline
\end{tabular}


There were 230 White, 13 Black/African American, 11 Asian or Pacific Islander, 10 American Indian or Alaska Native, and 224 Latino/Hispanic. Among them, 8 White, 2 Black/African American, 2 Asian or Pacific Islander, and 158 Latino/Hispanic workers reported they spoke or read English poorly or very poorly. In order to keep as many respondents as possible, yet create a categorical racial variable that made sense in terms of theory and literature, the LEP group included the 4 non-White limited English proficient respondents, and the 8 White LEP respondents were dropped from the dataset, limiting final responses used in the analysis to 480 .

All complete survey responses were merged with their respective workers' compensation administrative data by a data manager working at the WC agency. Prior to the author's access, all identifying information was stripped from the data. Both the Washington State Institutional Review Board and the Portland State University Human Subjects Research Review Committee reviewed the study protocol and determined it exempt from further IRB review because of the use of de-identified (i.e., no personal identifiers were included) survey and administrative data.

\section{Statistical Methods}

To account for non-response bias, data for this study were bootstrapped and replicate weights were calculated based on characteristics available in the WC agency data. These included age, gender, White/non-White probability, ${ }^{9}$ geographic location, and

\footnotetext{
${ }^{9}$ White/non-White probability to sample potential survey subjects only was estimated using the Bayesian Improved Surname Geocode (BISG) formula which uses both surname and residential address (combined with Census data) to determine the probability of White versus non-White group membership (Elliott et al., 2009).
} 
industry. "Survey" procedures in Stata for all regression analyses using Stata version 14.2, "SVY" statistical programs. A user-written program available for Stata (PARAMED) was used to test for mediation for continuous independent variables, and a series of regressions based upon the methods of Preacher and Hayes (2008) were used with categorical independent variables (UCLA: Statistical Consulting Group, 2016).

\section{Race and Racial Discrimination Measures}

\section{Race Categories}

As noted above in the theoretical framework section, measures for race include three distinct groups: White, English speakers, and two non-White groups: non-White English speakers and non-White limited English proficiency claimants. These categories were based on self-reported data

\section{Racial Discrimination Measures}

Perceived racial discrimination from health-care providers was measured using the Perceived Racial Discrimination Scale (PRDS) by Thorburn Bird, and Bogart (2001). This scale is a continuous variable with scores ranging from $0-7$ based upon 7 questions regarding a claimant's perception of their health-care providers. This scale, while not validated, is an adapted version of the "Everyday Discrimination Scale" developed by Williams, Yu, and Jackson (Williams, Yu, Jackson, \& Anderson, 1997), which has been validated in multiple studies (Clark, Coleman, \& Novak, 2004; Kim, Sellbom, \& Ford, 2014).

Perceived racial discrimination from workers' compensation agency employees was measured using modified questions from Johnson, Saha, Arbelaez, Beach, and 
Cooper (2004). in their study of racial and ethnic perceptions of bias and cultural competence (Johnson et al., 2004) The original questions come from the Commonwealth Fund 2001 Health Care Quality Study (Collins et al., 2002). I modified them to read: "Did you ever feel that any of the workers' compensation employees you dealt with ever judged you unfairly or treated you with disrespect because of how well you speak English?" (yes/no); "Do you think you would have been treated better by L\&I if you spoke English very well?" (yes/no); and "Do you think you would have been treated better by L\&I if you belonged to a different race or ethnic group?" (yes/no). A yes for any question was considered affirmative for perceived racial discrimination

Institutional racism was measured using "mundane" administrative barriers identified by MacEachen $(2000 ; 2010)$, as well as independent medical exam usage, described as anti-therapeutic by Lippel $(1999,2012)$. These structural barriers were counted and divided at the median value to indicate a burden was present if more than two barriers, and not present if less than or equal to two barriers. The literature contains no validated structural measures, so this was developed as an initial unweighted variable (giving equal weight to each type of administrative barrier) to identify if structural racism was present (i.e., did these multiple administrative barriers occur more amongst minorities than Whites?).

Perceived workplace discrimination was measured using modified questions from the Multi-City Survey of Urban Inequality (MCSUI) (Bobo et al., 2000). While not a validated measure of workplace discrimination, the MCSUI is an often-used unique 
dataset developed by some of the most respected social scientists in the field of residential segregation, racial inequality, and labor market studies (Bobo et al., 2000)

\section{Outcome Measures}

Multiple outcome measures were developed for this study. Due to the lack of validated measures for timeliness of care, it was assumed that timelier versus less timely follow-up care would be preferred. This is based on the literature regarding delayed appointments for workers' compensation care (Kirsh \& McKee, 2003; Premji, 2014a).

The adequacy of care outcome measure was developed based upon the specific diagnoses of carpal tunnel syndrome, acute low back pain, and rotator cuff tendonitis. Using the workers' compensation clinical care guidelines (for carpal tunnel syndrome), American College of Occupational and Environmental Medicine (ACOEM) best practices guidelines (rotator cuff syndrome and low back pain), and in consultation with a board certified occupational and internal medicine physicians, minimum medical care definitions were created. Minimum medical care was then assessed as either present $($ adequate care $=$ yes $)$, or not present $($ adequate care $=$ no). While not a validated measure per se, the clinical guidelines provided by the WC agency, as well as the guidelines from ACOEM, are evidence-based and developed by physicians practicing in occupational and environmental medicine.

The patient satisfaction outcome measure, a common construct used to measure quality of care, included two modified questions from the Patient Experience Measures of the Consumer Assessment of Healthcare Providers and Systems (CAHPS $\left.{ }^{\circledR}\right)$ Program (Agency for Health Care Policy and Research, 1998). The two questions were (1) overall 
satisfaction of provider, and (2) provider explanation of things in a way they could understand. These were reverse scored in this study from the CAHPS survey to match the scoring of other measures.

Administrative outcomes in Chapter 3 include four outcomes for workers based on the literature: First, timeliness of diagnostic approvals (yes/no), indicates whether or not diagnostic services were approved in a timely manner. This outcome is based upon WC treatment guidelines (Labor and Industries, 2014) or American College of Occupational and Environmental Medicine guidelines (ACOEM, 2016). Second, delays in wage replacement payments were also coded as (yes/no), based upon a statutory requirement Revised Code of Washington (RCW) 51.32.210 (RCW, 1972) that wage replacement (time loss checks) shall be issued within 14 days of a workers' compensation claim being accepted. Third, for language-appropriate services, I created a dichotomous variable based on WC administrative billing data combined with administrative data for language preference. If an injured worker indicated a language other than English to converse with the $\mathrm{WC}$ agency, and there were no billing records for translations or interpreters, language appropriate services was coded as 0 (not appropriate services), otherwise language appropriate services was coded as 1. A reverse scored variable (Not linguistically appropriate services) was created to aid interpretation of the results. Fourth, a count variable was created for Independent medical exams (IME) usage based on WC administrative data. IMEs are frequently used by WC agencies to move a claim towards closure, and has been discussed in the literature as anti-therapeutic and potentially damaging for mental health (Ison, 1986; Lippel, 1999). The IME count is over-dispersed 
with the variance greater than the mean so was modeled using negative binomial regression.

Chapter 4 examines the outcome variable of whether the worker felt they had returned to work too early. This outcome was based upon one survey question: "Do you feel you returned to work too early?" Returning to work too early was coded as one if a respondent answered "yes" and zero if they responded as "no." Based on the return-towork literature, there is evidence that returning to work as early as possible is the preferred outcome after an injury (Boden \& Ruser, 2003; Kyes et al., 1999), yet very little research exists regarding the negative consequences of returning to work too early. The literature that does exist regarding returning to work before one is medically ready has linked this outcome to re-injury (Galizzi, Leombruni, Pacelli, \& Bena, 2016; Garcy, Mayer, \& Gatchel, 1996) and to the creation of mental health disorders (Wall, Ogloff, \& Morrissey, 2007).

For the perceived discrimination variable in Chapter 4, I utilized two items adapted from the Multi-City Study of Urban Inequality (MCSUI) (Bobo et al., 2000). These items were: "Were you discriminated against at your work because of your race, color, or ethnicity?" (yes/no) and "Have you ever felt that others at your place of employment got promotions or pay raises faster than you did because of your race or ethnicity?" (yes/no).

\section{Chapter Summaries}

Chapter 2 explores the role of health-care providers in WC claim processes and potential causal mechanisms in producing racial inequality such as HCP actions and 
resultant inequities in quality of care; adequacy of treatment; and different levels of patient satisfaction. This study also assesses the role of perceived racial discrimination in these outcomes. Minority workers were more likely to report perceived racial discrimination from health-care providers, and this discrimination was associated with lower levels of patient satisfaction. This study was able to identify multiple flexible resources (income, education, and health-care provider communication), which appeared to partially mediate the effects of racial discrimination on health-service outcomes.

Chapter 3 explores the role of individual and institutional racial discrimination to describe how minorities experience WC agency processes, and how critical services are provided by the workers' compensation agency: timely diagnostic testing approvals, timely payments for partial wage replacement, and the use of independent medical exams to manage a claim. Similar to the work of MacEachen (2010) and Lippel (1999), this study found that certain administrative barriers exist within the WC agency that create negative consequences for injured workers. This study advances the works of MacEachen (2010), and Lippel (1999) by quantitatively measuring disparate occurrences of these administrative barriers among minorities. This study adds to the literature by identifying racial differences in how these barriers affect an injured worker's health and also supports the FCT hypothesis that racial discrimination is a fundamental cause of poor health outcomes.

Chapter 4 continues the story of minorities in the WC system with an examination of the role of perceived workplace discrimination and the potential of workplace support to mediate workplace discrimination in the return-to-work process. This study found 
support for the hypothesis that racial discrimination suffered at work is associated with feeling one had returned to work too early after an injury. This study also adds to the literature by identifying potential areas for future interventions in returning minority workers to work: the role of return-to-work support. Workplace support was found to mediate a significant proportion of the direct association between returning to work too early and racial discrimination in the workplace.

Chapter 5 summarizes the study findings; compares and contrasts the results to prior literature; and provides a list of implications for the current situation of minorities in the Washington State workers' compensation system. It concludes with a discussion of what additional research should be conducted to explore the role of racial discrimination in workers' compensation. 


\section{References}

AAPOR. (2015). Standard Definitions: Final Dispositions of Case Codes and Outcome Rates for Surveys. Retrieved from https://www.aapor.org/EducationResources/For-Researchers/Poll-Survey-FAQ/Response-Rates-An-Overview.aspx

ACOEM. (2016). ACOEM's Occupational Medicine Practice Guidelines - 2016 Revision. from The Reed Group https://new.mdguidelines.com/Resources/ACOEM-Practice-Guidelines

Agency for Health Care Policy and Research, A. (1998). Consumer Assessments of Health Plans Study (CAHPS): Overview. Rockville, MD.

AHRQ, A. f. H. R. a. Q. (2015). 2014 National Healthcare Quality \& Disparities Report. Rockville, MD Retrieved from http://www.ahrq.gov/research/findings/nhqrdr/nhqdr14/index.html

Alonso-Villar, O., Del Rio, C., \& Gradin, C. (2012). The Extent of Occupational Segregation in the United States: Differences by Race, Ethnicity, and Gender. Industrial Relations, 51(2), 179-212.

Angelon-Gaetz, K. A., Richardson, D. B., \& Wing, S. (2010). Inequalities in the nuclear age: impact of race and gender on radiation exposure at the Savannah River Site (1951-1999). New Solut, 20(2), 195-210.

Azaroff, L. S., Levenstein, C., \& Wegman, D. H. (2004). The occupational health of Southeast Asians in Lowell: a descriptive study. Int J Occup Environ Health, 10(1), 47-54.

Bambra, C. (2011). Work, worklessness and the political economy of health inequalities. Journal of Epidemiology and Community Health, 65(9), 746-750.

Bartley, M., Ferrie, J., \& Montgomery, S. M. (2006). Health and labour market disadvantage: unemployment, non-employment, and job insecurity. In M. G. Marmot \& R. G. Wilkinson (Eds.), The Social Determinants of Health (Second ed., pp. 78-96). New York: Oxford University PRess.

Beardwood, B. A., Kirsh, B., \& Clark, N. J. (2005). Victims twice over: perceptions and experiences of injured workers. Qual Health Res, 15(1), 30-48.

Bertrand, M., \& Mullainathan, S. (2004). Are Emily and Greg More Employable Than Lakisha and Jamal? A Field Experiment on Labor Market Discrimination. The American Economic Review, 94(4), 991-1013.

Bhui, K., Stansfeld, S., McKenzie, K., Karlsen, S., Nazroo, J., \& Weich, S. (2005).

Racial/ethnic discrimination and common mental disorders among workers: Findings from the EMPIRIC study of ethnic minority groups in the United Kingdom. American Journal of Public Health, 95(3), 496-501.

BLS. (2017a). BLS Handbook of Methods Chapter 9. Occupational Safety and Health Statistics. Retrieved from https:/www.bls.gov/opub/hom/pdf/homch9.pdf

BLS. (2017b). Labor force characteristics by race and ethnicity, 2016. (1070). Bureau of Labor Statistics Retrieved from https://www.bls.gov/opub/reports/race-andethnicity/2016/pdf/home.pdf. 
BLS. (2017c). Survey of Occupational Injuries and Illnesses. Retrieved from https://www.bls.gov/opub/hom/soii/pdf/soii.pdf.

Bobo, L., Johnson, J., Oliver, M. L., Farley, R., Bluestone, B., Browne, I., . . ZubrinskyCharles, C. (2000). MULTI-CITY STUDY OF URBAN INEQUALITY, 1992-1994: [ATLANTA, BOSTON, DETROID, AND LOS ANGELES] [HOUSEHOLD SURVEY DATA]

Boden, L. I., \& Ruser, J. W. (2003). Workers' compensation "reforms," choice of medical care provider, and reported workplace injuries. Review of Economics and Statistics, 85(4), 923-929.

Bonacich, E. (1972). A theory of ethnic antagonism: the split labor market. American Sociological Review, 37(5), 547-559.

Bonauto, D. K., Smith, C. K., Adams, D. A., Fan, Z. J., Silverstein, B. A., \& Foley, M. P. (2010). Language preference and non-traumatic low back disorders in washington state workers' compensation. American Journal of Industrial Medicine, 53(2), 204-215. doi:10.1002/ajim.20740

Braveman, \& Gottlieb, L. (2014). The Social Determinants of Health: It's Time to Consider the Causes of the Causes. Public Health Reports, 129(1_suppl2), 19-31. doi:10.1177/00333549141291s206

Braveman, P. A., Cubbin, C., Egerter, S., Williams, D. R., \& Pamuk, E. (2010). Socioeconomic disparities in health in the united States: What the patterns tell us. American Journal of Public Health, 100(SUPPL. 1), S186-S196.

Browne, I., Hewitt, C., Tigges, L., \& Green, G. (2001). Why Does Job Segregation Lead To Wage Inequality among African Americans? Person, Place, Sector, or Skills? Social Science Research, 30(3), 471-495.

Cherniack, M. (1986). The Hawk's Nest Incident: America's worst indstrial disaster. New Haven, CT: Yale University Press.

Chibnall, J. T., Tait, R. C., Andresen, E. M., \& Hadler, N. M. (2006). Race differences in diagnosis and surgery for occupational low back injuries. Spine, 31(11), 12721275.

Chung-Bridges, K., Muntaner, C., Fleming, L. E., Lee, D. J., Arheart, K. L., LeBlanc, W. G., . . Davila, E. P. (2008). Occupational Segregation as a Determinant of US Worker Health. American Journal of Industrial Medicine, 51, 555-567.

Clark, R., Coleman, A. P., \& Novak, J. D. (2004). Brief report: Initial psychometric properties of the everyday discrimination scale in black adolescents. Journal of adolescence, 27(3), 363-368.

Collins, K. S., Hughes, D. L., Doty, M. M., Ives, B. L., Edwards, J. N., \& Tenney, K. (2002). Diverse communities, common concerns: assessing health care quality for minority Americans: Commonwealth Fund New York.

Cooke, C. R., Nallamothu, B., Kahn, J. M., Birkmeyer, J. D., \& Iwashyna, T. J. (2011). Race and tiemliness of transfer for revascularization in patients with acute myocardial infarction. Medical Care, 49(7), 662-667.

Dasinger, L. K., Krause, N., Thompson, P. J., Brand, R. J., \& Rudolph, L. (2001). Doctor proactive communication, return-to-work recommendation, and duration of 
disability after a workers' compensation low back injury. J Occup Environ Med, 43(6), 515-525.

Davis, T. Y., \& Moore, W. L. (2014). Spanish not spoken here: Accounting for the racialization of the Spanish language in the experiences of Mexican migrants in the United States. Ethnicities, 14(5), 676-697.

Dembe, A. E. (2001a). Access to medical care for occupational disorders: difficulties and disparities. J Health Soc Policy, 12(4), 19-33.

Dembe, A. E. (2001b). The social consequences of occupational injuries and illnesses. Am J Ind Med, 40(4), 403-417. doi:10.1002/ajim.1113 [pii]

Duncan, G. (2003). Workers' compensation and the governence of pain. Economy and Society, 32(3), 449-477.

Dunning, K. K., Davis, K. G., Cook, C., Kotowski, S. E., Hamrick, C., Jewell, G., \& Lockey, J. (2010). Costs by industry and diagnosis among musculoskeletal claims in a state workers compensation system: 1999-2004. American Journal of Industrial Medicine, 53(3), 276-284.

Elliott, M. N., Morrision, P. A., Fremont, A., McCaffrey, D. F., Pantoja, P., \& Lurie, N. (2009). Using the Census Bureeau's surname list to improve estimates of race/ethnicity and associated disparities. Health Serv Outcomes Res Method, 9 , 69-83.

Farmer, M. M., \& Ferraro, K. F. (2005). Are racial disparities in health conditional on socioeconomic status? Social Science \& Medicine, 60(1), 191-204. doi:10.1016/j.socscimed.2004.04.026

Feagin, J. (2000). Racist America. New York and London: Routledge.

Feagin, J., \& Bennefield, Z. (2014). Systemic racism and US health care. Social Science \& Medicine, 103, 7-14.

Flynn, M., TR., C., RJ., G., B., K., LJ., C., D., H., \& C., S. (2015). Overlapping vulnerabilities: the occupational safety and health of young workers in small construction firms. (2015-178). Cinncinati OH: U.S. Department of Health and Human Services, Centers for Disease Control and Prevention, National Institute for Occupational Safety and Health.

Galizzi, M., Leombruni, R., Pacelli, L., \& Bena, A. (2016). Injured workers and their return to work: Beyond individual disability and economic incentives. Evidencebased HRM: a Global Forum for Empirical Scholarship, 4(1), 2-29. doi:doi:10.1108/EBHRM-02-2015-0002

Garcy, P., Mayer, T., \& Gatchel, R. J. (1996). Recurrent or New Injury Outcomes After Return to Work in Chronic Disabling Spinal Disorders: Tertiary Prevention Efficacy of Functional Restoration Treatment. Spine, 21(8), 952-959.

Gleeson, S. (2016). Precarious Claims:The Promise and Failure of Workplace Protections in the United States. . Oakland California: University of California Press.

Graham, J. D., \& Holtgrave, D. R. (1990). Coke oven emissions: a case study of technology-based regulation. Risk, 1, 243.

Gravel, S., Vissandjee, B., Lippel, K., Brodeur, J. M., Patry, L., \& Champagne, F. (2010). Ethics and the compensation of immigrant workers for work-related injuries and 
illnesses. J Immigr Minor Health, 12(5), 707-714. doi:10.1007/s10903-008-92085

Grosfoguel, R. (2004). Race and ethnicity or racialized ethnicities? Identities within global coloniality. Ethnicities, 4(3), 315-336.

Hilgert, J. A. (2012). Building a Human Rights Framework for Workers' Compensation in the United States: Opening the Debate on First Principles. American Journal of Industrial Medicine, 55(6), 506-518.

Institute of Medicine. (2003). Unequal Treatment: Confronting Racial and Ethnic Disparities in Health Care. Washington, D.C.: The National Academies Press.

Ison, T. G. (1986). The therapeutic significance of compensation structures. Can. B. Rev., 64, 605 .

Johnson, R. L., Saha, S., Arbelaez, J. J., Beach, M. C., \& Cooper, L. A. (2004). Racial and ethnic differences in patient perceptions of bias and cultural competence in health care. Journal of General Internal Medicine, 19(2), 101-110.

Johnston, V., \& Bao, u. (2011). Race/Ethnicity-Related and Payer-Related Disparities in the Timeliness of Emergency Care in U.S. Emergency Departments. Journal of Health Care for the Poor and Underserved, 22(2), 606-620.

Kilgour, E., Kosny, A., McKenzie, D., \& Collie, A. (2014). Interactions Between Injured Workers and Insurers in Workers' Compensation Systems: A Systematic Review of Qualitative Research Literature. J Occup Rehabil. doi:10.1007/s10926-0149513-X

Kilgour, E., Kosny, A., McKenzie, D., \& Collie, A. (2014). Interactions Between Injured Workers and Insurers in Workers' Compensation Systems: A Systematic Review of Qualitative Research Literature. J Occup Rehabil, 1-22. doi:10.1007/s10926014-9513-x

Kim, G., Sellbom, M., \& Ford, K.-L. (2014). Race/ethnicity and measurement equivalence of the Everyday Discrimination Scale. Psychological Assessment, 26(3), 892.

Kirsh, B., \& McKee, P. (2003). The needs and experiences of injured workers: a participatory research study. Work, 21(3), 221-231.

Kochanek, K. D., Murphy, S. L., Xu, J., \& Arias, E. (2017). Mortality in the United States, 2016. (293). Centers for Disease Control and Prevention: CDC.

Kosny, A., MacEachen, E., Ferrier, S., \& Chambers, L. (2011). The role of health care providers in long term and complicated workers' compensation claims. J Occup Rehabil, 21(4), 582-590. doi:10.1007/s10926-011-9307-3

Kosny, A., MacEachen, E., Lifshen, M., Smith, P., Jafri, G. J., Neilson, C., . . Shields, J. (2012). Delicate dances: immigrant workers' experiences of injury reporting and claim filing. Ethn Health, 17(3), 267-290. doi:10.1080/13557858.2011.614327

Kyes, K. B., Wickizer, T. M., Franklin, G., Cain, K., Cheadle, A., Madden, C., . . . Weaver, M. (1999). Evaluation of the Washington State Workers' Compensation Managed Care Pilot Project I: medical outcomes and patient satisfaction. Med Care, 37(10), 972-981.

Labor and Industries, W. S. D. o. (2014). Medical Treatment Guidelines. Olympia, WA: Washington State Department of Labor and Industries Retrieved from 
http://www.Ini.wa.gov/ClaimsIns/Providers/TreatingPatients/TreatGuide/default.a sp? source $=\mathrm{FF}$.

Labor and Industries, W. S. D. o. (2015). Your Premium Dollars At Work: Washington's Workers' Compensation System. (F200-025-000). Olympia, Washington Retrieved from https://www.Ini.wa.gov/IPUB/200-025-000.pdf.

Link, B. G., \& Phelan, J. (1995). Social Conditions as Fundamental Causes of Disease. Journal of Health and Social Behavior, 80-94.

Lippel, K. (1999). Therapeutic and Anti-Therapeutic Consequences of Workers' Compensation. Int J Law Psychiatry, 22(5-6), 521-546.

Lippel, K. (2007). Workers describe the effect of the workers' compensation process on their health: a Quebec study. Int J Law Psychiatry, 30(4-5), 427-443. doi:10.1016/j.ijlp.2007.06.013

Lippel, K. (2012). Preserving workers' dignity in workers' compensation systems: an international perspective. Am J Ind Med, 55(6), 519-536. doi:10.1002/ajim.22022

Lipscomb, H. J., Loomis, D., McDonald, M. A., Argue, R. A., \& Wing, S. (2006). A conceptual model of work and health disparities in the United States. Int $J$ Health Serv, 36(1), 25-50.

Lloyd, J. (1971). Long-term mortality study of steel workers. V. Respiratory cancer in coke plant workers. Journal of Occupational Medicine, 13(2), 53-68.

Lutfey, K., \& Freese, J. (2005). Toward Some Fundamentals of Fundamental Causality: Socioeconomic Status and Health in the Routine Clinic Visit for Diabetes. American Journal of Sociology, 110(5), 1326-1372.

MacEachen, E. (2000). The mundane administration of worker bodies: from welfarism to neoliberalism. Health, Risk \& Society, 2(3), 315-327.

MacEachen, E., Kosny, A., Ferrier, S., \& Chambers, L. (2010). The "Toxic Dose" of System Problems: Why Some Injured Workers Don't Return to Work as Expected. J Occup Rehabil, 20(3), 349-366.

Massey, D. S. (2009). Racial formation in theory and practice: The case of Mexicans in the United States. Race and Social Problems, 1(1), 12-26.

Maume, D. J. (1999). Glass Ceilings and Glass Escalators: Occupational Segregation and Race and Sex Differences in Managerial Promotions. Work and Occupations, 26(4), 483-509.

Nevitt, C., Daniell, W., \& Rosenstock, L. (1994). WORKERS COMPENSATION FOR NONMALIGNANT ASBESTOS-RELATED LUNG-DISEASE. American Journal of Industrial Medicine, 26(6), 821-830. doi:10.1002/ajim.4700260611

Phelan, \& Link, B. G. (2015). Is Racism a Fundamental Cause of Inequalities in Health? Annual Review of Sociology, 41, 311-330.

Phelan, Link, B. G., \& Tehranifar, P. (2010). Social Conditions as Fundamental Causes of Health Inequalities: Theory, Evidence, and Policy Implications. Journal of Health and Social Behavior, 51, S28-S40. doi:10.1177/0022146510383498

Preacher, K. J., \& Hayes, A. F. (2008). Asymptotic and resampling strategies for assessing and comparing indirect effects in multiple mediator models. Behavioral Research Methods, 40, 879-891. 
Premji, S. (2014a). Barriers to Return-to-Work for Linguistic Minorities in Ontario: An Analysis of Narratives from Appeal Decisions. J Occup Rehabil, 1-11. doi:10.1007/s10926-014-9544-3

Premji, S. (2014b). Mechanisms of inequalities inhealth and safety: conceptual model and research agenda. Perspectives interdisciplinaires sur le travail et la santé, 16(2), $2-11$.

Premji, S., \& Krause, N. (2010). Disparities by ethnicity, language, and immigrant status in occupational health experiences among Las Vegas hotel room cleaners. American Journal of Industrial Medicine, 53(10), 960-975. doi:10.1002/ajim.20860

Premji, S., Lippel, K., \& Messing, K. (2008). We work by the second! Piecework remuneration and occupational health and safety from an ethnicity-and gendersensitive perspective. PISTES, 10(1).

Premji, S., Messing, K., \& Lippel, K. (2008). Broken English, Broken Bones? Mechanisms Linking Language Proficiency and Occupational Health in a Montreal Garment Factory. International Journal of Health Services, 38(1), 1-19.

Press, R., Carrasquillo, O., Sciacca, R. R., \& Giardina, E.-G. V. (2008). Racial/Ethnic Disaparities in Time to Follow-Up after an Abnormal Mammogram. Journal of Women's Health, 17(6), 923-930.

Quillian, L., Pager, D., Hexel, O., \& Midtbøen, A. H. (2017). Meta-analysis of field experiments shows no change in racial discrimination in hiring over time. Proceedings of the National Academy of Sciences, 114(41), 10870-10875. doi:10.1073/pnas.1706255114

Industrial Insurance. Compensation-Right to and Amount, 32 C.F.R. (1972).

Roberts, R. K., Swanson, N. G., \& Murphy, L. R. (2004). Discrimination and occupational mental health. Journal of Mental Health, 13(2), 129-142.

Robinson, J. C. (1984). Racial Inequality and the Probability of Occupation-Related Injury or Illness. The Milbank Memorial Fund Quarterly. Health and Society, 62(4), 567-590. doi:10.2307/3349837

Rosa, J. (2016). Standardization, racialization, languagelessness: Raciolinguistic ideologies across communicative contexts. Journal of Linguistic Anthropology, 26(2), 162-183.

Rosa, J., \& Flores, N. (2017). Unsettling race and language: Toward a raciolinguistic perspective. Language in Society, 46(5), 621-647.

Rudolph, L., Dervin, K., Cheadle, A., Maizlish, N., \& Wickizer, T. (2002). What Do Injured Workers Think About Their Medical Care and Outcomes After Work Injury? Journal of Occupational \& Environmental Medicine, 44(5), 425-434.

Safran, E. S., Cohen, L. P., Caplan, L. S., Ohuabunwa, U. K., \& Pharagood-Wade, F. (2005). Barriers to occupational and environmental medicine services in the southeastern United States. Journal of occupational and environmental medicine / American College of Occupational and Environmental Medicine, 47(3), 219-225.

Scherzer, T., Rugulies, R., \& Krause, N. (2005). Work-related pain and injury and barriers to workers' compensation among Las Vegas hotel room cleaners. Am J Public Health, 95(3), 483-488. doi:10.2105/AJPH.2003.033266 
Seabury, S. A., Terp, S., \& Boden, L. I. (2017). Racial And Ethnic Differences In The Frequency Of Workplace Injuries And Prevalence Of Work-Related Disability. Health Affairs, 36(2), 266-273. doi:10.1377/hlthaff.2016.1185

Shannon, C. A., Rospenda, K. M., Richman, J. A., \& Minich, L. M. (2009). Race, Racial Discrimination, and the Risk of Work-Related Illness, Injury, or Assault: Findings From a National Study. Journal of Occupational \& Environmental Medicine, 51(4), 441-448.

Skolasky, R. L., Albert, T. J., Vaccaro, A. R., \& Riley, L. H. (2009). Patient satisfaction in the cervical spine research society outcomes study: relationship to improved clinical outcome. The Spine Journal, 9(3), 232-239. doi:http://dx.doi.org/10.1016/j.spinee.2008.03.001

Tait, R. C., Chibnall, J. T., Andresen, E. M., \& Hadler, N. M. (2004). Management of occupational back injuries: differences among African Americans and Caucasians. Pain, 112(3), 389-396. doi:10.1016/j.pain.2004.09.027

Tait, R. C., Chibnall, J. T., Andresen, E. M., \& Hadler, N. M. (2006). Disability Determination: Validity With Occupational Low Back Pain. Journal of Pain, 7(12), 951-957.

Thorburn Bird, S., \& Bogart, L. M. (2001). Perceived Race-Based and Socioeconomic Status (SES)- Based Discrimination in Interactions with Health Care Providers. Ethnicity \& disease, 11(3), 554-563.

UCLA: Statistical Consulting Group. (2016). Stata FAQ: How can I do mediation analysis with a categrical IV in Stata? Retrieved from http://www.ats.ucla.edu/stat/stata/faq/mediation cativ.htm

van Ryn, M., Burgess, D. J., Dovidio, J. F., Phelan, S. M., Saha, S., Malat, J., . . Perry, S. (2011). The Impact of Racism on Clinician Cognition, Behavior, and Clinical Decision Making. Du Bois Review: Social Science Research on Race, 8(01), 199218. doi:doi:10.1017/S1742058X11000191

Wall, C. L., Ogloff, J. R. P., \& Morrissey, S. A. (2007). Psychological Consequences of Work Injury: Personality, Trauma and Psychological Distress Symptoms of Noninjured Workers and Injured Workers Returning To, or Remaining at Work. International Journal of Disability Management, 2(2), 37-46. doi:10.1375/jdmr.2.2.37

Williams, D. R., Mohammed, S. A., Leavell, J., \& Collins, C. (2010). Race, socioeconomic status, and health: Complexities, ongoing challenges, and research opportunities. In N. E. Adler \& J. Stewart (Eds.), Biology of Disadvantage: Socioeconomic Status and Health (Vol. 1186, pp. 69-101).

Williams, D. R., Yu, Y., Jackson, J., S., \& Anderson, N. B. (1997). Racial differences in physical and mental health. Socio-economic status, stress and discrimination. Journal of Health Psychology, 2(3), 335-351.

Wingfield, A. H. (2009). Racializing the Glass Escalator: Reconsidering Men's Experiences with Women's Work. Gender \& Society, 23(1), 5-26. 


\section{Chapter 2: Health Services in Workers' Compensation: Is Provider Racial Discrimination a Key Factor in Racial Inequalities in Occupational Injury Outcomes?}

\section{Work-related Injuries and Illnesses}

Work-related injuries and illnesses (WRII) are a major source of personal and economic hardship in the United States. Each year, over eight million US workers suffer work-related injuries and illnesses at an annual cost of \$250 billion (Leigh, 2011). Workers of color and those with limited English proficiency (LEP) suffer disproportionately from WRII. Numerous studies have shown elevated rates among minorities for a range of work-related outcomes including: work-related homicides (Menendez et al. 2013), (Menendez, Konda, Hendricks, \& Amandus, 2013)heat-related deaths (Gubernot, Anderson, \& Hunting, 2015), hospitalization for traumatic work injury (Sears, Bowman, \& Hogg-Johnson, 2015), and occupational respiratory diseases (Stanbury \& Rosenman, 2014). Additionally, while overall incidence of WRII has declined over the past hundred years, racial disparities still persist. The rate of work injuries among Black men was 1.78 times higher than the rate among White men in 1968 (Robinson, 1987), and this disparity has continued (1988-2000) (Strong and Zimmerman 2005).

\section{Health Care for Work-Related Injuries and Illnesses}

Timely and appropriate healthcare is critical to ensuring maximal recovery from work-related injuries and illnesses. Like rates of injuries and illnesses, healthcare experiences differ by race/ethnicity. For general health care (non-work-related), 
minorities receive lower quality of care than their non-Latino White (hereafter referred to as Whites) counterparts with the same medical condition, regardless of income or health insurance status (Institute of Medicine, 2003). While sparse, the literature on treatment for WRII by race/ethnicity suggests a similar pattern of healthcare disparities, with minorities experiencing limited access to skilled healthcare providers, differences in medical treatment, and lower patient satisfaction (Chibnall, Tait, Andresen, \& Hadler, 2006b; Dembe, Savageau, Amick, \& Banks, 2005; Rudolph, Dervin, Cheadle, Maizlish, \& Wickizer, 2002; Tait, Chibnall, Andresen, \& Hadler, 2004).

\section{Access to Providers}

In an analysis of National Ambulatory Medical Care Survey data, Dembe et al. (2005) found that African Americans and Latinos were less likely than Whites were to see a physician during their visits for work-related injuries and illnesses (58\% less likely for African Americans and 64\% less likely for Latinos). Although few studies have documented limited English proficient (LEP) workers' experiences with WRII health care, those who have focused on LEP workers have found limited opportunities for treatment by language-concordant providers, and insufficient availability of interpreter services when seeking healthcare in emergency rooms or walk-in clinics (Kosny et al., 2012).

\section{Adequate Treatment}

In a series of studies on low back pain workers' compensation claimants, Chibnall, Tait, Andresen and Hadler (2006b) found significant disparities by race for diagnosis and treatment. Among their findings was the increased proportion of Whites 
who were given a specific medical diagnosis, compared to African Americans (Whites were 40\% more likely than African Americans). Specific back pain diagnoses are associated with lower treatment costs and lower disability ratings than non-specific diagnoses (Chibnall, Tait, Andresen, \& Hadler, 2005, 2006a; Chibnall, Tait, \& Merys, 2000; Tait et al., 2004). Dembe et al. (2005) also reported differences by race/ethnicity in the medical treatment provided for work-related injuries and illnesses: Latinos were almost half as likely to be prescribed medications than non-Latinos. In addition, Latinos were 2.5 times more likely to require prior authorization for treatment than non-Latinos were.

\section{Patient Satisfaction}

Compared to White, English-speaking injured workers, minority LEP report lower satisfaction with the doctor-patient relationship in the California workers' compensation (WC) system (Rudolph et al., 2002); the same holds true among the largely Latino immigrant population of Las Vegas hotel room cleaners(Premji \& Krause, 2010). This is concerning because patient satisfaction has been linked to better outcomes following WRII (Dasinger, Krause, Thompson, Brand, \& Rudolph, 2001; Skolasky, Albert, Vaccaro, \& Riley, 2009).

\section{Mechanisms for Disparities}

The increased rate of WRII among minorities is often explained as the result of poor socioeconomic status (SES), racial and ethnic occupational segregation, and inadequate job-safety training for low-skilled minority workers and linguistic minorities (Chung-Bridges et al., 2008; Lipscomb, Loomis, McDonald, Argue, \& Wing, 2006; 
Premji \& Krause, 2010). Yet few of these hypothesized causes for disparities by racialized group status in the health outcomes that follow a work-related injury or illness have been studied.

Whereas inadequate health insurance coverage is a major cause of general health outcome inequality among minorities (Institute of Medicine, 2003, 2012), workers' compensation insurance provides seemingly equitable insurance coverage for all injured workers (so long as workers' compensation laws cover them). Even in a system that guarantees healthcare for all individuals, (Institute of Medicine, 2003) however, minorities report poorer healthcare experiences, as documented by Lasser, Himmelstein, and Woolhandler (2006) in minorities' perceptions of limited access, poorer quality of care, and dissatisfaction when accessing care in Canada's universal healthcare system(Lasser, Himmelstein, \& Woolhandler, 2006).

Disparities in health service access and provider bias (implicit and explicit) may be potential causes of differences in health outcomes for minority workers (Institute of Medicine, 2003; Lipscomb et al., 2006; Moskowitz, Stone, \& Childs, 2012; Michelle van Ryn et al., 2011).

In the broader (non-workers' compensation) healthcare literature, physician bias is associated with inadequate or delayed care for minority patients (Institute of Medicine, 2003; Johnson, Saha, Arbelaez, Beach, \& Cooper, 2004; M. van Ryn, 2002; Michelle van Ryn et al., 2011; M. van Ryn \& Burke, 2000; Weech-Maldonado et al., 2003). In a qualitative study of workers' compensation claimants in Ontario, Canada, Beardwood, 
Kirsh, and Clark (2005), noted frequent instances among workers of color of perceived racial discrimination when seeking treatment for WRII.

The literature summarized above clearly describes worse rates of injury and lower quality of care for minorities seeking treatment in a workers' compensation system. To date, however, few studies have speculated why this consistent picture endures, and even fewer have posited a theoretical rationale for these racial disparities that could be tested.

\section{Theoretical Framework}

The conceptual framework for this study is grounded in Link and Phelan's (1995) fundamental cause theory which asserts there are enduring social conditions that perpetuate inequalities in health, regardless of the precise mechanisms that link them to health disparities. According to Link and Phelan, four basic criteria indicate a potential fundamental cause. First, a fundamental cause affects multiple health outcomes. Second, a fundamental cause influences multiple risk factors via multiple mechanisms. Third, avoiding or ameliorating the association between a fundamental cause and health inequity involves the use of flexible resources, such as power, social connections, and money. Fourth, the association between the fundamental cause and health outcome is persistent, even if identified mechanisms linking them are eliminated (Link \& Phelan, 1995).

Phelan and Link (2015)have also proposed that racism, independent of socioeconomic status (SES), is a fundamental cause of health inequalities (Feagin, 2000; Feagin \& Bennefield, 2014). Even after adjusting for socioeconomic status (SES), disparities still exist by race/ethnicity and language in many health outcomes and quality of health services provided (Cooke, Nallamothu, Kahn, Birkmeyer, \& Iwashyna, 2011; 
Hannan et al., 1999; Institute of Medicine, 2003; Press, Carrasquillo, Sciacca, \& Giardina, 2008; Reddan, Szczech, Klassen, \& Owen, 2000; Shavers et al., 2012). Fundamental cause theory provides a solid framework to test this study's hypotheses and to focus on racialized minorities in a workers' compensation healthcare system.

In classifying racial status in this study, I follow many social theorists (Massey, 2009; Rosa, 2016; D. R. Williams, Mohammed, Leavell, \& Collins, 2010) in combining linguistic minority status along with racial and ethnic identity to create three mutually exclusive "racial" categories: White English speakers, non-White English speakers, and non-White Limited English speakers.

\section{Fundamental Cause and Work-Related Injuries and Illnesses}

Racial discrimination affects multiple outcomes related to worker health, such as increased risk of WRII, delayed care (Dembe, 2001; Moure-Eraso \& Friedman-Jimenez, 2004), inadequate care (Chibnall et al. 2006b; Premji and Krause 2010), and inequalities in treatment (Tait et al. 2004). Racial discrimination affects worker health through multiple mechanisms: occupational segregation (Chung-Bridges et al., 2008; Lipscomb et al., 2006; Murray, 2003), access to care (Kosny et al., 2012; MacEachen, 2000; MacEachen, Kosny, Ferrier, \& Chambers, 2010), and provider bias (Johnson et al., 2004; Moskowitz et al., 2012; M. van Ryn, 2002; Michelle van Ryn et al., 2011). White workers, however, secure more desirable jobs with lower risks of WRII, coupled with benefits like employer-provided health insurance and paid time off, allowing them to seek treatment outside the WC system and avoid the bureaucratic hassles of the WC system if they choose to do so. 
To my knowledge, no studies have quantified the role of provider racial discrimination in health services for work-related injuries. In the non-workers' compensation health care literature, it is acknowledged that actions of health care providers are critical in determining health outcomes (Institute of Medicine, 2003). It is also well recognized that racial discrimination, or at the very least racial bias among health care providers is critical in understanding racial and ethnic differences in health outcomes (Cooper et al., 2012; Institute of Medicine, 2003), yet no such body of works exist when examining racial and ethnic differences in work-related injury health care. It is critical that workers' compensation health care be examined with at least the same rigor and scrutiny as non work-related health care, or inequalities will persist. Using workers' compensation claimant's administrative data and survey responses, this study will test the role of racial discrimination from health-care providers on three specific health-service outcomes for WRII: timeliness of care received, adequacy of care, and patient satisfaction. After controlling for SES factors of education, occupation, and household income, I hypothesize that injured workers of color and LEP will have: (1) longer delays in receiving care, (2) less adequate care, and (3) lower patient satisfaction with their health-care provider compared to White, English-speaking injured workers, and that provider discrimination will mediate the relationship between minority status and these outcomes. 


\section{Methods}

\section{Data Sources: Workers' Compensation Claims Data}

All employers in Washington State are required to provide workers' compensation insurance coverage for their employees (RCW 1961). In the event of a work-related injury or illness, workers' compensation insurance pays for medical services and, if an injured worker is unable to work, partial wage replacement. Most employers purchase the required workers' compensation insurance from the state-run program, referred to as the Washington State Fund.

I identified cases from Washington State funded workers' compensation claims data. To control for potential effects of SES, I limited claims to those in three industries, defined by the North American Industry Classification System (National Technical Information Service, 2002): the construction sector, the accommodation and food services sector, and the janitorial services industry. To minimize treatment differences due to injury type, I further limited claims to the following six injury types, based on Occupational Injury and Illness Classification codes assigned at claim filing: rotator cuff syndrome, carpal tunnel syndrome, low back pain, hospitalized burns, amputations, and hand/wrist fractures. I excluded claims limited to medical aid, as these are generally less severe injuries with few medical service encounters. Instead, I focused on compensable claims, which are claims eligible for benefits beyond medical aid, including lost wages for work absence, permanent partial disability, and permanent total disability. Claims meeting the above criteria for injuries between 2008 and 2013 were extracted from the Washington State funded workers' compensation claims database. 


\section{Survey Data}

Claimants were stratified by a race proxy (White or non-White), then sampled for participation in a survey to augment the administrative data. I oversampled non-white claimants to increase the number of responses among the group. Survey items assessed satisfaction with health-care services provided, perceptions of provider discrimination, and contributed additional demographic and health-related information not available in the workers' compensation administrative data. Surveys were conducted in the worker's preferred language and were administered via mail, online, or telephone. My goal, based on available resources, was to gather 500 completed surveys. The survey was conducted by the Washington State University's Social and Economic Sciences Research Center (SESRC) to collect information about perceived discrimination, household income, preand post-injury health status, and additional covariates that are not available in the administrative data from the workers' compensation system. The survey was conducted using multiple methods; mail, telephone, and internet survey instruments. Telephone surveys were conducted in the respondents preferred language.

\section{Outcome Measures}

I evaluated three outcome measures: timeliness of care, adequacy of care, and patient satisfaction. Timeliness of care was measured using workers' compensation administrative billing data to describe the number of days from the initial medical visit to the first follow-up visit. Generally, claimants have discretion about the date of injury to scheduling the first medical visit (e.g., when to seek initial treatment for a sore shoulder), but the health-care provider determines, at least in part, the date of the follow-up visit. 
Fewer days from an initial medical visit to follow-up visit reflects more timely care. As there are no formal guidelines in the best-practice literature for timely care, I assessed days between follow-up care, with the assumption that fewer days would be preferable, based upon the literature indicating claimants frequently didn't receive care when they wanted to (Kirsh \& McKee, 2003; Premji, 2014).

Adequacy of care was assessed for the three musculoskeletal disorders only (rotator cuff syndrome, carpal tunnel syndrome, and low back pain), and was based on the agency's Medical Treatment Guidelines (Labor and Industries, 2014) as well as 'best practice' guidelines from the American College of Occupational and Environmental Medicine (ACOEM) (2016), and in consultation with a Board Certified Occupational Medicine and Internal Medicine physician. Care was dichotomized as either adequate or inadequate. Table 1 includes definitions of adequate care by injury type.

\section{Table 1}

Adequate Care Case Definitions

\begin{tabular}{lll}
\hline Condition & Any one of the following & $\begin{array}{l}\text { Plus any one of the } \\
\text { following }\end{array}$ \\
\hline $\begin{array}{l}\text { Carpal tunnel } \\
\text { syndrome }\end{array}$ & $\begin{array}{l}\text { Splint or PT within 14 days } \\
\text { Follow-up visit with PCP within 14 days }\end{array}$ & $\begin{array}{l}\text { NCV with 45 days } \\
\text { CT surgery within 90 days }\end{array}$ \\
\hline $\begin{array}{l}\text { Rotator cuff } \\
\text { syndrome }\end{array}$ & $\begin{array}{l}\text { Follow-up visit with PCP within 14 days } \\
\text { MRI within 60 days }\end{array}$ & No additional criteria \\
\hline Low back pain & PT within 60 days & \\
& $\begin{array}{l}\text { Follow-up visit with PCP within 14 days } \\
\text { MRI within 60 days }\end{array}$ & No additional criteria \\
& PT within 60 days \\
& Chiropractic visit within 60 days & \\
\hline
\end{tabular}

Patient satisfaction with the attending provider was assessed with two survey items. The first question asked: "How much do you agree or disagree with the following 
statement: Overall, I'm very satisfied with the medical care I have received for my workrelated injury." The second question asked: "How much do you agree or disagree with the following statement: My health-care provider fully explained my treatment and options in a way that I could understand." Both questions used the 4-point scale: strongly agree, agree, disagree, and strongly disagree. Patient satisfaction was defined as the sum of the responses to the two questions.

\section{Independent Variables}

Respondents' self-reported race and English proficiency were collected in the survey data, but I did not have large enough samples to keep self-reported race, ethnicity, or language in the analyses. Respondents were therefore grouped into one of three categories: non-Latino Whites who spoke English well or very well, non-Whites who spoke English well or very well, and non-Whites who did not speak English well or very well (LEP).

Racial discrimination was measured using the Perceived Racial Discrimination Scale (PRDS) (Thorburn Bird \& Bogart, 2001) and was gathered via self-report from those surveyed. The scale consists of seven yes/no questions. The questions were the following:

(1) During treatment for your work-related injury, were you ever treated with less courtesy than other people because of your race, color or ethnicity?

(2) During treatment for your work-related injury, were you ever treated with less respect than other people because of your race, color or ethnicity? 
(3) During treatment for your work-related injury, did you ever receive poorer services than others, because of your race, color, or ethnicity?

(4) During treatment for your work-related injury, did you ever have a doctor or nurse act as if he or she thinks you are not smart because of your race, color, or ethnicity?

(5) During treatment for your work-related injury, did you ever have a doctor or nurse act as if he or she is afraid of you because of your race, color, or ethnicity?

(6) During treatment for your work-related injury, did you ever have a doctor or nurse act as if he or she was better than you because of your race, color, or ethnicity?

(7) During treatment for your work-related injury, did you ever feel like a doctor or nurse was NOT listening to what you were saying because of your race, color, or ethnicity?

Responses were summed across the seven questions to produce a single value that ranged from 0-7. Higher scores reflect higher levels of perceived racial discrimination.

\section{Mediating Variable}

Income (household income dichotomized at the median level of $\$ 35,000$ ) and education (high school degree or higher) were used to test for mediation of SES on the relationships between race or racial discrimination and the outcomes in this study. Additional potential mediators include physician indications at first patient visit that worker time loss would be required for the timeliness of care outcome, and physician communication (asking about work-related duties) for the patient satisfaction outcome. 


\section{Covariates}

Demographic information included worker age at the time of injury and gender. Health-care-related covariates included injury type (dichotomized into traumatic or musculoskeletal disorder) and occupation.

\section{Statistical Methods}

Survey weights were calculated to reflect the population of injured workers from which the sample was drawn. To compute survey weights, design weights (the inverse of the probability of selection for the survey) were adjusted for non-response; logistic regression models estimated response propensity by race, age, gender, geographic location, and industry. I then created replicate weights using the bootstrap method to estimate sampling variances. Separate regression models were developed for each outcome to test associations between the dependent (outcome) variables and the primary independent variables (measures of racial discrimination) while including potential confounders such as age, gender, and income. Negative binomial regression was used to model timeliness of care. Ordinary Least Squares regression was used to model patient satisfaction. Logistic regression was used to model adequacy of care.

Worker age at injury and worker gender were included in all regression models. Additional covariates were tested in bivariate relationships with all outcomes, but if they did not meet statistical significance (defined as $\mathrm{p}<0.05$ ), they were not retained in final models. Immigrant status was excluded from analyses due to the significant correlation with LEP status (significant at 0.01 with Bonferroni adjustment), and the large number of missing data (missing for almost a quarter of the sample). 


\section{Mediation Analysis}

Mediation analyses were conducted to assess potential mechanisms of provider communication and household income that may be associated with race or racial discrimination and the outcomes studied. A method developed by Preacher and Hayes (2008) to model categorical independent variables was used to model mediation with racial categories and a Stata-user written program, "PARAMED", was used to model mediation with a continuous independent variable (Dunn et al., 2015; Emsley \& Liu, 2013).

Stata version 14.2 was used to conduct all analyses. All reported statistics are based on survey-weighted analyses with the exception of mediation testing. An analysis was conducted on de-identified data (i.e., data that do not include any personally identifiable information). The Washington State Institutional Review Board and the Portland State University Human Subjects Research Review Committee (HSRRC) both reviewed the study protocol and determined it exempt from further IRB review because of the study's use of de-identified survey and administrative data.

\section{Results}

\section{Study Population}

Claims meeting the study-inclusion criteria for industry, injury type, and time-loss payment eligibility totaled 6,593. From these claims, I sampled 3,520 claimants from the Washington State workers' compensation agency, for participation in the survey: 1,350 White injured workers and 2,170 non-White injured workers. Of those sampled, 1,554 lacked a functional telephone number and were considered ineligible. A total of 550 
injured workers were interviewed, with $488(90 \%)$ providing complete responses to the survey. Using the American Association of Public Opinion Research (AAPOR) guidelines (AAPOR, 2015), I calculated a response rate of $25 \%$.

\section{General Characteristics}

Based on the survey-weighted data, $47 \%$ of the population were White English speakers, almost 20\% were non-White English speakers, and approximately 34\% were non-LEP (English as a second language with limited English skills, or no English language skills).

Table 2

Survey Respondent Characteristics by Race, Ethnicity, and Language Status

\begin{tabular}{|c|c|c|c|c|c|c|}
\hline Variables & $\begin{array}{l}\text { Survey } \\
\text { sample }\end{array}$ & $\begin{array}{l}\text { Weighted } \\
\text { Sample }\end{array}$ & $\begin{array}{c}\text { White, } \\
\text { English } \\
\mathrm{N}=223 \\
\text { Weighted } \\
\% \\
\end{array}$ & $\begin{array}{l}\text { Non-White } \\
\text { English } \\
\mathrm{N}=95 \\
\text { Weighted \% } \\
\end{array}$ & $\begin{array}{l}\text { Non-White } \\
\text { LEP* } \\
\mathrm{N}=160 \\
\text { Weighted \% } \\
\end{array}$ & $\mathrm{p}$-value \\
\hline $\begin{array}{l}\text { Age at time of } \\
\text { injury, mean }(\mathrm{SD})^{\mathrm{a}}\end{array}$ & $42.1(11.4)$ & $\begin{array}{l}\begin{array}{l}41.5 \\
(11.9) \\
1263\end{array}\end{array}$ & $43.9(10.9)$ & $36.9(11.0)$ & $37.6(11.2)$ & $<0.001$ \\
\hline Female & $121(24.8)$ & (22.0) & 21.4 & 15.4 & 29.1 & 0.024 \\
\hline Married & $282(57.3)$ & 57.3 & 55.0 & 56.8 & 64.5 & 0.234 \\
\hline $\begin{array}{l}\text { Household income } \\
\text { More than } \\
\$ 35,000 / \text { year } \\
\text { Education: At least } \\
\text { high school or } \\
\text { equivalent }\end{array}$ & 228.0 & 55.9 & 66.8 & 51.5 & 29.9 & $<0.001$ \\
\hline $\begin{array}{l}\text { Industry } \\
\text { Accommodation } \\
\text { and Food } \\
\text { Services }\end{array}$ & $120(24.9)$ & 26.4 & 25.2 & 31.4 & 25.5 & $<0.001$ \\
\hline Janitorial & 77 (16.0) & 13.5 & 9.5 & 9.0 & 30.9 & \\
\hline Construction & $285(59.1)$ & 60.1 & 66.2 & 59.6 & 43.5 & \\
\hline
\end{tabular}




\begin{tabular}{|c|c|c|c|c|c|c|}
\hline $\begin{array}{l}\text { Health care } \\
\text { provider (HCP) } \\
\text { asked about work } \\
\text { duties } \\
\text { Injury was an } \\
\text { MSD }^{\mathrm{b}}\end{array}$ & 424 (89.3) & 91.2 & 94.6 & 89.7 & 82.8 & $<0.001$ \\
\hline Injury type & & & & & & $<0.001$ \\
\hline Traumatic $^{\mathrm{c}}$ & $34(7.0)$ & 6.2 & 4.5 & 9.1 & 8.5 & \\
\hline $\begin{array}{l}\text { Low back pain } \\
\text { Carpal tunnel } \\
\text { syndrome } \\
\text { Rotator cuff } \\
\text { syndrome }\end{array}$ & $\begin{array}{l}55(11.4) \\
175(36.2)\end{array}$ & $\begin{array}{l}12.2 \\
36.8\end{array}$ & $\begin{array}{l}14.5 \\
42.3\end{array}$ & $\begin{array}{l}13.3 \\
30.0\end{array}$ & $\begin{array}{r}5.0 \\
27.0\end{array}$ & \\
\hline $\begin{array}{l}\text { Official protest of } \\
\text { claim by employer }\end{array}$ & 107 (22.2) & $\begin{array}{r}22.7 \\
\mathbf{2 3 6 3}\end{array}$ & 23.0 & 22.3 & 22.0 & 0.975 \\
\hline $\begin{array}{l}\text { Opioids prescribed } \\
\text { Number of days of } \\
\text { time loss indicated } \\
\text { by HCP at first } \\
\text { visit } \\
\text { No days } \\
\text { indicated }\end{array}$ & $324(67.1)$ & (69.7) & 76.0 & 66.4 & 54.5 & $<0.001$ \\
\hline $\begin{array}{l}\text { Less than } 4 \text { days } \\
\text { Between } 4 \text { and } 13 \\
\text { days } \\
\text { More than } 13 \\
\text { days }\end{array}$ & $\begin{array}{l}67(13.9) \\
91(18.8)\end{array}$ & 13.6 & 11.1 & $\begin{array}{l}16.7 \\
20.0\end{array}$ & $\begin{array}{l}16.5 \\
26.5\end{array}$ & \\
\hline $\begin{array}{l}\text { Perceived racial } \\
\text { discrimination } \\
(\text { PRDS) mean } \\
(\mathrm{SD})^{\mathrm{a}}\end{array}$ & $0.77(1.47)$ & $\begin{array}{r}0.72 \\
(1.40)\end{array}$ & $0.5(0.9)$ & $1.11(1.89)$ & $1.03(2.23)$ & $<0.001$ \\
\hline $\begin{array}{l}\text { Days from injury to } \\
\text { follow-up care, } \\
\text { median (Q1-Q3) }\end{array}$ & $4(2,7)$ & $4(2,7)$ & $4(2,9)$ & $4(2,7)$ & $3(1,5)$ & $0.002^{\circ}$ \\
\hline $\begin{array}{l}\text { Not adequate care } \\
\text { for all MSDs }\end{array}$ & $90(20.0)$ & & 15.1 & 20.1 & 27.8 & 0.026 \\
\hline $\begin{array}{l}\text { Patient satisfaction, } \\
\text { mean }(\mathrm{SD})^{\mathrm{a}}\end{array}$ & $6.1(.1)$ & $6.1(1.5)$ & $6.2(1.3)$ & $5.8(1.9)$ & $5.8(1.7)$ & 0.010 \\
\hline
\end{tabular}

Note. ${ }^{*}$ LEP $=$ Limited English proficient. Bold font indicates significant results.

${ }^{\mathrm{a}} \mathrm{SD}=$ standard deviation.

${ }^{\mathrm{b}} \mathrm{MSD}=$ musculoskeletal disorders.

${ }^{\mathrm{C}}$ Traumatic injuries include: burn that required hospitalization, hand or wrist fracture, and/or amputation.

${ }^{\mathrm{d}}$ Kruskal Wallis test for medians. 
Table 2 provides descriptive information about the study population of injured workers by minority status. Compared to White English speakers, non-White and LEP claimants were younger, less likely to have completed high school, and less likely to have an annual household income over $\$ 35,000$. Over $60 \%$ of English speakers, both White and non-White, were employed in the construction industry. Compared to English speakers, fewer LEP workers were employed in construction (48.6\%) and instead were more likely to be employed in janitorial services (28.1\%). While few injuries were classified as traumatic, the proportion of traumatic injuries for non-White and LEP was double the proportion compared to White English-speakers ( $8.5 \%$ and $9.1 \%$ vs. $4.5 \%$, respectively). Low back pain was the most prevalent injury among minorities, while rotator cuff syndrome was the most prevalent injury among White English speakers. LEP and non-White English speakers were less likely to be prescribed opioid treatment. LEP workers had fewer social-support resources than English speakers: lower levels of support from their employer in returning to work, less likelihood of having health insurance through their work, and less likelihood of belonging to a union (all p-values were $<0.05$, data not shown).

Perceived racial discrimination scores were lowest among White English speakers (mean=0.5), and twice as high among non-White English speakers (mean=1.1) and LEP (mean=1.0), reflecting more perceived racial discrimination among minority groups. 
The median number of days from the initial medical visit to follow-up care was lowest for LEP (3 days), and higher for both White and non-White English speakers (4 days for both).

Approximately $20 \%$ of those with a musculoskeletal disorder (MSD) failed to receive care that was classified as adequate. Percentages of workers receiving adequate care differed moderately by minority status, ranging from $15.1 \%$ of White English speakers to $27.8 \%$ of LEP. Patient satisfaction differed by minority status and was highest among White English speakers.

\section{Multivariable Models}

Timeliness of care. Table 3 presents regression models produced to investigate the relationship between minority status and timeliness of care with health-care provider indicating that work time loss would be needed at the initial visit as the potential mediator. In Table 3, Model 1 is an age and gender adjusted negative binomial regression model presenting the relationship between racial categories and timeliness of care. Results are presented as incident risk ratios (IRRs). Non-White LEP workers were statistically different in timeliness of care $(I R R=0.60)($ Table 3, Model 1$)$, although opposite of what was hypothesized. My results show that the incidence rate of expected days between appointments among LEP was 0.61 times the incidence rate of White English speakers in waiting time between first and second medical visits for their WRII. In other words, Whites had 1.6 times the incidence rate of expected days between appointments compared to LEP. In Table 3, Model 2 presents results from the multivariable regression model with the addition of covariates (household income, high 
school or higher education level, and occupation). Non-White LEP still had significantly more timely care than English-speaking Whites (IRR 0.56, 95\% CI: 0.30-1.04). In Table 3, Model 3 includes the hypothesized mediator, physician estimate of time loss during the initial visit. Physicians estimating time loss was significantly related to timeliness of care, and the LEP patient category was still statistically significant, although the IRR did not change dramatically from the original model (0.56 compared to 0.58$)$.

\section{Table 3}

Timeliness of Care for Minorities, Effects of Racial Discrimination from Health Care Providers.

\begin{tabular}{|c|c|c|c|c|}
\hline \multirow[b]{2}{*}{ Variables } & \multicolumn{2}{|c|}{$\begin{array}{l}\text { Model } 1 \text { Age, Gender adjusted } \\
\qquad(\mathrm{n}=411)\end{array}$} & \multicolumn{2}{|c|}{$\begin{array}{l}\text { Model } 2 \text { adjusted mediation testing } \\
\qquad(\mathrm{n}=411)\end{array}$} \\
\hline & $\begin{array}{c}\text { Incidence } \\
\text { Rate } \\
\text { Ratios } \\
\end{array}$ & $\begin{array}{l}\text { Normal-based } \\
\qquad(95 \% \mathrm{CI}) \\
\end{array}$ & $\begin{array}{c}\text { Incidence } \\
\text { Rate } \\
\text { Ratios }\end{array}$ & $\begin{array}{l}\text { Normal-based } \\
\qquad(95 \% \mathrm{CI}) \\
\end{array}$ \\
\hline $\begin{array}{l}\text { Race } \\
\text { White, English } \\
\text { speaking }\end{array}$ & 1.00 & & 1.00 & \\
\hline $\begin{array}{l}\text { Non-white, English } \\
\text { speaking }\end{array}$ & 0.83 & $(0.51,1.35)$ & 0.83 & $(0.53,1.31)$ \\
\hline Non-White, LEP* & 0.56 & $(0.35,0.89)$ & 0.58 & $(0.34,0.98)$ \\
\hline $\begin{array}{l}\text { Age (in years) at time of } \\
\text { injury }\end{array}$ & 1.01 & $(0.99,1.03)$ & 1.01 & $(0.99,1.02)$ \\
\hline Female & 2.08 & $(1.04,4.07)$ & 1.39 & $(0.81,2.38)$ \\
\hline PRDS** & 0.99 & $(0.88,1.10)$ & 1.00 & $(0.90,1.10)$ \\
\hline $\begin{array}{l}\text { Household income } \\
\geq \$ 35,000 \text { a year }\end{array}$ & & & 1.06 & $(0.66,1.70)$ \\
\hline $\begin{array}{l}\text { High school or higher } \\
\text { education }\end{array}$ & & & 0.91 & $(0.47,1.75)$ \\
\hline Industry/Occupation & & & & \\
\hline Construction & & & 1.00 & \\
\hline $\begin{array}{l}\text { Accommodation/Food } \\
\text { Services }\end{array}$ & & & 1.42 & $(0.81,2.50)$ \\
\hline Janitorial Services & & & 1.33 & $(0.75,2.37)$ \\
\hline $\begin{array}{l}\text { Physician estimated } \\
\text { time-loss at first visit }\end{array}$ & & & 0.52 & $(0.37,0.74)$ \\
\hline
\end{tabular}


Note. Negative binomial regression, incident rate ratios (IRRs) presented. Bold font indicates significant results.

*LEP $=$ Limited English Proficient.

**MSD $=$ musculoskeletal disorder (rotator cuff syndrome, carpal tunnel syndrome, or low back injury)

*** PRDS scale ranges from $0-7$, reflecting low levels of perceived racial discrimination to high levels.

Adequacy of care. In Table 4, Model 1 presents the age and gender-adjusted results for minority workers and adequacy of care. Compared to Whites, Non-White LEP had almost twice the odds of receiving inadequate care (Table 4, Model 1). SES covariates were entered into Model 2 and appear to mediate the association between racial group status and inadequate care; both household income and education (high school degree or higher) reduced the odds of suffering inadequate health care by about half. Non-White LEP workers were no longer significantly at risk for higher odds of inadequate care (Table 4, Model 2).

Table 4

Adequacy of care for injured workers, and mediation of flexible resources.

\begin{tabular}{|c|c|c|c|c|}
\hline \multirow[b]{2}{*}{ Variables } & \multicolumn{2}{|c|}{$\begin{array}{c}\text { Model } 1 \text { age, gender } \\
\text { adjusted model }(\mathrm{n}=388)\end{array}$} & \multicolumn{2}{|c|}{$\begin{array}{l}\text { Model } 2 \text { full model with } \\
\text { mediators }(\mathrm{n}=388)\end{array}$} \\
\hline & $\begin{array}{c}\text { Observed } \\
\mathrm{OR}^{\mathrm{c}}\end{array}$ & $\begin{array}{l}\text { Normal-based } \\
(95 \% \mathrm{CI})\end{array}$ & $\begin{array}{c}\text { Observed } \\
\mathrm{OR}^{\mathrm{c}}\end{array}$ & $\begin{array}{c}\text { Normal-based } \\
(95 \% \mathrm{CI})\end{array}$ \\
\hline \multicolumn{5}{|l|}{ Racialized group } \\
\hline White, English speaker & 1.00 & & 1.00 & \\
\hline Non-White, English speaker & 1.50 & $(0.67,3.36)$ & 1.14 & $(0.44,2.99)$ \\
\hline Non-White, LEP ${ }^{a}$ & 1.88 & $(0.98,3.58)$ & 1.23 & $(0.57,2.67)$ \\
\hline Female & 1.99 & $(1.07,3.71)$ & 1.22 & $(0.49,3.07)$ \\
\hline Age (in years) at time of injury & 0.98 & $(0.95,1.01)$ & 0.98 & $(0.95,1.01)$ \\
\hline Perceived Racial Discrimination ${ }^{\mathrm{b}}$ & 1.00 & $(0.82,1.23)$ & 0.94 & $(0.76,1.17)$ \\
\hline Household income $>=\$ 35,000$ & & & 0.46 & $(0.23,0.89)$ \\
\hline At least a high school education & & & 0.56 & $(0.28,1.12)$ \\
\hline Industry/Occupation & & & & \\
\hline
\end{tabular}


Construction

1.00

Accommodation \& Food Services

1.55

$(0.60,3.99)$

Janitorial Services

0.81

$(0.35,1.86)$

Note. Adequate care was defined as care meeting Washington's workers' compensation medical treatment guidelines and the American College of Occupational and Environmental Medicine's best practice guidelines. Cases not meeting these guidelines were considered not adequate care. Bold font indicates statistically significant at $\mathrm{p}$-value 0.05 . Bold font indicates significant results.

${ }^{\text {a LEP }}=$ Limited English Proficient.

bPRDS scale ranges from $0-7$, reflecting low levels of perceived racial discrimination to high levels. ${ }^{\mathrm{c}} \mathrm{OR}=$ odds ratio.

To assess the role of flexible resources, mediation analyses were conducted; the results are presented in Table 5. The overall proportion of the relationship between nonWhite LEP and inadequate care that is mediated by household income is $37 \%$ (Table 5 , Model 1). Indirect effects for non-White English speakers and non-White LEP are statistically significant. In Table 5, Model 2 presents mediation testing for education (high school or higher). Education appears to have a greater association with the relationship of racial group category and inadequate care, accounting for approximately $62 \%$ of the association between non-White LEP and inadequate care.

Table 5

Mediation Analysis of Inadequate Care and Household Income and Education.

\begin{tabular}{|c|c|c|c|c|}
\hline & \multicolumn{2}{|c|}{$\begin{array}{l}\text { Model } 1 * \\
\text { of relationship } \\
\text { nadequate care and } \\
\text { ousehold income }\end{array}$} & \multicolumn{2}{|c|}{$\begin{array}{l}\text { Model } 2 * * \\
\text { of relationship } \\
\text { inadequate care and } \\
\text { education }\end{array}$} \\
\hline & $\mathrm{N}=388$ & & $\mathrm{~N}=388$ & \\
\hline Mediation results & $\begin{array}{l}\text { Observed } \\
\text { Coefficient }\end{array}$ & $\begin{array}{l}\text { Bias } \\
\text { Corrected }^{\ddagger} \\
\text { Confidence } \\
\text { Intervals } \\
\end{array}$ & $\begin{array}{l}\text { Observed } \\
\text { Coefficient }\end{array}$ & $\begin{array}{l}\text { Bias } \\
\text { Corrected }^{\ddagger} \\
\text { Confidence } \\
\text { Intervals } \\
\end{array}$ \\
\hline Direct effect & 0.12 & $(-0.04,0.28)$ & 0.04 & $(-0.13,0.22)$ \\
\hline Indirect effect & 1.05 & $(0.60,1.51)$ & 0.07 & $(0.01,0.15)$ \\
\hline $\begin{array}{l}\text { Percent of total effect that is } \\
\text { mediated }\end{array}$ & $37.2 \%$ & & $62.1 \%$ & \\
\hline
\end{tabular}


Note. *Model 1 controlling for race, gender, age, perceived racial discrimination, education (high school or higher) and occupation. **Model 2 controlling for race, gender, age, perceived racial discrimination, household income, and occupation.

${ }^{\ddagger}$ Bias corrected indirect effects.

Patient satisfaction. In Table 6, Model 1 provides age- and gender-adjusted survey weighted linear regression models for the relationship between minority status and patient satisfaction. Racial status is not significant but perceived racial discrimination appears to reduce the level of patient satisfaction. In Table 6, Model 2 adjusted for additional covariates but perceived racial discrimination was still significantly related to patient satisfaction. This indicates that the addition of flexible resources (e.g., household income and health-care provider (HCP asking about work duties)) may have reduced the effect of discrimination, but not eliminated it.

Table 6

Patient Satisfaction by Minority Status, and Effects of Racial Discrimination from Health-Care Providers.

\begin{tabular}{|c|c|c|c|c|}
\hline \multirow[b]{2}{*}{ Variables } & \multicolumn{2}{|c|}{$\begin{array}{l}\text { Model } 1 \text { covariate adjusted } \\
\text { model }(\mathrm{n}=380)\end{array}$} & \multicolumn{2}{|c|}{$\begin{array}{l}\text { Model } 2 \text { full model with } \\
\text { mediator }(\mathrm{n}=380)\end{array}$} \\
\hline & $\begin{array}{c}\text { Observed } \\
\text { Coefficient }\end{array}$ & $\begin{array}{c}\text { Normal- } \\
\text { based } \\
(95 \% \mathrm{CI})\end{array}$ & $\begin{array}{c}\text { Observed } \\
\text { Coefficient }\end{array}$ & $\begin{array}{c}\text { Normal-based } \\
(95 \% \mathrm{CI})\end{array}$ \\
\hline \multicolumn{5}{|l|}{ Race, ethnicity, language } \\
\hline White, English speaker & (ref) & & (ref) & \\
\hline Non-White, English speaker & -0.18 & $(-0.61,0.26)$ & -0.03 & $(-0.44,0.38)$ \\
\hline Linguistic minority, any race/ethnicity & -0.04 & $(-0.44,0.36)$ & 0.02 & $(-0.35,0.40)$ \\
\hline Age (in years) at time of injury & 0.02 & $(0.00,0.03)$ & 0.02 & $(0.00,0.03)$ \\
\hline Female & -0.09 & $(-0.46,0.28)$ & -0.15 & $(-0.51,0.21)$ \\
\hline Household income $>\$ 35,000 /$ year & 0.54 & $(0.19,0.88)$ & 0.39 & $(0.07,0.72)$ \\
\hline At least a high school degree & -0.29 & $(-0.65,0.07)$ & -0.34 & $(-0.72,0.03)$ \\
\hline \multicolumn{5}{|l|}{ Physician indicated time loss } \\
\hline No time loss indicated & (ref) & & (ref) & \\
\hline Less than 4 days & 0.10 & $(-0.38,0.59)$ & 0.09 & $(-0.39,0.57)$ \\
\hline 4-13 days of time loss & $\begin{array}{l}-0.33 \\
55\end{array}$ & $(-0.77,0.11)$ & -0.31 & $(-0.72,0.10)$ \\
\hline
\end{tabular}


14 or more days of time loss Did your HCP* ask about your work duties?

Injury was a musculoskeletal disorder Perceived racial discrimination scale (PRDS)**

R-squared

Note. Linear regression models presented. Bold font indicates statistical significance at $\mathrm{p}$-value $\leq 0.05$

${ }^{*} \mathrm{HCP}=$ Health care provider

**PRDS scale ranges from $0-7$, reflecting low levels of perceived racial discrimination to high levels.

Single mediator models were computed to assess the role of income and HCP communication on patient satisfaction and perceived racial discrimination, the results of which are presented in Table 7. Indirect effects for both mediators indicate over a third of the effects of the association between perceived racial discrimination and patient satisfaction is mediated via household income and HCP communication, Table 7.

Table 7

Mediation of Perceived Racial Discrimination on Patient Satisfaction and Health-Care Provider Inquiring About Work Duties or Household Income.

\begin{tabular}{lllll}
\hline & \multicolumn{1}{c}{ Model 1* } & \multicolumn{1}{c}{ Model 2** } \\
\hline & $\begin{array}{l}\text { Mediation of relationship between } \\
\text { patient satisfaction and race, via } \\
\text { household income }\end{array}$ & $\begin{array}{l}\text { Mediation of relationship between } \\
\text { patient satisfaction and race, via } \\
\text { health care professional asking } \\
\text { about work duties }\end{array}$ \\
\hline & Observed & Bias Corrected & Observed & Bias Corrected \\
\hline Mediation results & Coefficient & Confidence Intervals & Coefficient & Confidence Intervals \\
\hline $\begin{array}{l}\text { Direct effect } \\
\begin{array}{l}\text { Indirect effect } \\
\text { Percent of total effect } \\
\text { that is mediated }\end{array}\end{array}$ & -0.34 & $(-0.44,-0.24)$ & -0.34 & $(-0.44,-0.24)$ \\
\hline
\end{tabular}

Note. Models 1 and 2 are single mediator models.

*Model 1 adjusted for race, perceived racial discrimination, gender, age, education, occupation, health care provider asking about work.

** Model 2 adjusted for race, perceived racial discrimination, gender, age, household income, education, and occupation. 


\section{Discussion}

Under the fundamental cause theoretical framework (Phelan \& Link, 2015), I expected a stronger relationship between racial discrimination and less favorable healthservices outcomes among work-injured minorities, after controlling for SES factors. Although my analyses did not support all hypotheses, the current study produced a few notable results. First, among English speakers, I found no difference in health-service outcomes between White and non-White workers. Second, among non-English speakers, timeliness of care was better compared to White English-speaking injured workers in adjusted models.

While racialized group statuses were significantly different for all three outcomes in bivariate analyses (Table 2), similar to prior research findings (Dasinger et al., 2001; Dembe et al., 2005; Kosny et al., 2012), only LEP status was significant in age/gender adjusted and full models. It might be the models over-controlled for certain socioeconomic factors (income, education, occupation, etc.), or it might be the models provide evidence that SES is a stronger factor than racial discrimination in explaining inequalities in WRII health care (Table 2). While it is impossible to say in this crosssectional study if racial discrimination caused lower SES resources or vice versa, it is clear that the connection between minority group membership and SES is significant.

Household income and education were significantly associated with inadequate care and significantly mediated the relationship between inadequate care and LEP status (Tables 4 and 5). In addition, household income and HCP inquiries were significantly associated with patient satisfaction in multivariable models (Table 6) and in the 
mediation analyses (Table 7). These results are in line with what FCT would expect to find, as flexible resources can ameliorate some of the effects of a fundamental cause on the outcome. While the outcomes are subjective self-reported measures, they are important to explore in further research, as (in)adequate care and patient satisfaction are commonly used as measures of health care quality.

This study adds to the prior literature in three primary ways. First, this is the first study to my knowledge to test patient's perception of provider racial discrimination as an important factor in differences in work-related health care by minority group status. In general, this study found that race does matter. Fundamental cause theory, as well as many studies investigating the structural nature of racism, posit that income and education inequalities are a result of racial discrimination; therefore, the results of this study, which show income and education to be related to the studied outcomes, may, in fact, be expressing racial discrimination effects (Phelan and Link 2015; Williams 1999; Williams 2012). Second, this is the first study to my knowledge to examine the potential mediating role of income, education, and health-care provider communication in workrelated injury health care adequacy and patient satisfaction. Patient satisfaction has been associated with long-term health and successfully returning to work in prior studies (Feuerstein, Huang, Shaw, Miller, \& Wood, 2003). Third, this study utilized both administrative injury data as well as survey data to capture the quantitative details associated with minority status among a group with near-universal health insurance. The universal nature of workers' compensation insurance allowed us to study factors 
unrelated to health insurance status, which may have muddied true differences in care between minorities and Whites in previous studies of health care inequalities.

\section{Limitations}

There are several limitations to this study, which may account for the statistically insignificant findings in the health-service outcomes assessed. First, the low response rate increases the potential for non-response bias. Although I attempted to account for differences by survey participation, there were likely/least-likely characteristics not accounted for in the non-response models. For example, workers with the highest levels of perceived racial discrimination may have been least likely to participate in the survey, but there was no way to measure this outside of the survey. Second, differences among racial/ethnic groups may not have been detected due to residual confounding that occurred by grouping all non-White English-speaking workers together. Third, the perceived discrimination measure used in this study may not have captured the distinct effect of provider bias, apart from general racial discrimination. Validation of providerspecific measures would assist future studies in better capturing this specific type of discrimination. It may also be that respondents were unwilling to admit to provider discrimination for some fear of retaliation, as the survey was conducted at the request of the workers' compensation agency. Fourth, despite limiting the study population to select industries in an attempt to eliminate differences in SES across minority status and to isolate the effects of race, differences were evident in household income and education levels. These SES characteristics, significant predictors of patient satisfaction and adequate care in this study, may mask the effects of racism. 
Although I hypothesized that provider racial discrimination causes a patient's dissatisfaction with the care they receive, it is also possible that a patient's dissatisfaction will cause feelings of discrimination. A reverse causal pathway would have implications for any potential intervention.

The outcome measures chosen for this study may not have been adequate to detect differences in care. While the adequate care outcome is based upon clinical recommendations from the American College of Occupational and Environmental Medicine, my timeliness of follow-up care and patient satisfaction measures are not validated measures. Timeliness of follow-up care is not often studied, and to my knowledge, no guidelines exist for this measure. For low back pain, however, follow-up care within a week (or fewer days) has been recommended (Van Tulder et al., 2006).

The findings from this study may have limited generalizability to other populations for two reasons. First, the racial and ethnic makeup of Washington State differs from many other regions. Compared to estimates for the United States, Washington contains a greater percentage of Asians (6\% vs. 10\%) and a lower percentage African Americans (12\% vs. 3\%) (Office of Financial Management, 2016). The relative size of minority groups may affect relationships between race, racism, and health services. Second, workers' compensation systems differ by state. Washington State's system in which the state is the sole provider of workers' compensation insurance is unique, as workers' compensation insurance is generally obtained through the private market in most other states. Health services for work injuries may be uniform in Washington because there is only one workers' compensation insurer. 


\section{Conclusion}

It is clear from this initial study that race and language matter for WC health-care outcomes. Under the fundamental cause theoretical framework, I should have found stronger relationships between racial discrimination and less favorable health-services outcomes for non-White and LEP patients. While evidence of a relationship between perceived discrimination and inadequate care as well as patient satisfaction were found in age- and gender-adjusted models, it is interesting that these relationships did not remain in covariate-adjusted models for inadequate care. Some key issues may help to explain this, as well as to point to promising directions for future research.

Additional studies utilizing the fundamental cause theoretical framework are needed to understand the explicit role discrimination from health-care providers has on quality of care in WC health services. There are many distinct differences between general health insurance and the social system of WC insurance, but both utilize the service of health-care providers with explicit and implicit biases. It is important for further research to identify aspects of provider bias in WC systems so that necessary policy changes can be made to eliminate racial inequalities in WC health systems.

Fundamental cause theory posits that changing proximal treatments or processes will not change the underlying problem of racism or racial discrimination effects on health outcomes. This study examined only one specific type of racial discrimination and this discrimination perception information was collected post outcome. More significant issues of racial discrimination — both structural and personal—-likely occurred both prior to and concurrent with provider discrimination, thus shaping first, the risk of injury for 
minorities, and second, their attitudes towards providers. This study provides a glimpse of this in that minorities entered and remained in the workplace with fewer social and economic (flexible) resources than their White counterparts. In addition, this study found that that not only was household income a strong predictor of better outcomes for inadequate care and satisfaction, income mediated perceived discrimination. Racial discrimination is an inextricably linked aspect of SES for minorities, and SES is a strong predictor of health inequities (Phelan and Link 2015; Williams and Mohammed 2009; Williams 2012). In line with Phelan and Link (2015), this study suggests that racism cannot be ignored in studies of work-related injury and illness health-care inequalities for minorities. 


\section{References}

AAPOR. (2015). Standard Definitions: Final Dispositions of Case Codes and Outcome Rates for Surveys. Retrieved from https://www.aapor.org/EducationResources/For-Researchers/Poll-Survey-FAQ/Response-Rates-An-Overview.aspx

ACOEM. (2016). ACOEM's Occupational Medicine Practice Guidelines - 2016 Revision. from The Reed Group https://new.mdguidelines.com/Resources/ACOEM-Practice-Guidelines

Beardwood, B. A., Kirsh, B., \& Clark, N. J. (2005). Victims twice over: perceptions and experiences of injured workers. Qual Health Res, 15(1), 30-48.

Chibnall, J. T., Tait, R. C., Andresen, E. M., \& Hadler, N. M. (2005). Race and socioeconomic differences in post-settlement outcomes for African American and Caucasian Workers' Compensation claimants with low back injuries. Pain, 114(3), 462-472.

Chibnall, J. T., Tait, R. C., Andresen, E. M., \& Hadler, N. M. (2006a). Clinical and social predictors of application for social security disability insurance by workers' compensation claimants with low back pain. Journal of occupational and environmental medicine / American College of Occupational and Environmental Medicine, 48(7), 733-740. doi:10.1097/01.jom.0000214357.14677.5a

Chibnall, J. T., Tait, R. C., Andresen, E. M., \& Hadler, N. M. (2006b). Race differences in diagnosis and surgery for occupational low back injuries. Spine, 31(11), 1272 1275 .

Chibnall, J. T., Tait, R. C., \& Merys, S. C. (2000). Disability management of low back injuries by employer-retained physicians: Ratings and costs. American Journal of Industrial Medicine, 38(5), 529-538. doi:10.1002/10970274(200011)38:5<529::aid-ajim5>3.0.co;2-s

Chung-Bridges, K., Muntaner, C., Fleming, L. E., Lee, D. J., Arheart, K. L., LeBlanc, W. G., . . Davila, E. P. (2008). Occupational Segregation as a Determinant of US Worker Health. American Journal of Industrial Medicine, 51, 555-567.

Cooke, C. R., Nallamothu, B., Kahn, J. M., Birkmeyer, J. D., \& Iwashyna, T. J. (2011). Race and tiemliness of transfer for revascularization in patients with acute myocardial infarction. Medical Care, 49(7), 662-667.

Cooper, L. A., Roter, D. L., Carson, K. A., Beach, M. C., Sabin, J. A., Greenwald, A. G., \& Inui, T. S. (2012). The associations of clinicians' implicit attitudes about race with medical visit communication and patient ratings of interpersonal care. American Journal of Public Health, 102(5), 979-987.

Dasinger, L. K., Krause, N., Thompson, P. J., Brand, R. J., \& Rudolph, L. (2001). Doctor proactive communication, return-to-work recommendation, and duration of disability after a workers' compensation low back injury. J Occup Environ Med, 43(6), 515-525.

Dembe, A. E. (2001). Access to medical care for occupational disorders: difficulties and disparities. J Health Soc Policy, 12(4), 19-33. 
Dembe, A. E., Savageau, J. A., Amick, B. C., 3rd, \& Banks, S. M. (2005). Racial and ethnic variations in office-based medical care for work-related injuries and illnesses. Journal of the National Medical Association, 97(4), 498-507.

Dunn, G., Emsley, R., Liu, H., Landau, S., Green, J., White, I., \& Pickles, A. (2015). Evaluation and validation of social and psychological markers in randomised trials of complex interventions in mental health: a methodological research programme. Health Technology Assessment, 19(93), 148. doi:10.3310/hta19930

Emsley, R., \& Liu, H. (2013). PARAMED: Stata module to perform causal mediation analysis using parametric regression models. Boston College, Department of Economics.

Feagin, J. (2000). Racist America. New York and London: Routledge.

Feagin, J., \& Bennefield, Z. (2014). Systemic racism and US health care. Social Science \& Medicine, 103, 7-14.

Feuerstein, M., Huang, G., D., Shaw, W. S., Miller, V., I., \& Wood, P. M. (2003). Integrated Case Management for Work-Related Upper-Extremity Disorders: Impact of Patient Satisfaction on Health and Work Status. Journal of Occupational and Environmental Medicine, 45(8), 803-812.

Gubernot, D. M., Anderson, G. B., \& Hunting, K. L. (2015). Characterizing Occupational Heat-Related Mortality in the United States, 2000-2010: An Analysis Using the Census of Fatal Occupational Injuries Database. American Journal of Industrial Medicine, 58(2), 203-211. doi:10.1002/ajim.22381

Hannan, E. L., van Ryn, M., Burke, J., Stone, D., Kumar, D., Arani, D., . . DeBuono, B. A. (1999). Access to coronary artery bypass surgery by race/ethnicity and gender among patients who are appropriate for surgery. Medical Care, 37(1), 68-77.

Institute of Medicine. (2003). Unequal Treatment: Confronting Racial and Ethnic Disparities in Health Care. Washington, D.C.: The National Academies Press.

Institute of Medicine. (2012). How far have we come in reducing health disparities?: Progress since 2000: Workshop summary. Washington, DC: National Academies Press.

Industrial Insurance. Employments and Occupations Covered, 12 C.F.R. § 020 (1961).

Johnson, R. L., Saha, S., Arbelaez, J. J., Beach, M. C., \& Cooper, L. A. (2004). Racial and ethnic differences in patient perceptions of bias and cultural competence in health care. Journal of General Internal Medicine, 19(2), 101-110.

Kirsh, B., \& McKee, P. (2003). The needs and experiences of injured workers: a participatory research study. Work, 21(3), 221-231.

Kosny, A., MacEachen, E., Lifshen, M., Smith, P., Jafri, G. J., Neilson, C., . . Shields, J. (2012). Delicate dances: immigrant workers' experiences of injury reporting and claim filing. Ethn Health, 17(3), 267-290. doi:10.1080/13557858.2011.614327

Labor and Industries, W. S. D. o. (2014). Medical Treatment Guidelines. Olympia, WA: Washington State Department of Labor and Industries Retrieved from http://www.Ini.wa.gov/ClaimsIns/Providers/TreatingPatients/TreatGuide/default.a sp? source $=$ FF.

Lasser, K. E., Himmelstein, D. U., \& Woolhandler, S. (2006). Access to Care, Health Status, and Health Disparities in the United States and Canada: Results of a 
Cross-National Population-Based Survey. American Journal of Public Health, 96(7), 1300-1307. doi:10.2105/ajph.2004.059402

Leigh, J. P. (2011). Economic burden of occupational injury and illness in the United States. Milbank Q, 89(4), 728-772. doi:10.1111/j.1468-0009.2011.00648.x

Link, B. G., \& Phelan, J. (1995). Social Conditions as Fundamental Causes of Disease. Journal of Health and Social Behavior, 80-94.

Lipscomb, H. J., Loomis, D., McDonald, M. A., Argue, R. A., \& Wing, S. (2006). A conceptual model of work and health disparities in the United States. Int $J$ Health Serv, 36(1), 25-50.

MacEachen, E. (2000). The mundane administration of worker bodies: from welfarism to neoliberalism. Health, Risk \& Society, 2(3), 315-327.

MacEachen, E., Kosny, A., Ferrier, S., \& Chambers, L. (2010). The "Toxic Dose" of System Problems: Why Some Injured Workers Don't Return to Work as Expected. J Occup Rehabil, 20(3), 349-366.

Massey, D. S. (2009). Racial formation in theory and practice: The case of Mexicans in the United States. Race and Social Problems, 1(1), 12-26.

Menendez, C. C., Konda, S., Hendricks, S., \& Amandus, H. (2013). Disparities in workrelated homicide rates in selected retail industries in the United States, 2003-2008. J Safety Res, 44, 25-29. doi:10.1016/j.jsr.2012.12.002

Moskowitz, G. B., Stone, J., \& Childs, A. (2012). Implicit stereotyping and medical decisions: Unconscious stereotype activation in practitioners' thoughts about African Americans. American Journal of Public Health, 102(5), 996-1001.

Moure-Eraso, R., \& Friedman-Jimenez, G. (2004). Occupational health Among Latino Workers: A Needs Assessment and Recommended Interventions. New Solutions, 14(4), 319-347.

Murray, L. R. (2003). Sick and tired of being sick and tired: scientific evidence, methods, and research implications for racial and ethnic disparities in occupational health. Am J Public Health, 93(2), 221-226.

National Technical Information Service, N. (2002). North American Industry Classification System. United States, 2002. Springfield, VA: National Technical Information Service

Office of Financial Management, W. S. (2016, 12/3/2016). Estimates of April 1 population by age, sex, race and Hispanic origin. Small Area Demographic Estimates (SADE). Version: 20161203_R03_VM. Retrieved from http://www.ofm.wa.gov/pop/asr/default.asp

Phelan, \& Link, B. G. (2015). Is Racism a Fundamental Cause of Inequalities in Health? Annual Review of Sociology, 41, 311-330.

Premji, S. (2014). Barriers to Return-to-Work for Linguistic Minorities in Ontario: An Analysis of Narratives from Appeal Decisions. J Occup Rehabil, 1-11. doi:10.1007/s 10926-014-9544-3

Premji, S., \& Krause, N. (2010). Disparities by ethnicity, language, and immigrant status in occupational health experiences among Las Vegas hotel room cleaners. American Journal of Industrial Medicine, 53(10), 960-975. doi:10.1002/ajim.20860 
Press, R., Carrasquillo, O., Sciacca, R. R., \& Giardina, E.-G. V. (2008). Racial/Ethnic Disaparities in Time to Follow-Up after an Abnormal Mammogram. Journal of Women's Health, 17(6), 923-930.

Reddan, D. N., Szczech, L. A., Klassen, P. S., \& Owen, W. F. (2000). Racial Inequity in America's ESRD Program. Seminars in Dialysis, 13(6), 399-403. doi:10.1046/j.1525-139x.2000.00109.x

Robinson, J. C. (1987). Trends in Racial Inequality and Exposure to Work-Related Hazards, 1968-1986. The Milbank Quarterly, 65(Supplement 2 (Part 2)), 404-420.

Rosa, J. (2016). Standardization, racialization, languagelessness: Raciolinguistic ideologies across communicative contexts. Journal of Linguistic Anthropology, 26(2), 162-183.

Rudolph, L., Dervin, K., Cheadle, A., Maizlish, N., \& Wickizer, T. (2002). What Do Injured Workers Think About Their Medical Care and Outcomes After Work Injury? Journal of Occupational \& Environmental Medicine, 44(5), 425-434.

Sears, J. M., Bowman, S. M., \& Hogg-Johnson, S. (2015). Disparities in occupational injury hospitalization rates in five states (2003-2009). Am J Ind Med, 58(5), 528540. doi:10.1002/ajim.22427

Shavers, V. L., Fagan, P., Jones, D., Klein, W. M. P., Boyington, J., Moten, C., \& Rorie, E. (2012). The state of research on racial/ethnic discrimination in the receipt of health care. American Journal of Public Health, 102(5), 953-966.

Skolasky, R. L., Albert, T. J., Vaccaro, A. R., \& Riley, L. H. (2009). Patient satisfaction in the cervical spine research society outcomes study: relationship to improved clinical outcome. The Spine Journal, 9(3), 232-239. doi:http://dx.doi.org/10.1016/j.spinee.2008.03.001

Stanbury, M., \& Rosenman, K. D. (2014). Occupational health disparities: A state public health-based approach. American Journal of Industrial Medicine, 57(5), 596-604.

Strong, L. L., \& Zimmerman, F. J. (2005). Occupational Injury and Absence From Work Among African American, Hispanic, and Non-Hispanic White Workers in the National Longitudinal Survey of Youth. American Journal of Public Health, 95(7), 1226-1232.

Tait, R. C., Chibnall, J. T., Andresen, E. M., \& Hadler, N. M. (2004). Management of occupational back injuries: differences among African Americans and Caucasians. Pain, 112(3), 389-396. doi:10.1016/j.pain.2004.09.027

Thorburn Bird, S., \& Bogart, L. M. (2001). Perceived Race-Based and Socioeconomic Status (SES)- Based Discrimination in Interactions with Health Care Providers. Ethnicity \& disease, 11(3), 554-563.

van Ryn, M. (2002). Research on the provider contribution to race/ethnicity disparities in medical care. Medical Care, 40(1 Suppl), I140-151.

van Ryn, M., Burgess, D. J., Dovidio, J. F., Phelan, S. M., Saha, S., Malat, J., . . Perry, S. (2011). The Impact of Racism on Clinician Cognition, Behavior, and Clinical Decision Making. Du Bois Review: Social Science Research on Race, 8(01), 199218. doi:doi:10.1017/S1742058X11000191

van Ryn, M., \& Burke, J. (2000). The effect of patient race and socio-economic status on physicians' perceptions of patients. Social Science and Medicine, 50(6), 813-828. 
Van Tulder, M., Becker, A., Bekkering, T., Breen, A., Gil del Real, M. T., Hutchinson, A., ... Malmivaara, A. (2006). Chapter 3 European guidelines for the management of acute nonspecific low back pain in primary care. European Spine Journal, 15, s169-s191.

Weech-Maldonado, R., Morales, L. S., Elliott, M., Spritzer, K., Marshall, G., \& Hays, R. D. (2003). Race/ethnicity, language, and patients' assessments of care in Medicaid managed care. Health Services Research, 38(3), 789-808.

Williams, D., R. (2012). Miles to Go before We Sleep: Racial Inequities in Health. Journal of Health and Social Behavior, 53(3), 279-295.

Williams, D. R. (1999). Race, socioeconomic status and health. The added effects of racism and discrimination. Annals of the New York Academy of Sciences, 896, 173-188.

Williams, D. R., \& Mohammed, S. A. (2009). Discrimination and racial disparities in health: evidence and needed research. Journal of behavioral medicine, 32(1), 2047. doi:10.1007/s10865-008-9185-0

Williams, D. R., Mohammed, S. A., Leavell, J., \& Collins, C. (2010). Race, socioeconomic status, and health: Complexities, ongoing challenges, and research opportunities. In N. E. Adler \& J. Stewart (Eds.), Biology of Disadvantage: Socioeconomic Status and Health (Vol. 1186, pp. 69-101). 


\section{Chapter 3: The Role of Workers' Compensation Policies and Procedures in Racial Inequalities in Work-Related Injury Outcomes}

\section{Background}

Minorities face a combination of risks in the workplace: they are more likely to work in low-wage, high-hazard jobs, more likely to be injured on the job, and more likely to have difficulty in obtaining care in the workers' compensation (WC) system (AlonsoVillar, Del Rio, \& Gradin, 2012; Buchanan et al., 2010; Dembe, 2001; Lipscomb, Loomis, McDonald, Argue, \& Wing, 2006). Minority workers are also less likely to have health insurance (Sommers et al., 2014), and therefore rely more heavily on workers' compensation to treat their work-related injuries and illnesses (Premji \& Krause, 2010; Smith, Kosny, \& Mustard, 2009). Recent studies suggest, however, that minorities receive lower standards of care from workers' compensation than non-Latino Whites (hereafter referred to as Whites) (Bonauto et al., 2010; Gravel et al., 2010; Kosny et al., 2012). Scholars have also investigated structural factors as significant barriers for workers in accessing their rights to speedy and efficient workers' compensation services (Lippel, 2007, 2012; MacEachen, 2000; MacEachen, Kosny, Ferrier, \& Chambers, 2010). The workers' compensation system appears to be flawed for not only injured workers in general but also for racial minorities in particular although racial discrimination in WC agencies remains understudied.

The purpose of this study is to address this gap in the research by assessing potential mechanisms in a state-fund-controlled WC agency that may increase barriers to services for workers of color and LEP workers. This study is grounded in fundamental 
cause theory (FCT) (Link \& Phelan, 1995; Phelan \& Link, 2015), which states that certain social processes are basic to explaining inequalities in health outcomes. Until these social processes are addressed, inequalities in multiple health outcomes (via multiple mechanisms) will continue. Racial discrimination is the fundamental social process examined in this study.

The remainder of this section provides context through a brief primer on WC systems, a discussion of what is known about WC system barriers for injured workers and then a discussion of FCT and how it is used to frame this study. This section will conclude with a description of the research hypotheses tested.

\section{Workers' Compensation: A Brief Primer}

In the early $20^{\text {th }}$ century, workers' compensation (WC) systems were created in the United States to stem rising numbers of tort litigation cases brought by workers against their employers due to injuries suffered on the job. WC organizations in the United States operate as 'no-fault' ${ }^{10}$ social insurance systems to provide needed medical care and some wage replacement benefits for workers who sustain injuries on the job (Duncan, 2003).

Workers' compensation systems in the United States operate independently and may be state or federally administered (in 49 states, U.S. territories, and for various

\footnotetext{
${ }^{10}$ In workers' compensation systems, "no-fault" means that neither the worker or the employer are held responsible for an injury or illness; the system will pay for the health care and time loss of the injured worker. This also means that neither party can be sued to cover costs for the injury or illness.
} 
federally covered groups). ${ }^{11}$ In most workers' compensation systems, there are five stakeholder groups: (1) the government agency who oversees laws and regulations, (2) private insurance companies, (3) health care providers approved (and willing) to accept WC cases, (4) the workplace, and (5) injured workers. Washington State is a sole-source workers' compensation system, ${ }^{12}$ so the first two stakeholder groups are combined and housed in the Department of Labor and Industries. All companies with employees in Washington State are required to have workers' compensation insurance.

To my knowledge, no data exist to map workers' compensation adequacy historically by racial group membership. Given social and political contexts, however, there have likely always been racial inequalities in coverage and adequacy as workers' compensation systems developed during the Great Migration, the Immigration Act of 1924, and the development of Jim Crow laws. ${ }^{13}$ Recent research has begun to document a host of primarily administrative and structural factors associated with differences in workers' compensation care between Whites and racialized minorities (Kosny et al., 2012; S. Premji, 2014).

\footnotetext{
${ }^{11}$ Texas is the only state that does not require employers to cover their employees with workers' compensation insurance.

${ }^{12}$ Federal and Maritime employees are covered under other WC insurance systems. Washington State WC covers approximately two-thirds of all employees and all but about 450 self-insured entities.

${ }^{13}$ Briefly, the Great Migration (1914-1970), chronicles one of the largest migrations of Americans from the South to the North. For the Immigration Act of 1924 created immigration quotas based on national origin, and Jim Crow laws (racial segregation) developed after Reconstruction and were in place until the mid1960s. For more information on the Great Migration see Wilkerson, (2011) and also Gregory, (2005). More information regarding the Immigration Act of 1924 see Ngai, (1999). Additional information regarding Jim Crow laws can be found in multiple online and text sources including Packard, (2002).
} 


\section{Administrative Barriers in Workers' Compensation}

A multitude of administrative barriers in workers' compensation agencies have been identified in recent literature and include delays in adjudication, paperwork, and approvals. The majority of research about WC systems has been produced over the past 10-15 years, and the bulk of this research has employed qualitative methodologies (c.f., Bonauto et al., 2010; Chibnall, Tait, Andresen, \& Hadler, 2005, 2006a; Friedman, Ruestow, \& Forst, 2012). Most studies investigating the effectiveness of WC agencies have found that the majority of claims move efficiently through various WC systems (Lippel, 1999, 2012), but for the more complex or serious injuries, research has identified some common "anti-therapeutic" (Lippel, 1999) and "toxic" (MacEachen et al., 2010) themes. Among the common issues found in the literature are injured workers being treated with hostility, contempt, and suspicion (Beardwood, Kirsh, \& Clark, 2005; Strunin \& Boden, 2004), as well as experiencing delays in both medical care and wagereplacement benefits (Bonauto et al., 2010; MacEachen et al., 2010). These antitherapeutic system failures appear to affect racialized minorities more than Whites (Gravel et al., 2010; Kosny et al., 2012; Scherzer, Rugulies, \& Krause, 2005). Racialized minorities also appear to suffer worse treatment for the same injury compared to Whites (Chibnall et al., 2006a; Chibnall, Tait, Andresen, \& Hadler, 2006b; Tait, Chibnall, Andresen, \& Hadler, 2004), and have lower post settlement payments compared to Whites (Chibnall et al., 2005; Friedman et al., 2012).

MacEachen, (2000) frames difficulties in WC experiences for injured workers from a socio-political perspective, specifically the rise of neoliberalism and the decline of 
the welfare state. This emerged in WC systems as the decline of shared or no-fault responsibility for treating injured workers (welfare state ideal) and the rise of personal responsibility, stigma, and disdain for those who are injured (neoliberal thought) (MacEachen, 2000). To MacEachen and colleagues, the convergence of a host of "mundane" administrative issues create a "toxic dose" of administrative barriers that lead to adverse WC outcomes for those with either more complex injuries or those who are LEP minorities (Kosny et al., 2012; MacEachen, 2000; MacEachen et al., 2010).

A systematic review of qualitative studies focusing on WC-system impacts to injured workers was conducted by Kilgour, Kosny, McKenzie and Collie in 2014. Among the major themes they identified were issues considered "mundane" in isolation from one another, such as form letters filled with confusing medical and technical jargon, inconsistent information, delayed and inconsistent wage-replacement payments, and delays in treatment approvals (Kilgour, Kosny, McKenzie, \& Collie, 2014). Individually, these administrative irregularities may be dealt with but it is possible to see how these barriers could become overwhelming when combined. This qualitative review covered six countries (Australia, Canada, New Zealand, Sweden, and the United States) and included multiple states, provinces, and cities. Remarkable similarities were found considering the differences in WC systems studied. Very little research in the Kilgour et al review reported specifically on LEP or racial and ethnic minorities, other than to say communication issues were exacerbated for LEP workers (MacEachen, Kosny, \& Ferrier, 2007) (MacEachen, Kosny and Ferrier 2007). 
Two studies not included in the 2014 systematic review have looked explicitly at immigrant populations in Canada and found that immigrants faced greater difficulties with medical and legal issues as well as the aforementioned administrative barriers (Gravel et al., 2010; Kosny et al., 2012). In the Gravel et al study (2010), 104 interviews were assessed based on 37 expert-determined criteria to more objectively assess the legal, administrative, and medical aspects of injured workers' compensation claim processes. Among other results, Gravel and colleagues found that immigrants experienced patterns of incomplete paperwork (due to having others fill it out), a lack of understanding of written legal decisions, and more difficulties in making themselves understood by the WC agency (Gravel et al., 2010). In a series of 28 in-depth interviews of immigrants in Ontario, Kosny et al. (2014) found issues very similar to previously reviewed studies; in addition, they found immigrants who thought they understood workers' compensation and medical personnel, only to realize later (after decisions were made), that they did not fully comprehend what they were being told. This caused considerable delays and in some cases premature closing of claims. All of these administrative barriers can cause injured workers to give up fighting for their rights; what MacEachen and colleagues call the "toxic dose" of system problems, which might lead to permanent and/or premature exit from the labor force (MacEachen et al., 2010).

From a medico-legal perspective, Lippel has assessed workers' compensation systems as having both therapeutic and anti-therapeutic aspects that need to be further investigated and potentially modified (Lippel, 1999, 2012). Among the therapeutic aspects of the old (tort) system, Lippel notes that many injured workers feel vindicated 
when they are allowed to tell their side of the story; going to trial gives their injury or illness legitimacy which is sometimes missing in the WC process. Overall, Lippel notes that WC systems allow for swift treatment and wage replacement among injured workers with obvious physical injuries, bypassing the old system of suing one's employer in order to receive medical care (Guyton, 1999). The anti-therapeutic aspects of workers' compensation for "invisible"14 injuries, however, can cause serious physical and mental health issues.

Among the anti-therapeutic aspects of WC are the increasing use of independent medical exams (IME), lack of face-to-face communication, and being unable to have one's day in court to legitimize their injury and experiences. In addition, those with multiple IMEs are labeled as a 'malingerer,' or as suffering 'secondary gain syndrome', thereby stigmatizing injured workers (Lippel, 1999, 2012). ${ }^{15}$ The stigma attached to these terms may cloud the judgment of the claim adjudicator which is a common theme found among studies (Beardwood et al., 2005; Gravel et al., 2010; Kosny et al., 2012; Scherzer et al., 2005; Strunin \& Boden, 2004).

\footnotetext{
${ }^{14}$ Invisible injuries are those not apparent to the naked eye: injuries such as soft tissue disorders (e.g., musculoskeletal disorders) and for some WC systems psychological/mental injuries such as post-traumatic stress disorder (PTSD). The Washington State WC system does not accept mental diagnoses as the primary injury/illness, with the exception of a new addition to the Revised Code of Washington 51.08, covering PTSD for law enforcement and firefighters, effective 6/7/2018. Full text here: http://lawfilesext.leg.wa.gov/biennium/2017-18/Pdf/Bills/Senate\%20Passed\%20Legislature/6214S.PL.pdf\#page $=1$. Mental health diagnoses are sometimes accepted as secondary or tertiary to the original physical injury or illness.

${ }^{15}$ Malingering refers to people who are exacerbating or faking an injury in order to avoid working. Secondary gain syndrome refers to injured workers deriving some benefit to being off work with an injury, so much so that they may continue to feign illness/injury in order to prolong the situation.
} 
The qualitative and quantitative literature regarding the treatment of injured workers of color and LEP workers in WC systems point to potential institutionally created injustices. From the current review of the literature, procedures appear to be biased, are not carried out consistently, and create additional physical and mental stress for injured workers, especially those who are LEP.

\section{Theoretical Framework}

This study is grounded in Link and Phelan's (1995) fundamental cause theory (FCT) which explains how racial discrimination is a fundamental cause of inequality in the WC process. The major emphasis of FCT is that there are social processes that are fundamental or basic in producing inequalities in health outcomes, and that these inequalities will continue until we address basic or fundamental causes. While Link, Phelan, and others have devoted most of their theoretical work to the investigation of how socioeconomic status (SES) is a fundamental cause of these inequalities, these scholars have more recently investigated racism — independent of SES — as a fundamental cause of health inequalities (Clouston et al., 2017; Masters, Link, \& Phelan, 2015; Phelan \& Link, 2015). Clouston et al. found that in more preventable causes of mortality (colon cancer, in this case), somewhere between 12,000-14,000 deaths among Blacks in the United States could have been prevented with a faster uptake of colorectal cancer screening (Clouston et al., 2017). In Masters et al.'s study, the authors found that while educational attainment had a significant linear effect on more preventable causes of death (in line with FCT), there were significant differences within cohorts by race, ethnicity, and gender; there was a less significant effect for ethnic and racial minorities, as well as 
for all women (Masters et al., 2015). To date, there have been no similar attempts to study occupational injuries or workers' compensation issues in a fundamental cause framework.

In addition to utilizing an FCT framework, this study builds on multiple social scientists' research in public health, sociology, and anthropology in describing how ethnicity and language are racialized (Davis \& Moore, 2014; Massey, 2009; Rosa, 2016; Williams, Mohammed, Leavell, \& Collins, 2010). Immigrants in the United States, specifically non-White immigrants or non-Christian White immigrants, currently face significant political, social, and legal obstacles to receiving basic assistance, refuge, citizenship, and equal rights. Spanish-speaking immigrants, for example, have long been considered racialized via a complex set of language and phenotypical characteristics (Massey, 2009). A widening group of non-Latino immigrants of various races, ethnicities, and religious backgrounds are currently undergoing a series of racial projects ${ }^{16}$; thus reducing their status or distancing them from "Whiteness" (Golshan, 2018; Southern Poverty Law Center, 2018). This study uses these theoretical arguments to categorize non-White LEP people (hereafter referred to as LEP) as a racialized minority group.

\section{Objectives and Hypotheses of the Study}

The purpose of this study is to investigate racial differences in workers' compensation administrative processes to identify inequalities associated with minority group status and

\footnotetext{
${ }^{16}$ Racial projects, a concept articulated by Omi and Winant to describe a social process of racializing groups, or of re-defining what race means and how that meaning of race organizes social systems (Omi \& Winant, 1994).
} 
to test associations between outcomes and perceived racial discrimination. Under an FCT framework, I expect to find inequalities in outcomes in WC processes, even when controlling for important socioeconomic characteristics. The hypotheses to be tested are:

1. Injured workers of color and LEP workers will be associated with worse outcomes for administrative processes than English speaking Whites will. In particular, they will experience: (a) longer waiting time for diagnostic services, (b) longer waiting time for time-loss payments, (c) more likelihood of perceiving racial discrimination, and (d) more independent medical exams.

2. Increasing numbers of administrative barriers will be associated with minority status, compared to English-speaking Whites.

3. Increasing numbers of administrative barriers will be associated with worse general health after a work-related injury.

\section{Methods}

\section{Study population}

The study sample is comprised of 488 injured workers from the Washington State statefund WC systems with accepted, compensable ${ }^{17}$ claims from 2008 through 2013, using both WC administrative data as well as survey data. Inclusion criteria for this study are the following: specific industries (construction and services), specific traumatic injuries

\footnotetext{
${ }^{17}$ Compensable claims refer to those accepted WC claims that are categorized as either being temporary total disability (more than three days of time loss), kept on salary (employer continues to pay wages for a worker off work with an injury), total permanent disability (injured worker unable to work for wages anymore), fatal, or loss of earning power (employee injured in a way that precludes them from returning to work in the same pay level job they had before the injury). Compensable claims make up approximately $30 \%$ of all accepted claims in the Washington State state fund (SF) WC system, and are considered more severe than medical only claims (where a worker experience no or minimal missed work and was ineligible for wage replacement).
} 
(burns that required hospitalization, amputations, and/or hand/wrist fractures), and three common but more complex soft-tissue disorders (rotator cuff syndrome, low back injuries, and/or carpal tunnel syndrome). These injuries were selected for inclusion for the following reasons: (1) to compare outcomes controlling for the possibility that differences were due to varied injury types, and (2) to compare differences in outcomes between traumatic (i.e., hospitalized burn, amputation, and/or hand/wrist fracture), and non-traumatic (i.e., CTS, shoulder, and/or low-back problems); discretion in how a claim is treated appears to depend, in part, on the complexity of the injury (Lax \& Klein, 2008). Information about inclusion criteria come from the initial report of injury, which is completed by the health-care provider and injured worker.

A data manager at the Washington Department of Labor and Industries (L\&I) merged the administrative and survey data, so the author was unable to view personally identifiable information. The Washington State Institutional Review Board and the Portland State University Human Subjects Research Review Committee both provided approval for this study as exempt research.

Sampling methods. Data for all injured workers who met the study inclusion criteria were extracted from the L\&I data warehouse resulting in a population of 6,593 injured workers. Because L\&I does not collect information regarding race or ethnicity, I used a Bayesian method (Elliott et al., 2009) to calculate probabilities of White/nonWhite workers within this population. The Bayesian Improved Surname Geocode (BISG) method developed by Elliott et al. (2009) uses a person's address and last name, along with United States' Census information to calculate the probability of racial or (Latino) 
ethnic group membership. Rather than attempt to sample using all six possible racial/ethnic probabilities, I created a dummy variable from the BISG results to White and not White (Latino, Black, Asian, Pacific Islander, and More than two races).

Contact information for all 6,593 injured workers was sent to a survey research group in order for them to construct a sampling frame that would consist of $1 / 3$ White and $2 / 3$ non-White subjects in order to obtain a larger sample of non-Whites in a predominantly White state.

Survey data collection. The survey research group contracted to perform the interviews developed a sampling frame of 1,350 Whites and 2,170 non-Whites. A total of 550 injured workers were interviewed, with 488 (89\%) providing complete responses to the survey, thus limiting this study to 488 subjects with a final overall response rate of 25\% using the American Association of Public Opinion Research (AAPOR) guidelines (AAPOR, 2015). The survey of injured workers asked a host of questions about the workers' compensation process, their satisfaction with the WC system, health-care services provided, as well as many questions related to their job such as hazards faced, in addition to demographic and SES (income and education) characteristics. Surveys were conducted in the worker's native language.

\section{Sampling Weights}

Sampling weights were constructed in order to account for the survey design and non-response characteristics available from the WC administrative data. HosmerLemeshow chi-square statistics were computed using a series of logistic regression models (surveyed/not surveyed) in order to establish appropriate weights. The final 
model used to calculate sampling weights included binary White/non-White, age, gender (male/female), geographic location of injured worker (based on WC agency service regions), industry, and interaction terms for White/non-White and gender as well as for industry and geography. Bootstrapped replicate weights $(\mathrm{n}=999)$ were computed and merged with the final dataset. Stata version 14.2 "SVY" commands were used to account for design and nonresponse to obtain weighted results as well as to compute all models.

\section{Measures}

Outcome measures and statistical methods. Timely approval of diagnostic services is calculated as a dichotomous yes/no variable based upon appropriate care, as defined by the American College of Occupational and Environmental Medicine (ACOEM) practice guidelines and/or Washington State treatment guidelines for appropriate care for specific injuries. Detailed information regarding appropriate care definition can be found elsewhere (Smith and Wuellner 2019 (submitted)). Briefly, this variable was coded a 1 if nerve conduction velocity testing was completed within 14 days of initial visit for CTS, or if a magnetic resonance imaging (MRI) was conducted within 45 days of initial visit for low back or shoulder injuries. This variable comes from medical billing records in the administrative WC data.

Time loss compensation delay was calculated using the state law that guides timeloss payments, the Revised Code of Washington (RCW) 51.32.210, ${ }^{18}$ which states that time loss payments must be sent within 14 days of the determination of a claim (as

\footnotetext{
${ }^{18}$ Revised Code of Washington (RCW) 51.32.310 located: http://app.leg.wa.gov/RCW/default.aspx?cite=51.32\&full=true $\# 51.32 .210$ accessed 4/9/2018
} 
accepted, rejected, provisional, etc.). A dummy variable was created to represent whether or not a payment was sent out within 14 days from the claim disability date; if yes, it was coded as 1 and if the time was longer than 14 days then timely compensation was coded as 0 . A reverse scored variable (Not timely compensation) was created to aid interpretation of the analysis.

Language-appropriate services is a dichotomous variable that comes from WC administrative billing data combined with administrative data for language preference. If an injured worker indicated a language other than English to converse with the WC agency, and there were no billing records for translations or interpreters, languageappropriate services was coded as 0 (not appropriate services). Otherwise, languageappropriate services was coded as 1 . A reverse scored variable (Not linguistically appropriate services) was created to aid interpretation of the results.

Perceived racial discrimination was measured using three variables: "Did you ever feel that any of the workers' compensation employees you dealt with ever judged you unfairly or treated you with disrespect because of how well you speak English?" (yes/no); "Do you think you would have been treated better by L\&I if you spoke English very well?" (yes/no); and "Do you think you would have been treated better by L\&I if you belonged to a different race or ethnic group?" (yes/no). A yes for any question was considered affirmative for perceived racial discrimination.

Independent medical exams (IMEs) is a count outcome from WC administrative data: a count of the number of IMEs for each claim. IME count is over-dispersed with the variance greater than the mean, so it is modeled using negative binomial regression. 
Administrative barriers is a dummy variable created by counting the number of WC administrative outcomes (timeliness of diagnostic approval and payment, perceived racial discrimination, and multiple IMEs) each claimant encountered and dichotomized at the mean. Administrative barriers are coded as a 0 if two or fewer barriers were encountered and coded as a 1 if more than two barriers were encountered.

General health comes from one question in the survey data: "In general, how would you rate your health now?" Responses include very poor, poor, good, and very good. This variable was dichotomized, into poor and good general health. I model this outcome as poor general health.

\section{Primary Independent Variable}

Racialized minority group status. Race, ethnicity, and language preferred were self-reported in the survey data, but due to low numbers in many racial groups, one variable was created with three mutually exclusive options: (1) White, English Speaking, (2) Non-White, English speaking, and (3) Non-White, Limited English proficiency (LEP). Eight White LEP subjects were excluded from analysis in order to create three mutually exclusive categories.

\section{Covariates}

Covariates include gender, age, education, household income, injury type, and industry employed. Gender was coded as male or female. Age was a continuous variable based upon injured workers age in years at the time of injury. Education was dichotomized into less than a high school education or high school or more education, and annual household income was dichotomized at the sample median $(<\$ 35,000$ or $\geq \$ 35,000)$. Injury type was 
categorized as one of four options: traumatic (burn that required hospitalization, amputation, or hand/wrist fracture), rotator cuff syndrome, carpal tunnel syndrome, or low back injury. Industry was coded as construction, accommodation and food services, or janitorial services, using North American Industry Classification System (NAICS) titles.

\section{Results}

\section{General Characteristics}

Table 1 provides descriptive information for the sample stratified by racial group. Significant differences were found across the groups; the socioeconomic variables (education, income, and industry sector) were significantly different between racial groups with much lower percentages of LEP workers having household incomes equal to or greater than $\$ 35,000$ per year. They were also less likely to have a high school or higher level of education (both $\mathrm{p}$-values $<0.001$ ).

Table 1

Descriptive Characteristics by Racial Group Status

\begin{tabular}{|c|c|c|c|c|c|c|}
\hline \multirow[t]{2}{*}{$\begin{array}{l}\text { Variable } \\
\text { Sample N }\end{array}$} & $\begin{array}{l}\text { Survey } \\
\text { sample }\end{array}$ & $\begin{array}{l}\text { Weighted } \\
\text { Sample }\end{array}$ & $\begin{array}{l}\text { White, } \\
\text { English } \\
(\mathrm{n}=224)\end{array}$ & $\begin{array}{l}\text { Non- } \\
\text { White } \\
\text { English } \\
(\mathrm{n}=97)\end{array}$ & $\begin{array}{l}\text { Non- } \\
\text { White } \\
\text { LEP* } \\
(\mathrm{n}=162)\end{array}$ & p-value \\
\hline & N (\%) & N (\%) & $\begin{array}{l}\text { Weighted } \\
\%\end{array}$ & $\begin{array}{l}\text { Weighte } \\
\text { d \% }\end{array}$ & $\begin{array}{l}\text { Weighte } \\
\text { d \% }\end{array}$ & \\
\hline Female & $121(25.1)$ & $1263(22.0)$ & 53.0 & 16.0 & 52.0 & 0.024 \\
\hline $\begin{array}{l}\text { Married } \\
\text { Household income }>=\end{array}$ & $282(58.6)$ & $3287(57.3)$ & 55 & 56.8 & 64.5 & 0.234 \\
\hline $\begin{array}{l}\$ 35 k \\
\text { At least a high school }\end{array}$ & $228(51.1)$ & $2965(55.9)$ & 66.8 & 51 & 29.9 & $<0.001$ \\
\hline degree & $337(70.3)$ & $4464(78.3)$ & 91.9 & 82.1 & 36.4 & $<0.001$ \\
\hline $\begin{array}{l}\text { Age at time of injury } \\
\text { (years) Mean(SD)*** }\end{array}$ & $42.1(0.5)$ & $41.5(0.4)$ & $\begin{array}{r}43.9 \\
(0.8)\end{array}$ & $\begin{array}{r}36.9 \\
(1.1)\end{array}$ & $\begin{array}{r}37.6 \\
(0.7)\end{array}$ & $<0.001$ \\
\hline
\end{tabular}




\begin{tabular}{|c|c|c|c|c|c|c|}
\hline $\begin{array}{l}\text { Has health insurance } \\
\text { through work }\end{array}$ & $195(41.1)$ & 2343 (41.4) & 43.2 & 52.2 & 27.2 & 0.002 \\
\hline $\begin{array}{l}\text { Has a primary care } \\
\text { provider }\end{array}$ & $298(62.2)$ & 3729 (65.7) & 75.5 & 54.8 & 47.6 & $<0.001$ \\
\hline $\begin{array}{l}\text { Saw primary care } \\
\text { provider for work injury }\end{array}$ & $113(37.8)$ & 1473 (39.2) & 40.4 & 39.2 & 33.6 & 0.663 \\
\hline Injury Type & & & & & & $<0.001$ \\
\hline Traumatic*** & $34(7.0)$ & $355(6.2)$ & 4.5 & 9.1 & 8.5 & \\
\hline $\begin{array}{l}\text { Low back pain } \\
\text { Carpal Tunnel }\end{array}$ & $219(45.3)$ & $\begin{array}{r}2572(44.8) \\
702.4\end{array}$ & 38.7 & 47.6 & 59.5 & \\
\hline $\begin{array}{l}\text { Syndrome } \\
\text { Shoulder (rotator }\end{array}$ & 55 (11.4) & (12.2) & 82.0 & 44.0 & 93.0 & \\
\hline $\begin{array}{l}\text { Shouider (rotator } \\
\text { cuff syndrome) }\end{array}$ & $175(36.2)$ & 14.5 & 13.3 & 5.0 & 12.2 & \\
\hline $\begin{array}{l}\text { Industry } \\
\text { Accommodation/ }\end{array}$ & & & & 3 & & $<0.001$ \\
\hline Janitorial Services & $\begin{array}{r}120(24.8) \\
77(15.9)\end{array}$ & $772(13.4)$ & $\begin{array}{r}25.2 \\
8.5\end{array}$ & $\begin{array}{r}31.4 \\
9\end{array}$ & 30.9 & \\
\hline Construction & $285(59.0)$ & $3442(60.1)$ & 66.2 & 59.6 & 43.5 & \\
\hline
\end{tabular}

Note. ${ }^{*}$ LEP $=$ Limited English proficiency

**Kruskal-Wallis equality-of-populations rank test

***Traumatic injuries are: burns that required hospitalization, amputations, and hand/wrist fractures.

Bold indicates statistically significant results $(\mathrm{p} \leq 0.05)$

Table 2 provides descriptive information of the bivariate relationships between racial categories and the outcomes of interest in this study. All outcomes were statistically significantly different ( -value $<0.05$ ) across groups except for not receiving timely payment and multiple IMEs. LEP and non-White English-speaking workers were likely than Whites to have longer wait times for diagnostic approvals, more likely to experience racial discrimination, and more likely to have more IMEs ordered. Additional outcomes also noted in Table 2 include a larger percent of both non-White racial categories felt they returned to work too early ( 49.4 and $50.3 \%$ compared to $33.7 \%$ of Whites). Both non-White English speakers and LEP speakers also had much lower median days of time loss than Whites did. 
Table 2

Associations by Racial Group Status and Administrative Outcomes

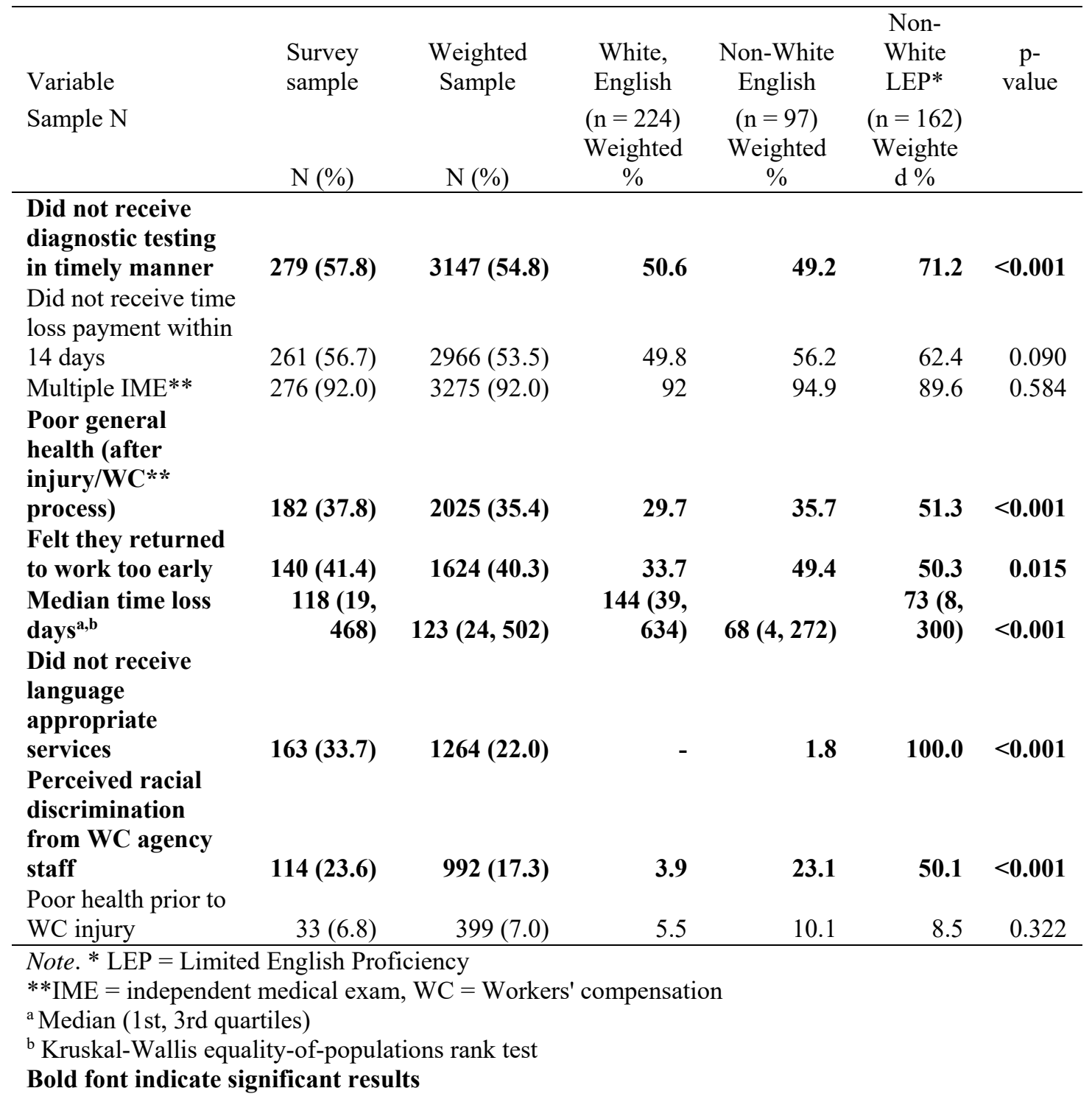




\section{Multivariable results}

Logistic regression results for longer wait times for diagnostic services (hypothesis 1a) are displayed in Table 3, Model 1. Only LEP workers are significantly more likely to wait for diagnostic services, having almost twice the odds of having to wait compared to Whites. Low back injuries are also significantly associated with longer wait times. SES (income and education) do not appear to be associated with this outcome.

Table 3, Model 2, presents the results for hypothesis 1b, longer wait times for wage-replacement payment. Only age is statistically significant and the real effect is very small, odds ratio (OR) 0.99 (95\% CI 0.97, 1.01), showing a $.01 \%$ decreased odds with each increasing year of age.

Table 3, Model 3 presents the results for hypothesis 1c, the likelihood of experiencing racial discrimination from WC agency staff. As expected, both non-White English speakers and LEP speakers showed significant odds of experiencing racial discrimination compared to Whites, although the confidence intervals are very large. SES variables appear to be protective, meaning they may decrease the odds of experiencing racial discrimination; both income and education appear to decrease the odds by half. 
Table 3

Multivariable Regression Analyses for Administrative Barriers

\begin{tabular}{|c|c|c|c|c|}
\hline Variables & $\begin{array}{c}\text { Model 1 } \\
\text { Not timely diagnostic } \\
\text { services (Logistic } \\
\text { regression) } \\
\text { Odds Ratio }(95 \% \mathrm{CI}) \\
\mathrm{N}=411 \\
\end{array}$ & $\begin{array}{c}\text { Not timely paid } \\
\text { (Logistic regression) } \\
\text { Odds Ratio }(95 \% \mathrm{CI}) \\
\mathrm{N}=389\end{array}$ & $\begin{array}{c}\text { Model } 3 \\
\text { Perceived racial } \\
\text { discrimination from } \\
\text { WC staff (Logistic } \\
\text { regression) } \\
\text { Odds Ratio }(95 \% \mathrm{CI}) \\
\mathrm{N}=411 \\
\end{array}$ & $\begin{array}{c}\text { Receiving more } \\
\text { IME* (Negative } \\
\text { binomial regression) } \\
\text { Incidence Rate } \\
\text { Ratio }(95 \% \mathrm{CI}) \\
\mathrm{N}=271\end{array}$ \\
\hline \multicolumn{5}{|l|}{ Race } \\
\hline White, English speaking & & (reference) & (reference) & (reference) \\
\hline Non-White, English speaking & $0.68(0.36,1.28)$ & $1.54(0.76,3.12)$ & $5.99(1.75,20.52)$ & $1.32(1.00,1.75)$ \\
\hline Non-White, LEP** & $1.85(0.99,3.45)$ & $1.65(0.87,3.13)$ & $18.07(5.30,61.67)$ & $1.34(1.03,1.76)$ \\
\hline Female & $1.10(0.54,2.25)$ & $1.90(0.82,4.38)$ & $0.46(0.16,1.30)$ & $0.93(0.68,1.28)$ \\
\hline Age at time of injury (years) & $0.99(0.97,1.01)$ & $0.99(0.97,1.01)$ & $0.98(0.94,1.02)$ & $1.0(0.99,1.01)$ \\
\hline Household income $>=\$ 35 \mathrm{k}$ & $0.89(0.53,1.49)$ & $0.79(0.46,1.33)$ & $0.47(0.23,0.96)$ & $0.79(0.62,1.01)$ \\
\hline At least a high school degree & $1.06(0.57,1.98)$ & $1.24(0.66,2.31)$ & $0.50(0.24,1.02)$ & $1.00(0.79,1.27)$ \\
\hline \multicolumn{5}{|l|}{ Type of musculoskeletal injury } \\
\hline Shoulder (rotator cuff syndrome) & (reference) & (reference) & (reference) & (reference) \\
\hline Low back pain & $1.97(1.14,3.40)$ & $1.03(0.60,1.78)$ & $0.90(0.41,1.94)$ & $0.85(0.69,1.06)$ \\
\hline Carpal Tunnel Syndrome & $0.93(0.43,1.99)$ & $0.80(0.37,1.74)$ & $2.02(0.67,6.10)$ & $0.97(0.70,1.36)$ \\
\hline \multicolumn{5}{|l|}{ Industry } \\
\hline Construction & (reference) & (reference) & (reference) & (reference) \\
\hline Accommodation/Food Service & $1.36(0.63,2.93)$ & $0.55(0.24,1.24)$ & $1.47(0.45,4.77)$ & $0.93(0.68,1.28)$ \\
\hline Janitorial Services & $1.19(0.59,2.39)$ & $1.07(0.49,2.33)$ & $0.88(0.39,2.01)$ & $0.87(0.58,1.30)$ \\
\hline
\end{tabular}

Note. ${ }^{*}$ IME $=$ Independent medical exams

$* *$ LEP $=$ Limited English proficient

Bold font indicate significant results 
Table 3, Model 4 presents the results for hypothesis 1d, which states non-Whites would experience more IMEs than Whites. The results support this hypothesis there appears to be an association between having higher-incidence rate ratios for IMEs among non-White English and LEP workers (32\% and 34\%, respectively), compared to Whites. Although the confidence interval crosses 1.00 (1.01) for household income (greater than or equal to $\$ 35,000)$, household income may be a protective factor in reducing the risk ratio of IMEs by about $20 \%$.

Logistic regression results presented in Table 4 indicate that both non-White English speakers and LEP speaker have increased odds of reporting more than two of the administrative barriers described in this study, although the confidence intervals for nonWhite, English speakers crosses 1.00. LEP speakers have more than 17 times the odds of having more than two IMEs compared to Whites. The confidence intervals are quite wide, showing some instability in this result. Education (having at least a high school degree) appears protective against multiple IMEs, decreasing the odds by almost half. Industry is also significant; working in food services, accommodations, or janitorial work increase the odds of experiencing more than two administrative barriers, from 2.6 to 3.9 times compared to those in the construction industry.

Table 4

Logistic Regression Model for More Than Two Administrative Barriers in Workers' Compensation

\begin{tabular}{lr}
\hline Variables & Odds Ratio (95\% CI) \\
\hline Race, ethnicity or LEP status & (reference) \\
White, English speaking & $1.78(0.74,4.28)$ \\
Non-White English speaking & $\mathbf{1 7 . 2 8}(\mathbf{7 . 5 9 , 3 9 . 3 1 )}$
\end{tabular}


\begin{tabular}{lr} 
Female & $0.40(0.16,1.02)$ \\
Age at time of injury (years) & $0.97(0.94,1.01)$ \\
Household income $\geq \$ 35,000$ annually & $0.78(0.38,1.58)$ \\
High school or higher education & $\mathbf{0 . 4 8}(\mathbf{0 . 2 2}, \mathbf{1 . 0 2})$ \\
Type of musculoskeletal disorder & \\
$\quad$ Rotator cuff syndrome & (reference) \\
$\quad$ Low back pain & $1.48(0.71,3.10)$ \\
$\quad$ Carpal tunnel syndrome & $1.14(0.36,3.66)$ \\
Industry & (reference) \\
$\quad$ Construction & $\mathbf{2 . 6 9}(\mathbf{0 . 9 5}, \mathbf{7 . 6 2})$ \\
$\quad$ Accommodation/Food Service & $\mathbf{3 . 0 9}(\mathbf{1 . 0 3 , 9 . 2 5 )}$ \\
$\quad$ Janitorial Services & $1.0(0.31,3.25)$ \\
Poor health before injury & $\mathbf{2 . 0 8}(\mathbf{1 . 0 8 , 3 . 9 9 )}$ \\
Poor general health after treatment for injury & \\
\hline Note. N=408 & \\
*LEP = Limited English Proficiency & \\
Bold font indicate significant results &
\end{tabular}

Hypothesis 3 (those who have multiple administrative barriers, will have higher odds of reporting poor general health) results are also presented in Table 4, showing a doubling in the odds of suffering poor general health for those with more than two administrative barriers during their WC experience, even when controlling for SES, industry, and injury type.

\section{Discussion}

This study sought to investigate racial discrimination in a workers' compensation agency, hypothesizing that racial discrimination is a fundamental cause of administrative inequalities in the claims processes that lead to inequalities in health. All hypotheses, except time-loss payment delays for injured minority workers (hypothesis $1 \mathrm{~b}$ ), were supported in this study with LEP workers having worse outcomes than English-speaking Whites and English-speaking non-Whites having a higher likelihood of suffering discrimination, as well as having more IMEs than Whites. 
This study adds to the literature by identifying $\mathrm{WC}$ administrative barriers that have been previously suggested in smaller, qualitative studies and explores how these barriers have been differentially applied across racialized groups. As Lippel notes in her review of the therapeutic and anti-therapeutic consequences of WC systems, for most workers with visible injuries, the process is speedy and efficient; for more complex injuries, however, there are some definite anti-therapeutic aspects in how WC systems operate (Lippel 1999). Prior qualitative literature has found similar consequences to those found in this current study (Kosny et al., 2012; MacEachen et al., 2010). The current study has expanded upon this by linking anti-therapeutic aspects of workers' compensation to worse general health outcomes for racialized minorities as compared to Whites.

My findings of longer waiting times for diagnostic testing is consistent with the findings from Kosny et al. in their in-depth interviews with new immigrants to Canada, where communication issues resulted in delays in care as well as misunderstandings about processes for payment (Kosny et al., 2012).

These current results indicate a deficiency in the Washington State WC system in providing consistent linguistically appropriate services to those not able to communicate in English. This finding is similar to results from Stephanie Premji in her review of cases filed in the Ontario Workplace Safety and Health Insurance Appeals Tribunal, where no systematic process was in place for linguistically appropriate services (Premji 2014). A recent investigation co-run by the U.S. Departments of Labor and Justice found the 
Washington State Department of Labor and Industries to be non-compliant with Title VI of the Civil Rights Act of 1964 in not having a systematic language assistance policy. ${ }^{19}$ My current study lends support to their findings.

This current study presents results that support the theoretical framework of FCT. The analysis conducted in this study clearly depicts a WC system where injured nonWhite and LEP workers have more barriers to an efficient and speedy recovery compared to White workers. In addition, minorities had fewer flexible resources in terms of household income and education, both of which may have helped to ameliorate the effect of the injury, manage the timeliness of appointments and approvals, and help to weather the effect of prolonged, reduced income for the injured worker.

Policies for language access and services examined in this study create barriers for LEP speakers and suggest racial discrimination in the WC agency is primarily structural. Policies and practices that exclude by omission or commission large sectors of the population they are intended to serve clearly have adverse health and work consequences.

Framing this study using FCT assisted in identifying potential institutional and systemic inequities in the WC system under investigation. More focused research regarding specific policy associations with poor outcomes found in this study should be conducted to identify the discriminatory consequences of policies on linguistic and racial

\footnotetext{
${ }^{19}$ A memorandum of understanding, along with the results of the joint investigation can be downloaded at https://www.justice.gov/opa/file/780156/download.
} 
minority workers who enter the WC system. In addition, counterfactual analyses may increase political awareness for the issue of inequitable services in this WC system. A counterfactual analysis to estimate the proportion of injured workers the WC agency could return to productive work, by implementing policy changes regarding language services for example, may be the impetus needed to improve services.

While this study adds significantly to the current literature by quantifying the existence of multiple administrative barriers, and their subsequent effects on injured workers, it is not without limitations. First, it is a cross-sectional study, which precludes me from assigning causation. Second, it is a small-sample study based upon a much larger population of WC claimants, although non-response weighting should have adjusted for some of the potential bias in standard errors. Third, and possibly most importantly, I did not have large enough numbers to keep the self-reported racial and ethnic categories and had to condense them into less specific groups. No doubt there are differences within the non-White English-speaking and LEP groups that could have clarified the inequalities I did find in this study. Even with the heterogeneous nature of racial, ethnic, and LEP group membership, however, I found striking differences in how minorities are treated in the WC system. These results need to be studied further so that policies and procedures in the WC system can be modified to reduce their discriminatory effects. 


\section{References}

AAPOR. (2015). Standard Definitions: Final Dispositions of Case Codes and Outcome Rates for Surveys. Retrieved from https://www.aapor.org/EducationResources/For-Researchers/Poll-Survey-FAQ/Response-Rates-An-Overview.aspx

Alonso-Villar, O., Del Rio, C., \& Gradin, C. (2012). The Extent of Occupational Segregation in the United States: Differences by Race, Ethnicity, and Gender. Industrial Relations, 51(2), 179-212.

Beardwood, B. A., Kirsh, B., \& Clark, N. J. (2005). Victims twice over: perceptions and experiences of injured workers. Qual Health Res, 15(1), 30-48.

Bonauto, D. K., Smith, C. K., Adams, D. A., Fan, Z. J., Silverstein, B. A., \& Foley, M. P. (2010). Language preference and non-traumatic low back disorders in washington state workers' compensation. American Journal of Industrial Medicine, 53(2), 204-215. doi:10.1002/ajim.20740

Buchanan, S., Vossenas, P., Krause, N., Moriarty, J., Frumin, E., Shimek, J. A. M., . . Punnett, L. (2010). Occupational injury disparities in the US hotel industry. American Journal of Industrial Medicine, 53(2), 116-125.

Chibnall, J. T., Tait, R. C., Andresen, E. M., \& Hadler, N. M. (2005). Race and socioeconomic differences in post-settlement outcomes for African American and Caucasian Workers' Compensation claimants with low back injuries. Pain, 114(3), 462-472.

Chibnall, J. T., Tait, R. C., Andresen, E. M., \& Hadler, N. M. (2006a). Clinical and social predictors of application for social security disability insurance by workers' compensation claimants with low back pain. Journal of occupational and environmental medicine / American College of Occupational and Environmental Medicine, 48(7), 733-740. doi:10.1097/01.jom.0000214357.14677.5a

Chibnall, J. T., Tait, R. C., Andresen, E. M., \& Hadler, N. M. (2006b). Race differences in diagnosis and surgery for occupational low back injuries. Spine, 31(11), 12721275.

Clouston, S. A. P., Rubin, M. S., Chae, D. H., Freese, J., Nemesure, B., \& Link, B. G. (2017). Fundamental causes of accelerated declines in colorectal cancer mortality: Modeling multiple ways that disadvantage influences mortality risk. Social Science \& Medicine, 187, 1-10. doi:https://doi.org/10.1016/j.socscimed.2017.06.013

Davis, T. Y., \& Moore, W. L. (2014). Spanish not spoken here: Accounting for the racialization of the Spanish language in the experiences of Mexican migrants in the United States. Ethnicities, 14(5), 676-697.

Dembe, A. E. (2001). Access to medical care for occupational disorders: difficulties and disparities. J Health Soc Policy, 12(4), 19-33.

Duncan, G. (2003). Workers' compensation and the governence of pain. Economy and Society, 32(3), 449-477.

Elliott, M. N., Morrision, P. A., Fremont, A., McCaffrey, D. F., Pantoja, P., \& Lurie, N. (2009). Using the Census Bureeau's surname list to improve estimates of race/ethnicity and associated disparities. Health Serv Outcomes Res Method, 9, 69-83. 
Friedman, L. S., Ruestow, P., \& Forst, L. (2012). Analysis of ethnic disparities in workers' compensation claims using data linkage. Journal of Occupational and Environmental Medicine, 54(10), 1246-1252.

Golshan, T. (2018). Trump: the US will not turn into a "migrant camp" or "refugee holding facility". Retrieved from https://www.vox.com/018/6/18/17475512/trump-migrant-camp-refugee-germany

Gravel, S., Vissandjee, B., Lippel, K., Brodeur, J. M., Patry, L., \& Champagne, F. (2010). Ethics and the compensation of immigrant workers for work-related injuries and illnesses. J Immigr Minor Health, 12(5), 707-714. doi:10.1007/s10903-008-92085

Gregory, J. N. (2005). The Southern Diaspora: How the Great Migrations of Black and White Southerners Transformed America. Chapel Hill, North Carolina: University of North Carolina Press.

Guyton, G. P. (1999). A Brief History of Workers' Compensation. The Iowa Orthopaedic Journal, 19, 106-107.

Kilgour, E., Kosny, A., McKenzie, D., \& Collie, A. (2014). Interactions Between Injured Workers and Insurers in Workers' Compensation Systems: A Systematic Review of Qualitative Research Literature. J Occup Rehabil, 1-22. doi:10.1007/s10926014-9513-X

Kosny, A., MacEachen, E., Lifshen, M., \& Smith, P. (2014). Another Person in the Room: Using Interpreters During Interviews With Immigrant Workers. Qual Health Res, 24(6), 837-845. doi:10.1177/1049732314535666

Kosny, A., MacEachen, E., Lifshen, M., Smith, P., Jafri, G. J., Neilson, C., . . Shields, J. (2012). Delicate dances: immigrant workers' experiences of injury reporting and claim filing. Ethn Health, 17(3), 267-290. doi:10.1080/13557858.2011.614327

Lax, M. B., \& Klein, R. (2008). More than meets the eye: social, economic and emotional impacts of work-related injury and illness. New Solutions, 18(3), 343-360.

Link, B. G., \& Phelan, J. (1995). Social Conditions as Fundamental Causes of Disease. Journal of Health and Social Behavior, 80-94.

Lippel, K. (1999). Therapeutic and Anti-Therapeutic Consequences of Workers' Compensation. Int J Law Psychiatry, 22(5-6), 521-546.

Lippel, K. (2007). Workers describe the effect of the workers' compensation process on their health: a Quebec study. Int J Law Psychiatry, 30(4-5), 427-443. doi:10.1016/j.ijlp.2007.06.013

Lippel, K. (2012). Preserving workers' dignity in workers' compensation systems: an international perspective. Am J Ind Med, 55(6), 519-536. doi:10.1002/ajim.22022

Lipscomb, H. J., Loomis, D., McDonald, M. A., Argue, R. A., \& Wing, S. (2006). A conceptual model of work and health disparities in the United States. Int J Health Serv, 36(1), 25-50.

MacEachen, E. (2000). The mundane administration of worker bodies: from welfarism to neoliberalism. Health, Risk \& Society, 2(3), 315-327.

MacEachen, E., Kosny, A., \& Ferrier, S. (2007). Unexpected barriers in return to work: lessons learned from injured worker peer support groups. Work, 29(2), 155-164.

MacEachen, E., Kosny, A., Ferrier, S., \& Chambers, L. (2010). The "Toxic Dose" of System Problems: Why Some Injured Workers Don't Return to Work as Expected. J Occup Rehabil, 20(3), 349-366. 
Massey, D. S. (2009). Racial formation in theory and practice: The case of Mexicans in the United States. Race and Social Problems, 1(1), 12-26.

Masters, R. K., Link, B. G., \& Phelan, J. C. (2015). Trends in education gradients of 'preventable' mortality: A test of fundamental cause theory. Social Science and Medicine, 127, 19-28. doi:10.1016/j.socscimed.2014.10.023

Ngai, M., M. (1999). The Architecture of Race in American Immigration Law: A Reexamination of the Immigration Act of 1924. The Journal of American History, 86(1), 67-92.

Omi, M., \& Winant, H. (1994). Racial formation in the United States: from the 1960s to the 1990s (2nd ed.). New York: Routledge.

Packard, J. M. (2002). American Nightmare: The History of Jim Crow: Macmillan.

Phelan, \& Link, B. G. (2015). Is Racism a Fundamental Cause of Inequalities in Health? Annual Review of Sociology, 41, 311-330.

Premji, \& Krause, N. (2010). Disparities by ethnicity, language, and immigrant status in occupational health experiences among Las Vegas hotel room cleaners. American Journal of Industrial Medicine, 53(10), 960-975. doi:10.1002/ajim.20860

Premji, S. (2014). Barriers to Return-to-Work for Linguistic Minorities in Ontario: An Analysis of Narratives from Appeal Decisions. J Occup Rehabil, 1-11. doi:10.1007/s 10926-014-9544-3

Rosa, J. (2016). Standardization, racialization, languagelessness: Raciolinguistic ideologies across communicative contexts. Journal of Linguistic Anthropology, 26(2), 162-183.

Scherzer, T., Rugulies, R., \& Krause, N. (2005). Work-related pain and injury and barriers to workers' compensation among Las Vegas hotel room cleaners. Am J Public Health, 95(3), 483-488. doi:10.2105/AJPH.2003.033266

Smith, P. M., Kosny, A. A., \& Mustard, C. A. (2009). Differences in access to wage replacement benefits for absences due to work-related injury or illness in Canada. American Journal of Industrial Medicine, 52(4), 341-349. doi:10.1002/ajim.20683

Sommers, B. D., Musco, T., Finegold, K., Gunja, M. Z., Burke, A., \& McDowell, A. M. (2014). Health reform and changes in health insurance coverage in 2014. New England Journal of Medicine, 371(9), 867-874.

Southern Poverty Law Center, S. (2018). Rise of the Aryan Circle. Retrieved from

Strunin, L., \& Boden, L. I. (2004). The workers' compensation system: worker friend or foe? Am J Ind Med, 45(4), 338-345. doi:10.1002/ajim.10356

Tait, R. C., Chibnall, J. T., Andresen, E. M., \& Hadler, N. M. (2004). Management of occupational back injuries: differences among African Americans and Caucasians. Pain, 112(3), 389-396. doi:10.1016/j.pain.2004.09.027

Wilkerson, I. (2011). The Warmth of Other Suns: The Epic Story of America's Great Migration. New York, NY: Vintage Books, a division of Random House.

Williams, D. R., Mohammed, S. A., Leavell, J., \& Collins, C. (2010). Race, socioeconomic status, and health: Complexities, ongoing challenges, and research opportunities. In N. E. Adler \& J. Stewart (Eds.), Biology of Disadvantage: Socioeconomic Status and Health (Vol. 1186, pp. 69-101). 


\section{Chapter 4: Pre-injury Racial Discrimination at Work, and Its Association with Post- Injury Return to Work for Minorities: Does Workplace Support Mediate Racial Discrimination?}

\section{Introduction}

Racial discrimination in the United States is associated with a host of health disparities between non-Latino Whites (henceforth referred to as simply Whites) and people of color, including those with limited English proficiency (LEP) (Gilbert C. Gee \& Ford, 2011; G. C. Gee, Ro, Shariff-Marco, \& Chae, 2009; Williams \& Mohammed, 2013). While racial discrimination can be found in almost all social, economic, and political spheres of everyday life, this study focuses on the effects of racial discrimination at work (pre-injury) on subsequent return-to-work (RTW) post-injury outcomes. In addition, this study will test the mediating effect of workplace support in reducing the effect of workplace discrimination on RTW. This study uses the conceptual framework of fundamental cause theory (FCT) (Link \& Phelan, 1995; Phelan \& Link, 2015) to structure the analysis on the premise that racial discrimination is a fundamental cause of racial, ethnic, and linguistic minority inequalities in RTW outcomes. This will be examined using a unique sample of injured-worker survey responses matched with their administrative records from the Washington State workers' compensation (WC) system.

The remainder of this section will summarize the literature regarding workplace racial discrimination and work-related injuries and illnesses, as well as what is known about racial differences in return-to-work rates after an injury. This section concludes with the potential role of workplace support in mediating the effects of racial discrimination on return-to-work outcomes. 


\section{Racial Discrimination and Workplace Injuries}

Work-related injuries and illnesses (WRII) are estimated as the eighth leading cause of death among adults in the United States between 2003 and 2008 (Hilgert, 2012). They pose a significant social and economic problems in the United States, with costs reaching into the hundreds of billions each year (Leigh, 2011), the majority of which are not covered by employer-funded workers' compensation (WC) systems. ${ }^{20}$ Instead, these costs are offset by private insurance, other social systems, or shouldered by injured workers and their families (Leigh \& Marcin, 2012).

Historical racial segregation and inequalities in occupations, education, wealth, and labor-market participation have resulted in a two-tiered occupational system in the United States, what Edna Bonacich referred to as a "split labor market" in her work comparing African Americans and Whites (Bonacich, 1972). Occupational segregation by race, ethnicity, and LEP status continues to be a significant issue and one of the stronger explanations for continuing disparities in work-related injury rates among minorities compared to Whites (BLS, 2017b; Chung-Bridges et al., 2008).

Historical trends in workplace-injury risk by racial/ethnic group status do not exist in national surveillance data. The main source of workplace-injury surveillance comes from the Bureau of Labor Statistics (BLS), but these data were not coded for occupation or race/ethnicity until the mid-1990s (BLS, 2017a). Even now, race/ethnicity classifications in these data are missing approximately $40 \%$ of the time (BLS, 2017c).

\footnotetext{
${ }^{20}$ In Washington State, the employer does not fund all of workers' compensation premiums as a portion are taken out of workers' paychecks.
} 
Evidence of historical occupational racial segregation, however, can be found in highprofile, catastrophic incidents such as acute silicosis cases in Gauley Bridge, West Virginia during the Great Depression and J. William Lloyd's classic study of long-term mortality among steelworkers. ${ }^{21}$ Both of these classic cases found Black workers in the most hazardous conditions (and with the highest exposure and premature mortality rates), even though they were the minority of employees. Workers inside the Gauley Bridge tunnel, exposed to almost pure silica, were almost exclusively Black, even though they were the minority of the population in the surrounding community (Cherniack, 1986). In the epidemiological studies of steelworkers, J. William Lloyd found that Black workers were more likely than White steelworkers to work on top of coke ovens, ${ }^{22}$ where they were exposed to much higher rates of known carcinogenic compounds (Lloyd, 1971).

Thirty years after Gauley Bridge, Robinson In a Current Population Survey (CPS) analysis thirty years after Gauley Bridge, Robinson found Black men had an injury rate of 5.7 per 100 workers compared to White men who had a rate of 3.2 per 100 workers in

\footnotetext{
${ }^{21}$ Gauley Bridge West Virginia was the site of one of the worst industrial incidents in American history. Union Carbide chose to dig through a mountain of (almost) pure silica using dry drilling techniques, even though wet drilling was considered much safer. Approximately 700 workers died between 1930 and 1935 . The local population was $80 \%$ White, but the workers chosen to dig inside the tunnel (site of most silica exposure) were $80 \%$ Black (Murray, 2003; Cherniack, 1986). In a series of papers, J. William Lloyd documented steelworker respiratory cancers compared to specifically coke plant workers respiratory cancers. Lloyd found that $74 \%$ of the workers who worked on the top of coke ovens (extremely high heat and highest exposure to coke oven fumes) were Black. This task also produced the largest numbers of lung cancer (Lloyd, JW. 1971).

${ }^{22}$ Coke ovens are where coke is produced. Coke is a vital component in iron and steel production. More information about this process and the carcinogens released into the air can be found in Graham and Holtgrave (1990).
} 
1968 (Robinson, 1987). While this analysis covered all occupations, Black men were still at higher risk of injury than White men.

Comparing the results from Robinson's study to more recent data (2000) from Strong and Zimmerman, an enduring higher rate of injuries was found Black men compared to White men. Black men had an injury rate of 4.8 per 100 workers, and White men a rate of 2.7 per 100 workers (Strong \& Zimmerman, 2005). From 1968 (two years before the mandatory reporting of injuries due to the Occupational Safety \& Health Act (OSHA) to 2000, the rate ratios are identical at 1.78 (Black men compared to White men) (Robinson, 1987). With safety and health advances in the 32 years between these two studies and the overall decline in injury rates for both Blacks and Whites, the ratio of injuries should be declining, not enduring.

When Robinson (1987) controlled for education and time-on-job rates using CPS data, the rate ratios between Black and White men increased by 24\% (Robinson, 1987), meaning that by controlling for education and job tenure, the disparity in injury rates increased, with Black men having almost twice the rate of injury compared to White men $(\mathrm{RR}=1.92)$. When Strong and Zimmerman (2005) controlled for age, gender, education, and a host of occupational factors (e.g., occupation, shift, tenure, pay, and union membership), Black and White men did not differ significantly in the odds of having an injury; Black men were $66 \%$ more likely to miss more work, however, which may be related to more severe injuries, or less adequate health services (Strong \& Zimmerman, 
2005). Both Robinson, Strong and Zimmerman hypothesized that discrimination may be the key factor in their findings.

While socioeconomic conditions have improved for many workers over time, racial and ethnic minorities are still represented disproportionally in high-hazard occupations (BLS, 2017b) and are more likely to suffer work-related injuries and illnesses. Even when controlling for levels of education-a common labor market indicator of higher paid, safer jobs — workers of color and LEP workers are still more likely than Whites to suffer higher rates of WRII (Seabury, Terp, \& Boden, 2017).

Workplace racial discrimination has a long history in America, and still appears to affect workers of color and LEP workers in hiring (Bertrand \& Mullainathan, 2004; Quillian, Pager, Hexel, \& Midtbøen, 2017), promotions (Maume, 1999; Wingfield, 2009), and occupational segregation into lower-paying jobs (Alonso-Villar, Del Rio, \& Gradin, 2012; Browne, Hewitt, Tigges, \& Green, 2001). Perceived racial discrimination is also associated with the risk of work-related injuries and illnesses (Shannon, Rospenda, Richman, \& Minich, 2009). In a national telephone survey, Shannon et al. found Blacks and Hispanics to be 8-10 times more likely to suffer discrimination at work, and those who suffered discrimination at work were twice as likely to suffer a work-related injury or illness (Shannon et al., 2009). Racial discrimination at work has also been associated with higher rates of mental-health illnesses (Bhui et al., 2005; Premji, Messing, \& Lippel, 2008; Roberts, Swanson, \& Murphy, 2004), similar to studies of the long-term unemployed (Bartley, Ferrie, \& Montgomery, 2006). Mental health issues, such as 
depression, impede physical recovery, extend time off work, as well as affect an injured worker's economic stability, social relationships, and sense of self-worth.

Racial discrimination has been associated with worse physical and mental health for minorities, including increased mortality (Okechukwa, Souza, Davis, \& de Castro, 2011); this powerful source of physical injury and mental stress, however, has not been studied as a potential cause of worse return-to-work outcomes.

\section{Racial Discrimination and Return to Work}

Return-to-work (RTW) is an important occupational health outcome for workers' compensation insurers as a measure of quality, for social scientists as a measure of the burden of occupational injuries on society, and for injured workers and their families as delayed return to work can have an economic and social impact (Dembe, 2001; N. Krause, Frank, Dasinger, Sullivan, \& Sinclair, 2001; Lax \& Klein, 2008). The longer a person is off work with an injury, the less likely they are to return to work. Prior research shows that for soft tissue disorders (musculoskeletal injuries) $90 \%$ of those injured return to work within 6 months; however, those who do not return to work within 6 months have a $50 \%$ chance of never returning to work, and this number increases to $85-90 \%$ after 1 year (Gamborg, Elliott, \& Curtis, 1991). Absences due to long illness have been linked to mental health issues such as depression and severe family strain (Beardwood, Kirsh, \& Clark, 2005; Dersh, Gatchel, Polatin, \& Mayer, 2002; Lax \& Klein, 2008). On the other hand, returning to work before the worker feels they are ready to return can also have serious negative consequences. Returning to work too early can create adverse physical, 
mental, and economic situations, in much the same way as never returning to work after an injury. Examples in the literature include increased risk of re-injury (Garcy, Mayer, \& Gatchel, 1996) as well as depression, sleep disorders, and anxiety (Wall, Ogloff, \& Morrissey, 2007).

It is important to return an injured worker to the job as soon as possible, but not any sooner than a worker feels medically ready to return. There are a host of physical, psychological and employer-related reasons why a person may not feel ready to return to work; however, research has found workplace support may reduce time off work and improve work satisfaction (Huang, Shaw, \& Chen, 2004; Shaw, Robertson, Pransky, \& McLellan, 2003). There is some evidence in the literature that racial, ethnic, and linguistic minorities may suffer higher rates of never returning to work, and of returning to work too early, as compared to their White, English speaking co-workers (S. Krause, Sternberg, Maides, \& Lottes, 1998; Meade, Lewis, Jackson, \& Hess, 2004).

\section{Workplace Discrimination, Injury, and Supervisor Support}

Workplace support, especially supervisory support, matters in how quickly people return to work, and in their ability to stay at work (Carroll, Rick, Pilgrim, Cameron, \& Hillage, 2010; Haveraaen, Skarpaas, Berg, \& Aas, 2016; N. Krause, Dasinger, \& Neuhauser, 1998). There appears to be some evidence that compared to White workers, workplace/supervisor support matters more to minorities' health and risk of injury. In a study of Latina manual laborers in North Carolina, Arcury, Grzywacz, Chen, Mora and Quandt, (2014), found a correlation between heavy workloads and poorer scores of 
mental health and higher scores of depressive symptoms; these were improved, however, when workers had strong supervisor support and higher workplace safety climate scores (Arcury, Grzywacz, Chen, Mora, \& Quandt, 2014). In a study of German mail carriers, Hoppe found that immigrant workers had higher stressors at work and these were modified by support from supervisors (Hoppe, 2011). Using data from the 2002 General Social Survey module on the Quality of Working Life, Roberts and colleagues found African American and Latino workers who reported discrimination at work had poorer mental health scores than African American and Latinos who did not feel they had been discriminated against (Roberts et al., 2004). Strunin and Bodin found a positive "welcome back" attitude from employers improved injured workers sense of value in their qualitative study, however, Blacks and Latinos stated they received fewer accommodations and offers of support than their White colleagues (Strunin \& Boden, 2000). In a cross-sectional study of 103 Latino agricultural crop- and horse-breeding workers in Kentucky, Swanberg, Clouser, Browning, Westneat, and Marsh (2013) found abusive supervisors increased the risk of WRII and missed work, and although not statistically significant, supervisor support and higher safety climate decreased the risk of injury or missed work (Swanberg, Clouser, Browning, Westneat, \& Marsh, 2013).

Though the literature on RTW accommodations and workplace support is vast, fewer studies have specifically examined racial, ethnic, and LEP groups compared to Whites. Nevertheless, enough evidence exists to hypothesize some form of discrimination at work may be affecting RTW outcomes. The links between racial, ethnic, and LEP discrimination and labor market options provide clear evidence that minorities in 
America are passed over for jobs and promotions; they are also fired for reasons other than work performance, including speaking out against injustices (Alonso-Villar et al., 2012; Bertrand \& Mullainathan, 2004; Browne et al., 2001; Browne \& Misra, 2003; Cokley, 2005). These trends lead to a host of differential risks for workers of color, including increased risk of injury, as well as fewer resources to come back to work and be productive.

While we lack explicit trend data, the literature summarized here provides us with evidence of the enduring nature of workplace discrimination, limited effects on both work and health over time, and some evidence that workplace support may act as a flexible resource, mitigating the effect of workplace racial discrimination on returning to work too early after an injury. Whether racial discrimination is a primary cause of poorer RTW outcomes is conceptually plausible but has not yet been tested.

\section{Conceptual Framework and Hypotheses}

The conceptual framework for this study is based on fundamental cause theory (FCT) developed by Link and Phelan (1995). FCT states broadly that a fundamental cause involves access to resources (i.e., money, prestige, power, knowledge, social support, or social networks (Link and Phelan 1995: p. 87)) and those with more resources can avoid or minimize the negative effects of a fundamental cause. In addition, a fundamental cause is enduring, regardless of the mechanism linking the fundamental cause to health disparities. 
In a recent analysis, Phelan and Link (2015) posit that racism is a fundamental cause of health disparities as a function of socioeconomic status (SES) and as independent of SES. In this study, I hypothesize workers of color and LEP workers will have worse RTW outcomes than their White counterparts, and that these poorer outcomes can be explained more by racial discrimination than other potential factors such as occupation, injury type, gender, education, and income. Borrowing from prior research (Grosfoguel, 2004; Massey, 2009; Williams, Mohammed, Leavell, \& Collins, 2010), this study considers ethnicity and LEP status as racialized, and have therefore created one race variable with mutually exclusive groups based upon self-reported race, ethnicity, and LEP status.

Income, wealth, and education create the social and economic context in which people enter the labor market; those with more resources are less likely to enter the labor market at the bottom, or in occupations with high physical risk factors for injury or death. Numerous studies support the link between racialized minority status and occupational segregation into higher-hazard occupations (Browne et al., 2001; de Castro, Fujishiro, Sweitzer, \& Oliva, 2006; Hellerstein \& Neumark, 2008); this segregation leads to increased risk of occupational injury or illness for minorities (Angelon-Gaetz, Richardson, \& Wing, 2010; Chung-Bridges et al., 2008; Friedman \& Forst, 2008; MoureEraso \& Friedman-Jimenez, 2004; Shannon et al., 2009). Based on the existing literature, this study will test the following hypotheses: 


\section{Hypotheses}

1. Among minorities, workplace discrimination will be associated with the feeling that they returned to work too early compared to Whites.

2. Among minorities, workplace discrimination effects will be mediated by supportive workplace behaviors during the return-to-work process.

\section{Materials and Methods}

\section{Data Sources}

This study analyzed a subset $(n=292)$ of workers who had returned to work from a larger study $(\mathrm{n}=488)$ of injured worker interviews matched with administrative data from Washington State's State Fund (SF) workers' compensation database for those with compensable claims ${ }^{23}$ injury dates from January 1, 2008 through December 31, 2013.

A data manager at the Department of Labor and Industries (L\&I) merged the data, so the author was blinded to personally identifiable information. The Washington State Institutional Review Board and the Portland State University Human Subjects Review both provided approval for this study as exempt research.

\section{Study Inclusion Criteria}

Inclusion criteria for this study required that subjects had returned to work by the time the survey was administered. Inclusion criteria for the larger study included claim

\footnotetext{
${ }^{23}$ Compensable claims refer to those accepted WC claims that are categorized as either being temporary total disability (more than three days of time loss), kept on salary (employer continues to pay wages for worker off work with an injury), total permanent disability (injured worker unable to work for wages anymore), fatal, or loss of earning power (employee injured in a way that precludes them from returning to work in the same pay level job they had before the injury). Compensable claims make up approximately $30 \%$ of all accepted claims in the Washington State SF WC system, and are considered more severe than medical-only claims, (where a worker experience no or minimal missed work and was ineligible for wage replacement).
} 
eligibility type (compensable claims), industry/occupation (construction and services), and specific injury types (three musculoskeletal disorders: rotator cuff syndrome, carpal tunnel syndrome, and low-back pain) and three traumatic injuries (burns that required hospitalization, amputations, and hand or wrist fractures).

Data used for selection criteria for the larger study come from codes for claim type, industry/occupation, and injury types. The codes were assigned by the Washington workers' compensation system based upon information provided by the health care provider and injured worker on the initial report of injury.

\section{Survey Data}

Of the 488 subjects completing the larger survey, 330 had returned to work at the time the survey was administered; data for this study are complete for only 292 subjects. The final response rate for the larger study was $25 \%$, according to the American Association of Public Opinion Research (AAPOR) guidelines (AAPOR, 2015). The survey was designed to elicit information regarding the workers' compensation process, as well as a series of questions related to their job such as hazards, discrimination faced at work, and support from their employer in returning to work. Surveys were conducted in the respondent's preferred language.

\section{Data Preparation and Analysis}

Frequency distributions were generated for all categorical data: an analysis of continuous data includes the mean, standard deviation, median and first and third quartiles to determine the best statistic to use for analyses. Cross-tabs were run to assess 
the association between racial discrimination and all demographic characteristics, as well as the primary independent variable (racial discrimination suffered at work), and the hypothesized mediating variable (return to work support from employer). In addition to data cleaning, the complex survey design required the calculation of replicate weights to account for both the sampling strategy (design weight) and to adjust for non-response (analytic weights).

Sampling weights. Sampling weights were determined by calculating the design weight (number sampled/number in population) where population equals the number of subjects drawn from WC data. Non-response, analytic weights were calculated by creating a dummy variable (surveyed/not surveyed), and a series of logistic regression models were run with variables that (a) existed for both the surveyed and non-surveyed groups and (b) might affect a person's decision to respond or not respond to the survey, including all possible interaction terms. The final non-response model included a race proxy (White/non-White), age, gender (male/female), geographic location (west side or east side of the state, divided using L\&I regions), industry, and interaction terms for gender and race as well as an interaction term for industry and geography.

Non-respondents differed from respondents in that they were more likely coded as non-White, female, older, and from the east side of the state. Hosmer-Lemeshow chisquare statistic (Hosmer and Lemeshow 1989) was used to identify the most appropriate model for developing replicate weights. Bootstrap replicate weights (999) were computed and merged with the survey and workers' compensation data to create the final dataset. 
Statistical analyses. All analyses were run using survey weighted data with bootstrap replicate weights with the "SVY" survey options in Stata version 14.2. Logistic regression was used to model the outcomes. Models were built using knowledge of important constructs from prior research to assess the hypothesized relationships between racialized minority status and RTW too early. Mediation was tested using the parametric regression Stata user-created program “PARAMED” (Dunn et al., 2015; Emsley \& Liu, 2013).

\section{Measures}

\section{Workplace Discrimination}

Pre-injury workplace discrimination was measured using two items adapted from the Multi-City Study of Urban Inequality (MCSUI) (Bobo et al., 2000). These items were: "Were you discriminated against at your work because of your race, color, or ethnicity?" (yes/no) and "Have you ever felt that others at your place of employment got promotions or pay raises faster than you did because of your race or ethnicity?" (yes/no). Questions about work were prefaced with the following phrase from the interviewer: "Please answer questions about work thinking about the company you were at when you were injured."

Return to work employer support. Workplace support in the RTW process was measured using one question from the survey: "How supportive of your return to work efforts has your employer been? (very supportive, supportive, unsupportive, or very unsupportive). This question was dichotomized and a dummy variable was created to 
model Poor (very unsupportive or unsupportive) and Good (very supportive or supportive) workplace support.

\section{Outcome measures}

Return to work too early. Return to work was measured with a dichotomous question "Do you feel you returned to work too early?" Returning to work too early was coded as one if a respondent answered "yes" and zero if they responded as "no."

\section{Primary independent variables}

Racialized group status. Although self-reported race, ethnicity, and LEP group membership data were collected, I did not have enough responses to retain the detailed racial and language preference groups. Therefore, this study collapsed racial, ethnic, and language-preference groups into one variable with three categories: non-Latino Whites who spoke English well or very well, non-Whites who spoke English well or very well, and non-White workers who did not speak English well or very well (LEP).

\section{Covariates}

Demographic information comes from both the survey and the WC administrative data, and includes age in years at the time of the injury, gender (binary male/female), income (dichotomized at the median $(\$ 35,000 /$ year), and level of education (dichotomized at high school or higher education/less than high school). In addition, injury type and industry/occupation (as described in sampling methods) are used as categorical covariates in this study's models. 


\section{Results}

Descriptive statistics across the racial groups are presented in Table 1. All

personal characteristics are statistically significantly different among the groups, with the exception of marital status. White English speakers are older (mean age 41.0) compared to non-White English speakers and LEP speakers (mean 36.1, 36.6 respectively). The most notable differences across racial groups are socioeconomic (SES), such as minorities being much less likely than Whites to have a household income of $\$ 35,000$ or more and LEP speakers being far less likely to have at least a high school (or equivalent) education (Table 1).

Table 1

Descriptive Characteristics of the Surveyed Population by Race, Ethnicity and LEP*

\begin{tabular}{|c|c|c|c|c|c|c|}
\hline$n=292$ & $\begin{array}{l}\text { Survey } \\
\text { sample }\end{array}$ & Weighted & $\begin{array}{c}\text { White, } \\
\text { English } \\
(\mathrm{n}=124)\end{array}$ & $\begin{array}{l}\text { Non-White } \\
\text { English } \\
(\mathrm{n}=59)\end{array}$ & $\begin{array}{r}\text { Non- } \\
\text { White } \\
\text { LEP* } \\
(\mathrm{n}=109)\end{array}$ & \\
\hline Variable & $\mathrm{N}(\%)$ & $\mathrm{N}(\%)$ & $\begin{array}{r}\text { Weighted } \\
\% \\
\end{array}$ & $\begin{array}{r}\text { Weighted } \\
\% \\
\end{array}$ & $\begin{array}{r}\text { Weighted } \\
\% \\
\end{array}$ & $\begin{array}{r}\mathrm{p}- \\
\text { value }\end{array}$ \\
\hline Age (mean, SE) & $\begin{array}{r}42.1 \\
(11.4)^{* *}\end{array}$ & $\begin{array}{r}41.5 \\
(0.40)^{* *}\end{array}$ & $\begin{array}{r}41.0 \\
(1.1)^{* *}\end{array}$ & $\begin{array}{r}36.1 \\
(1.5)^{* *}\end{array}$ & $\begin{array}{r}36.6 \\
(0.84)^{* *}\end{array}$ & $<0.001$ \\
\hline $\begin{array}{l}\text { Female } \\
\text { Number of } \\
\text { dependents }\end{array}$ & $71(24.3)$ & $711(20.3)$ & 17.6 & 16.4 & 29.8 & $\begin{array}{r}0.05 \\
<0.001\end{array}$ \\
\hline None & $62(21.2)$ & $903(25.8)$ & 38.7 & 14.1 & 3.8 & \\
\hline $\begin{array}{l}1-2 \text { dependents } \\
3 \text { or more } \\
\text { dependents }\end{array}$ & $\begin{array}{l}109(37.3) \\
121(41.4)\end{array}$ & $\begin{array}{l}1314(37.6) \\
1282(36.6)\end{array}$ & 41.6 & 37.9 & 27.5 & \\
\hline Married & $174(60.0)$ & $2042(58.5)$ & 60.7 & 63.7 & 58.5 & 0.477 \\
\hline $\begin{array}{l}\text { Household income }> \\
=35,000\end{array}$ & $162(55.5)$ & $2102(60.1)$ & 73 & 52.8 & 34.5 & $<0.001$ \\
\hline $\begin{array}{l}\text { At least a high } \\
\text { school degree }\end{array}$ & 198 (68.7) & $2681(77.6)$ & 92.2 & 88 & 33.4 & $<0.001$ \\
\hline Industry & & & & & & $<0.001$ \\
\hline $\begin{array}{l}\text { Accommodation/ } \\
\text { Food Services }\end{array}$ & $81(27.5)$ & $956.3(28.8)$ & 25.9 & 36.0 & 24.7 & \\
\hline
\end{tabular}




\begin{tabular}{lrrrrrr} 
Janitorial Services & $50(16.9)$ & $557.6(16.0)$ & 10.9 & 7.6 & 34.4 & \\
$\quad$ Construction & $164(55.6)$ & $1969(56.5)$ & 63.1 & 56.5 & 40.9 & \\
$\begin{array}{l}\text { Injury type } \\
\quad\end{array}$ & & & & & & 0.02 \\
$\quad$ Traumatic & $23(7.8)$ & $244(6.9)$ & $4.6(2.1)$ & $12.2(3.9)$ & $8.2(2.7)$ & \\
$\begin{array}{l}\text { Back } \\
\text { Carpal tunnel }\end{array}$ & $143(49.0)$ & $1711(48.9)$ & $44.4(4.6)$ & $45.1(7.2)$ & $63.3(4.6)$ & \\
$\begin{array}{l}\text { syndrome (CTS) } \\
\text { Shoulder injury }\end{array}$ & $26(8.9)$ & $361(10.3)$ & $13.8(3.1)$ & $9.8(4.5)$ & $2.2(1.3)$ & \\
$\begin{array}{l}\text { (rotator cuff } \\
\text { syndrome) }\end{array}$ & & & & & & \\
\hline
\end{tabular}

Note. ${ }^{*}$ LEP $=$ Limited English Proficient.

** Standard deviation

Workplace outcomes available for this analysis are listed in Table 2. There is a clear difference across racial status with outcomes except for subjects feeling they returned to work too early and poor return-to-work support from their employer. Of particular note are the much higher proportion of LEP workers who suffered discrimination at work (25.4\% compared to $19.1 \%$ for non-White, English speakers, and $2.1 \%$ for Whites), as well as those who reported poor general health after injury (LEP 44.9\% compared to Whites and non-White English speakers with 20.3\% and 22.3\%, respectively). Median time-loss days (days paid for partial wage replacement) were also significantly different for non-White English speakers and LEP workers, with median time-loss days of 34 and 29, respectively, compared to White, English-speaking workers (89 days). 
Table 2

Outcomes by Racial Group Status

\begin{tabular}{|c|c|c|c|c|c|c|}
\hline $\mathrm{n}=292$ & $\begin{array}{l}\text { Survey } \\
\text { sample }\end{array}$ & Weighted & $\begin{array}{l}\text { White, } \\
\text { English } \\
(\mathrm{n}=124)\end{array}$ & $\begin{array}{l}\text { Non-White } \\
\text { English } \\
(\mathrm{n}=59)\end{array}$ & $\begin{array}{l}\text { Non-White } \\
\text { LEP* } \\
(\mathrm{n}=109)\end{array}$ & \\
\hline Variable & N (\%) & N (\%) & Weighted \% & $\begin{array}{r}\text { Weighted } \\
\%\end{array}$ & $\begin{array}{r}\text { Weighted } \\
\%\end{array}$ & $\begin{array}{r}p- \\
\text { value }\end{array}$ \\
\hline $\begin{array}{l}\text { Poor general } \\
\text { health (AFTER } \\
\text { injury) } \\
\text { Perceived }\end{array}$ & $88(30.1)$ & $929.6(26.6)$ & 20.3 & 22.3 & 44.9 & $<0.001$ \\
\hline $\begin{array}{l}\text { discrimination at } \\
\text { work } \\
\text { Felt they }\end{array}$ & 39 (13.4) & $377.6(10.8)$ & 2.1 & 19.1 & 25.4 & $<0.001$ \\
\hline $\begin{array}{l}\text { returned to work } \\
\text { too early }\end{array}$ & $123(42.1)$ & $1460(41.7)$ & 36.3 & 47.8 & 50.3 & 0.09 \\
\hline $\begin{array}{l}\text { Poor return to } \\
\text { work (RTW) } \\
\text { support from } \\
\text { employer }\end{array}$ & $83(25.8)$ & $917.6(26.2)$ & 22.3 & 34.1 & 29.7 & 0.203 \\
\hline $\begin{array}{l}\text { Median } \\
(\mathrm{Q} 1, \mathrm{Q} 3)^{* *} \text { days } \\
\text { to return to work }\end{array}$ & $\begin{array}{r}56(6, \\
214)\end{array}$ & $62(8,127)$ & $89(20,227)$ & $34(1,189)$ & $29(3,196)$ & $<0.001$ \\
\hline
\end{tabular}

Note. ${ }^{*} \mathrm{LEP}=$ Limited English Proficient.

**Q1, Q3 $=25$ th percentile (quartile 1 or Q1) and 75th percentile (quartile 3 or Q3)

\section{Return to Work and Workplace Discrimination}

A series of logistic regression models testing this study's hypotheses were

conducted and are presented in Table 3. In bivariate logistic regression, both non-White English speakers and LEP speakers were more likely to feel they returned to work too early compared to Whites (OR 1.6 and 1.8 respectively), although only LEP status was statistically significant at $\mathrm{p}$-value $\leq 0.05$ (data not shown). Age- and gender-adjusted models are presented in Table 3, Model 1. Perceived workplace discrimination and not LEP is significant, with those suffering workplace discrimination having more than three 
times the odds of feeling they returned to work too early, compared to those who did not suffer workplace discrimination.

Table 3, Model 2 provides logistic regression results to test for hypothesis 2, which states that employer support in the RTW process would mediate the effects of workplace discrimination. This hypothesis is supported in Table 3, Model 2. Once RTW support is entered into the multivariable model (modeled as positive RTW support), only support is statistically significant, with an OR of 0.23 (approximately one-fifth as likely to feel they returned to work too early, compared to those without positive RTW support). Workplace discrimination is no longer significantly associated with RTW too early.

Table 3

Associations with Work Discrimination and Return-to-Work (RTW) Support.

\begin{tabular}{|c|c|c|c|c|c|c|}
\hline \multirow{3}{*}{$(\mathrm{N}=291)$} & \multicolumn{3}{|c|}{ Model 1} & \multicolumn{3}{|c|}{ Model 2} \\
\hline & \multicolumn{3}{|c|}{ Age and gender adjusted } & \multicolumn{3}{|c|}{ Full model, with mediator } \\
\hline & OR & $95 \% \mathrm{CI}$ & P-value & OR & $95 \% \mathrm{CI}$ & $\begin{array}{c}\text { P- } \\
\text { value }\end{array}$ \\
\hline \multicolumn{7}{|l|}{$\begin{array}{l}\text { Race, ethnicity, and language } \\
\text { minorities }\end{array}$} \\
\hline White, English speaking & (ref) & & & (ref) & & \\
\hline Non-white, English speaking & 1.49 & $(0.74,3.02)$ & 0.268 & 1.07 & $(0.45,2.55)$ & 0.877 \\
\hline Non-White, LEP* & 1.36 & $(0.75,2.47)$ & 0.306 & 0.98 & $(0.40,2.41)$ & 0.966 \\
\hline $\begin{array}{l}\text { Workplace discrimination, prior } \\
\text { to injury }\end{array}$ & 3.22 & $(1.37,7.57)$ & 0.007 & 2.55 & $(0.80,8.14)$ & 0.114 \\
\hline Female & 1.88 & $(1.05,3.38)$ & 0.035 & 2.12 & $(0.81,5.58)$ & 0.126 \\
\hline Age (in years) at time of injury & 0.98 & $(0.95,1.00)$ & 0.093 & 0.97 & $(0.94,1.01)$ & 0.118 \\
\hline At least a high school education & & & & 0.69 & $(0.30,1.59)$ & 0.384 \\
\hline Household income & & & & 0.59 & $(0.28,1.23)$ & 0.158 \\
\hline \multicolumn{7}{|l|}{$\geq \$ 35,000 /$ yearly } \\
\hline Injury type & & & & & & \\
\hline Traumatic injury** & & & & (ref) & & \\
\hline Low back pain & & & & 1.76 & $(0.30,10.40)$ & 0.530 \\
\hline Carpal tunnel syndrome & & & & 2.18 & $(0.25,18.94)$ & 0.480 \\
\hline Rotator cuff syndrome & & & & 1.55 & $(0.25,9.56)$ & 0.636 \\
\hline
\end{tabular}


Industry

Construction

(ref)

Accommodation and Food

0.71

$(0.25,2.01)$

0.520

Services

Janitorial Services

$0.54 \quad(0.22,1.32) \quad 0.176$

Positive workplace support, after

$0.23 \quad(0.10,0.51)<0.001$

injury

Note. Logistic regression models for Return to Work too Early.

$*$ LEP $=$ Limited English Proficient

**Traumatic injury includes: hand/wrist fracture, burn that required hospitalization, and amputation

Bold font indicates significant values

Table 4 presents results of formal mediation testing, using odds ratios to describe results. Mediation via positive RTW support is maintained in Table 4, with approximately $49 \%$ of the effect of workplace discrimination on increased risk of RTW too early, mediated through positive RTW support.

Table 4

Mediation of Association Between Return to Work (RTW) too Early and Workplace Discrimination, via RTW Support

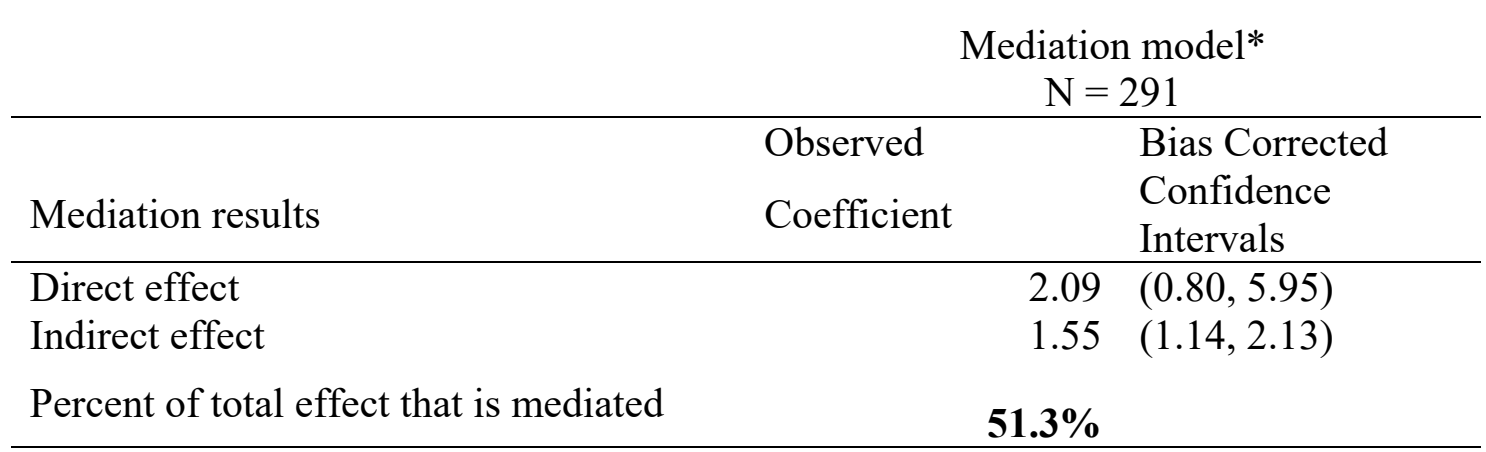

Note. ${ }^{*}$ Controlling for race, gender, age, income, injury type, education (high school or higher) and occupation 


\section{Discussion}

Work-related injuries and illnesses are more common among minority workers who are also more likely to work in high-hazard occupations (Seabury et al., 2017; Strong \& Zimmerman, 2005). The occurrence of a work-related injury, however, is not the end of the story, and in itself does not determine subsequent socioeconomic status. How injured workers heal and return to work is critical in determining lifetime social, economic, and health sequelae. Workers of color and LEP workers face uphill battles in many aspects of life due to historical and current racial discrimination, yet this factor is understudied in the return-to-work literature. This study sought to address this gap by testing whether workplace racial discrimination was related to subsequent return to work outcomes and to evaluate the role of support from employers in mediating associations between discrimination and return-to-work outcomes. Support was found for both hypotheses in the current analyses.

The current study supports prior research that minorities were more likely to report workplace racial discrimination (Shannon et al., 2009) and that LEP workers were more likely to report they felt they returned to work too early (N. Krause et al., 1998; Meade et al., 2004).

This study also extends occupational health disparity literature by utilizing fundamental cause theory to explicitly test for associations between racial discrimination and poor work-related injury outcomes. The current study also broadens the RTW literature by finding significant associations between workplace discrimination and 
workplace support and RTW outcomes. Compared to Whites, minorities were significantly more likely to report workplace discrimination and to report that they returned to work before they felt ready. For minorities, the subjective return-to-work-tooearly outcome is confirmed by administrative data, with a shorter time off work of 55-60 days, fewer than Whites (Whites had a median of 89 days). In addition, as expected under fundamental cause theory, the outcome was modified by a potential flexible resource-a supportive work environment—regardless of actual days to return to work. More research is needed to identify specific support mechanisms to reduce RTW disparities.

While this study's measures of both workplace discrimination and RTW support were very general, they still produced hypothesized results, more specific measures of these constructs may increase our understanding of how they are linked to RTW outcomes. While this study cannot determine exactly what type of supportive workplace factors were responsible for these findings, the literature regarding workplace support hypothesizes that trust (i.e., workplace believes your injury is real and significant) (Linton, Boersma, Traczyk, Shaw, \& Nicholas, 2016), supervisor's ability and willingness to provide accommodation at work (Kristman et al., 2017), and co-worker support (Ahlstrom, Hagberg, \& Dellve, 2013) all contribute to better RTW outcomes for injured workers. It is likely some or all of these features of a supportive workplace are present in this study.

To my knowledge, this is the first occupational health study to utilize fundamental cause theory to test the association between poor return-to-work outcomes and racial 
discrimination suffered at work, as well as to test the mediating role of return-to-work support. There are clear racial differences, and while I lack additional data and resources to explore these issues by specific race, ethnicity, or language, this study has definite policy implications.

Racialized minorities are likely victims of administrative, social, and workplace discrimination that negatively affect their ability to rebound after an injury. Even after controlling for education and occupation it was workplace discrimination suffered prior to the injury that was most strongly associated with the worker's feeling that they returned to work too early. This is as expected if racial discrimination is a fundamental cause of poor injury outcomes.

While a promising first look at the association between racial discrimination and return to work, there are limitations to this study which may affect the generalizability of the results. First, I focused on only three broad industry groups: accommodation and food service; construction; and janitorial), which have different individual and job characteristics than other occupations. In identifying comparable lower-wage occupations with physically demanding work, however, these groups of workers most likely share similar characteristics in terms of wages and freedom to direct their how they complete tasks. Second, this study was cross-sectional, which limits the ability to draw clear causal links between workplace discrimination and return-to-work outcomes. It may be that a feeling of returning to work too early might have increased a worker's sense of prior workplace discrimination. Third, this study could not utilize specific self-reported racial 
and ethnic group membership in the analyses. Even though I attempted to oversample non-White/non-English participants, numbers for specific racial groups were too small; therefore, racial/ethnic group memberships were aggregated, thus losing potentially significant differences between American Indians and Blacks or Asians and Pacific Islanders, for example, as they experience differential social, economic, and political disparities compared to Whites. Fourth, this study utilizes data from only one state which has different occupational, industrial, racial, and immigrant profiles than most other states. Finally, this current study did not have complete information on nativity status which may be important in explaining LEP worker outcomes.

It is also likely that there are important characteristics I could not measure which might affect a specific racial, ethnic, or LEP groups' ability to recover after a WRII. The fact that this study was able to identify disparities in both racial discrimination RTW support and injured workers feeling they returned to work too early, most likely means that the effects seen by racialized group status are conservatively measured for certain specific racial/ethnic groups.

There are also limitations from a conceptual standpoint: (a) assuming that workplace discrimination was acting alone in the relationship between injury and my self-reported outcome of returning to work too early; and (b) that this relationship could be adequately studied in a small cross-sectional study. Racial discrimination has been extensively researched in terms of disparate health outcomes for people of different racial and ethnic backgrounds. Most of this literature details large gaps in health outcomes 
between Whites and minorities in a host of diseases and injuries (e.g., de Castro, Gee, \& Takeuchi, 2008; Institute of Medicine, 2003; Okechukwu, Souza, Davis, \& de Castro, 2014; Shavers et al., 2012), yet to more precisely assess the role of workplace discrimination in work-related outcome disparities, longitudinal studies are needed. It is clear, however, from the present study that racialized minority status is an important factor to consider when investigating occupational injury outcomes. As the measure of RTW support was very general, it may be capturing a form of racial discrimination; more specific workplace support measures should be used in future studies to identify exactly what aspects of workplace support (or discrimination) are more salient for injured minority workers.

Although not all tenets of FCT could be examined in this cross-sectional study, the results are consistent in many ways with what the theory would expect to find. For example, I found many characteristics to be significantly different by racialized minority status, with Whites having more protective resources (education and income) and nonWhites suffering more racial discrimination at work and having more dependents to care for with fewer resources. In multivariable models, discrimination at work was significantly higher for those who felt they returned to work too early.

Using FCT to frame this study provided much-needed structure in the interpretation of results. Minorities are overrepresented in certain low-wage, high-risk occupations; even when controlling for income and education there is a clear impact on post-work-related injury that puts minorities at an added disadvantage in recovering and 
returning to normal work life. Racial discrimination is an important construct to consider when examining health outcomes and must be included in studies investigating workrelated injuries and illnesses and return-to-work outcomes. 


\section{References}

AAPOR. (2015). Standard Definitions: Final Dispositions of Case Codes and Outcome Rates for Surveys. Retrieved from https://www.aapor.org/Education-

Resources/For-Researchers/Poll-Survey-FAQ/Response-Rates-An-Overview.aspx

Ahlstrom, L., Hagberg, M., \& Dellve, L. (2013). Workplace Rehabilitation and Supportive Conditions at Work: A Prospective Study. J Occup Rehabil, 23(2), 248-260. doi:10.1007/s10926-012-9391-z

Alonso-Villar, O., Del Rio, C., \& Gradin, C. (2012). The Extent of Occupational Segregation in the United States: Differences by Race, Ethnicity, and Gender. Industrial Relations, 51(2), 179-212.

Angelon-Gaetz, K. A., Richardson, D. B., \& Wing, S. (2010). Inequalities in the nuclear age: impact of race and gender on radiation exposure at the Savannah River Site (1951-1999). New Solut, 20(2), 195-210.

Arcury, T. A., Grzywacz, J. G., Chen, H., Mora, D. C., \& Quandt, S. A. (2014). Work Organization and Health Among Immigrant Women: Latina Manual Workers in North Carolina. American Journal of Public Health, 104(12), 2445-2452. doi:10.2105/AJPH.2013.301587

Bartley, M., Ferrie, J., \& Montgomery, S. M. (2006). Health and labour market disadvantage: unemployment, non-employment, and job insecurity. In M. G. Marmot \& R. G. Wilkinson (Eds.), The Social Determinants of Health (Second ed., pp. 78-96). New York: Oxford University PRess.

Beardwood, B. A., Kirsh, B., \& Clark, N. J. (2005). Victims twice over: perceptions and experiences of injured workers. Qual Health Res, 15(1), 30-48.

Bertrand, M., \& Mullainathan, S. (2004). Are Emily and Greg More Employable Than Lakisha and Jamal? A Field Experiment on Labor Market Discrimination. The American Economic Review, 94(4), 991-1013.

Bhui, K., Stansfeld, S., McKenzie, K., Karlsen, S., Nazroo, J., \& Weich, S. (2005). Racial/ethnic discrimination and common mental disorders among workers: Findings from the EMPIRIC study of ethnic minority groups in the United Kingdom. American Journal of Public Health, 95(3), 496-501.

BLS. (2017a). BLS Handbook of Methods Chapter 9. Occupational Safety and Health Statistics. Retrieved from https://www.bls.gov/opub/hom/pdf/homch9.pdf

BLS. (2017b). Labor force characteristics by race and ethnicity, 2016. (1070). Bureau of Labor Statistics Retrieved from https://www.bls.gov/opub/reports/race-andethnicity/2016/pdf/home.pdf.

BLS. (2017c). Survey of Occupational Injuries and Illnesses. Retrieved from https://www.bls.gov/opub/hom/soii/pdf/soii.pdf.

Bobo, L., Johnson, J., Oliver, M. L., Farley, R., Bluestone, B., Browne, I., . . Z ZubrinskyCharles, C. (2000). MULTI-CITY STUDY OF URBAN INEQUALITY, 1992-1994: [ATLANTA, BOSTON, DETROID, AND LOS ANGELES] [HOUSEHOLD SURVEY DATA] 
Bonacich, E. (1972). A theory of ethnic antagonism: the split labor market. American Sociological Review, 37(5), 547-559.

Browne, I., Hewitt, C., Tigges, L., \& Green, G. (2001). Why Does Job Segregation Lead To Wage Inequality among African Americans? Person, Place, Sector, or Skills? Social Science Research, 30(3), 471-495.

Browne, I., \& Misra, J. (2003). The intersection of gender and race in the labor market. Annual Review of Sociology, 29, 487-513. doi:10.1146/annurev.soc.29.010202.100016

Carroll, C., Rick, J., Pilgrim, H., Cameron, J., \& Hillage, J. (2010). Workplace involvement improves return to work rates among employees with back pain on long-term sick leave: a systematic review of the effectiveness and costeffectiveness of interventions. Disability and Rehabilitation, 32(8), 607-621. doi:10.3109/09638280903186301

Cherniack, M. (1986). The Hawk's Nest Incident: America's worst indstrial disaster. New Haven, CT: Yale University Press.

Chung-Bridges, K., Muntaner, C., Fleming, L. E., Lee, D. J., Arheart, K. L., LeBlanc, W. G., .. . Davila, E. P. (2008). Occupational Segregation as a Determinant of US Worker Health. American Journal of Industrial Medicine, 51, 555-567.

Cokley, K. O. (2005). Racial(ized) identity, ethnic identity, and Afrocentric values: Conceptual and methodological challenges in understanding African American identity. Journal of Counseling Psychology, 52(4), 517-526.

de Castro, A. B., Fujishiro, K., Sweitzer, E., \& Oliva, J. (2006). How Immigrant Workers Experience Workplace Problems: A Qualitative Study. Archives of Environmental \& Occupational Health, 61(6), 249-258.

de Castro, A. B., Gee, G. C., \& Takeuchi, D. T. (2008). Workplace discrimination and health among Filipinos in the United States. Am J Public Health, 98(3), 520-526. doi:AJPH.2007.110163 [pii]

10.2105/AJPH.2007.110163

Dembe, A. E. (2001). The social consequences of occupational injuries and illnesses. Am $J$ Ind Med, 40(4), 403-417. doi:10.1002/ajim.1113 [pii]

Dersh, J., Gatchel, R. J., Polatin, P., \& Mayer, T. (2002). Prevalence of psychiatric disorders in patients with chronic work-related musculoskeletal pain disability. Journal of Occupational and Environmental Medicine, 44(5), 459-468.

Dunn, G., Emsley, R., Liu, H., Landau, S., Green, J., White, I., \& Pickles, A. (2015). Evaluation and validation of social and psychological markers in randomised trials of complex interventions in mental health: a methodological research programme. Health Technology Assessment, 19(93), 148. doi:10.3310/hta19930

Emsley, R., \& Liu, H. (2013). PARAMED: Stata module to perform causal mediation analysis using parametric regression models. Boston College, Department of Economics.

Friedman, L. S., \& Forst, L. (2008). Ethnic disparities in traumatic occupational injury. $J$ Occup Environ Med, 50(3), 350-358. doi:10.1097/JOM.0b013e3181617324

00043764-200803000-00013 [pii] 
Gamborg, B. L., Elliott, W. S., \& Curtis, K. W. (1991). Chronic Disability Syndrome: Failing to diagnose disability can jeoparadize rehabilitation. Canadian Family Physician, 37, 1966.

Garcy, P., Mayer, T., \& Gatchel, R. J. (1996). Recurrent or New Injury Outcomes After Return to Work in Chronic Disabling Spinal Disorders: Tertiary Prevention Efficacy of Functional Restoration Treatment. Spine, 21(8), 952-959.

Gee, G. C., \& Ford, C. L. (2011). Strucutral Racism and Health Inequities: Old Issues, New Directions. Du Bois Review, 8(1), 115-132.

Gee, G. C., Ro, A., Shariff-Marco, S., \& Chae, D. (2009). Racial discrimination and health among asian americans: Evidence, assessment, and directions for future research. Epidemiologic Reviews, 31(1), 130-151.

Graham, J. D., \& Holtgrave, D. R. (1990). Coke oven emissions: a case study of technology-based regulation. Risk, 1, 243.

Grosfoguel, R. (2004). Race and ethnicity or racialized ethnicities? Identities within global coloniality. Ethnicities, 4(3), 315-336.

Haveraaen, L. A., Skarpaas, L. S., Berg, J. E., \& Aas, R. W. (2016). Do psychological job demands, decision control and social support predict return to work three months after a return-to-work (RTW) programme? The rapid-RTW cohort Study. Work \& Stress, 53(1), 61-71.

Hellerstein, J. K., \& Neumark, D. (2008). Workplace segregation in the United States: Race, ethnicity, and skill. Review of Economics and Statistics, 90(3), 459-477.

Hilgert, J. A. (2012). Building a Human Rights Framework for Workers' Compensation in the United States: Opening the Debate on First Principles. American Journal of Industrial Medicine, 55(6), 506-518.

Hoppe, A. (2011). Psychosocial working conditions and well-being among immigrant and German low-wage workers. Journal of occupational health psychology, 16(2), 187.

Huang, Y.-H., Shaw, W. S., \& Chen, P. Y. (2004). Worker perceptions of organizational support and return-to-work policy: Associations with post-injury job satisfaction. Work, 23(3), 225-232.

Institute of Medicine. (2003). Unequal Treatment: Confronting Racial and Ethnic Disparities in Health Care. Washington, D.C.: The National Academies Press.

Krause, N., Dasinger, L. K., \& Neuhauser, F. (1998). Modified Work and Return to Work: A Review of the Literature. J Occup Rehabil, 8(2), 113-139. doi:10.1023/A:1023015622987

Krause, N., Frank, J. W., Dasinger, L. K., Sullivan, T. J., \& Sinclair, S. J. (2001). Determinants of duration of disability and return-to-work after work-related injury and illness: Challenges for future research. American Journal of Industrial Medicine, 40(4), 464-484.

Krause, S., Sternberg, M., Maides, J., \& Lottes, S. (1998). Employment after spinal cord injury: differences related to geographic region, gender, and race. Arch Phys Med Rehabil, 79(6), 615-624. 
Kristman, V. L., Shaw, W. S., Reguly, P., Williams-Whitt, K., Soklaridis, S., \& Loisel, P. (2017). Supervisor and Organizational Factors Associated with Supervisor Support of Job Accommodations for Low Back Injured Workers. J Occup Rehabil, 27(1), 115-127. doi:10.1007/s10926-016-9638-1

Lax, M. B., \& Klein, R. (2008). More than meets the eye: social, economic and emotional impacts of work-related injury and illness. New Solutions, 18(3), 343-360.

Leigh, J. P. (2011). Economic burden of occupational injury and illness in the United States. Milbank Q, 89(4), 728-772. doi:10.1111/j.1468-0009.2011.00648.x

Leigh, J. P., \& Marcin, J. P. (2012). Workers' compensation benefits and shifting costs for occupational injury and illness. Journal of Occupational and Environmental Medicine, 54(4), 445-450.

Link, B. G., \& Phelan, J. (1995). Social Conditions as Fundamental Causes of Disease. Journal of Health and Social Behavior, 80-94.

Linton, S. J., Boersma, K., Traczyk, M., Shaw, W., \& Nicholas, M. (2016). Early Workplace Communication and Problem Solving to Prevent Back Disability: Results of a Randomized Controlled Trial Among High-Risk Workers and Their Supervisors. J Occup Rehabil, 26(2), 150-159. doi:10.1007/s10926-015-9596-Z

Lloyd, J. (1971). Long-term mortality study of steel workers. V. Respiratory cancer in coke plant workers. Journal of Occupational Medicine, 13(2), 53-68.

Massey, D. S. (2009). Racial formation in theory and practice: The case of Mexicans in the United States. Race and Social Problems, 1(1), 12-26.

Maume, D. J. (1999). Glass Ceilings and Glass Escalators: Occupational Segregation and Race and Sex Differences in Managerial Promotions. Work and Occupations, 26(4), 483-509.

Meade, M. A., Lewis, A., Jackson, M. N., \& Hess, D. W. (2004). Race, employment, and spinal cord injury. Arch Phys Med Rehabil, 85(11), 1782-1792.

Moure-Eraso, R., \& Friedman-Jimenez, G. (2004). Occupational health Among Latino Workers: A Needs Assessment and Recommended Interventions. New Solutions, 14(4), 319-347.

Okechukwa, C., Souza, K., Davis, K., \& de Castro, B. (2011). Discrimination, Harassment, Abuse and Bullying in The Workplace: Contribution of Workplace Injustice to Occupational Health Disparities. Paper presented at the Eliminating Health and Safety Disparities At Work Conference, Chicago, Illinois. http://www.aoecdata.org/conferences/healthdisparities/whitepapers/WorkplaceInjustice.pdf

Okechukwu, C. A., Souza, K., Davis, K. D., \& de Castro, A. B. (2014). Discrimination, harassment, abuse, and bullying in the workplace: Contribution of workplace injustice to occupational health disparities. American Journal of Industrial Medicine, 57(5), 573-586. doi:10.1002/ajim.22221

Phelan, \& Link, B. G. (2015). Is Racism a Fundamental Cause of Inequalities in Health? Annual Review of Sociology, 41, 311-330. 
Premji, S., Messing, K., \& Lippel, K. (2008). Broken English, Broken Bones? Mechanisms Linking Language Proficiency and Occupational Health in a Montreal Garment Factory. International Journal of Health Services, 38(1), 1-19.

Quillian, L., Pager, D., Hexel, O., \& Midtbøen, A. H. (2017). Meta-analysis of field experiments shows no change in racial discrimination in hiring over time. Proceedings of the National Academy of Sciences, 114(41), 10870-10875. doi:10.1073/pnas.1706255114

Roberts, R. K., Swanson, N. G., \& Murphy, L. R. (2004). Discrimination and occupational mental health. Journal of Mental Health, 13(2), 129-142.

Robinson, J. C. (1987). Trends in Racial Inequality and Exposure to Work-Related Hazards, 1968-1986. The Milbank Quarterly, 65(Supplement 2 (Part 2)), 404-420.

Seabury, S. A., Terp, S., \& Boden, L. I. (2017). Racial And Ethnic Differences In The Frequency Of Workplace Injuries And Prevalence Of Work-Related Disability. Health Affairs, 36(2), 266-273. doi:10.1377/hlthaff.2016.1185

Shannon, C. A., Rospenda, K. M., Richman, J. A., \& Minich, L. M. (2009). Race, Racial Discrimination, and the Risk of Work-Related Illness, Injury, or Assault: Findings From a National Study. Journal of Occupational \& Environmental Medicine, 51(4), 441-448.

Shavers, V. L., Fagan, P., Jones, D., Klein, W. M. P., Boyington, J., Moten, C., \& Rorie, E. (2012). The state of research on racial/ethnic discrimination in the receipt of health care. American Journal of Public Health, 102(5), 953-966.

Shaw, W. S., Robertson, M. M., Pransky, G., \& McLellan, R. K. (2003). Employee Perspectives on the Role of Supervisors to Prevent Workplace Disability After Injuries. J Occup Rehabil, 13(3), 129-142. doi:10.1023/a:1024997000505

Strong, L. L., \& Zimmerman, F. J. (2005). Occupational Injury and Absence From Work Among African American, Hispanic, and Non-Hispanic White Workers in the National Longitudinal Survey of Youth. American Journal of Public Health, 95(7), 1226-1232.

Strunin, L., \& Boden, L. (2000). Paths of Reentry: Employment Experiences of Injured Workers. American Journal of Industrial Medicine, 38, 373-384.

Swanberg, J. E., Clouser, J. M., Browning, S. R., Westneat, S. C., \& Marsh, M. K. (2013). Occupational health among Latino horse and crop workers in Kentucky: The role of work organization factors. Journal of agromedicine, 18(4), 312-325.

Wall, C. L., Ogloff, J. R. P., \& Morrissey, S. A. (2007). Psychological Consequences of Work Injury: Personality, Trauma and Psychological Distress Symptoms of Noninjured Workers and Injured Workers Returning To, or Remaining at Work. International Journal of Disability Management, 2(2), 37-46. doi:10.1375/jdmr.2.2.37

Williams, D. R., \& Mohammed, S. A. (2013). Racism and Health I: Pathways and Scientific Evidence. American Behavioral Scientist, 57(8), 1152-1173.

Williams, D. R., Mohammed, S. A., Leavell, J., \& Collins, C. (2010). Race, socioeconomic status, and health: Complexities, ongoing challenges, and research 
opportunities. In N. E. Adler \& J. Stewart (Eds.), Biology of Disadvantage: Socioeconomic Status and Health (Vol. 1186, pp. 69-101).

Wingfield, A. H. (2009). Racializing the Glass Escalator: Reconsidering Men's Experiences with Women's Work. Gender \& Society, 23(1), 5-26. 


\section{Chapter 5: Summary of Findings, Limitations, and Directions for Future Research}

The primary goal of this project was to describe the role of racial discrimination in a workers' compensation (WC) system by examining three primary actors within it: the health-care provider, the WC agency, and the workplace. Much is known about workers of color and those with limited English proficiency (LEP) in the workplace, yet very little is known about differences in WC system outcomes between minorities and Whites. Minorities are segregated into low-wage, high-hazard occupations, placing them at greater risk of suffering a work-related injury or illness (WRII) than Whites (AngelonGaetz, Richardson, \& Wing, 2010; Briggs et al., 2003; Orrenius \& Zavodny, 2009; PriceGlynn \& Rakovski, 2012). The higher proportion of minority workers with occupational injuries is an enduring characteristic of the American workforce documented from at least the 1960s through the first decade of the 21st century (Buchanan et al., 2010; Robinson, 1987; Strong \& Zimmerman, 2005). While the magnitude and types of WRII are well studied, post-injury sequelae have not received the same amount of attention, particularly for minorities.

Research available suggests that racialized minorities suffer worse outcomes in health care received for their WRII (Dembe, Savageau, Amick, \& Banks, 2005; Tait, Chibnall, Andresen, \& Hadler, 2004), and face significant administrative barriers when dealing with a WC agency (Beardwood, Kirsh, \& Clark, 2005; Bonauto et al., 2010; Dembe, 2001; E. Kilgour, A. Kosny, D. McKenzie, \& A. Collie, 2014; A. Kosny et al., 
2012). Prior research has also shown that the workplace has the power to affect injured workers in experiencing positive or negative return-to-work (RTW) outcomes (Krause, Dasinger, \& Neuhauser, 1998; Meade, Lewis, Jackson, \& Hess, 2004; Premji, 2014). Workplaces can improve RTW outcomes by working with injured workers in developing modified work assignments, ensuring they do not return them too early (Galizzi, Leombruni, Pacelli, \& Bena, 2016).

Despite what is known about WRII risk and WC system outcomes for minority workers, there are still some significant gaps in the literature; chiefly among them are potential causes for these disparities. Socioeconomic status (SES) has been considered as a primary cause of occupational segregation into riskier jobs, but even after controlling for SES factors of education and income, minority workers are still at higher risk for injury (Alonso-Villar, Del Rio, \& Gradin, 2012; Seabury, Terp, \& Boden, 2017). Second, WC is a no-fault social insurance system designed to pay for both medical care and provide some wage-replacement benefits to all injured workers regardless of SES, race, gender, nativity, and other demographic characteristics, so SES should not affect outcomes in WC insurance. Third, very few large data sets exist with which to examine health care and WC agency outcomes for WRII by race and LEP status. Subsequently, the majority of work in this area is qualitative, using self-reported health outcomes from injured workers (Elizabeth Kilgour, Agnieszka Kosny, Donna McKenzie, \& Alex Collie, 2014; A. Kosny et al., 2012; Premji, 2014; Premji \& Krause, 2010; Premji, Messing, \& Lippel, 2008). Fourth, for workplace discrimination, much has been documented in the literature, ranging from obtaining employment (Bertrand \& Mullainathan, 2004; Fryer, 
Pager, \& Spenkuch, 2013), to obtaining promotions and equal pay for minority workers compared to Whites (Grodsky \& Pager, 2001; Kmec, 2003; Stewart \& Dixon, 2010). Very few studies, however, have explicitly studied racial discrimination and injury risk (Shannon, Rospenda, Richman, \& Minich, 2009). Although some have suggested racial discrimination as a cause of injury risk (Robinson, 1987; Strong \& Zimmerman, 2005), they have not tested this hypothesis. Even though the workplace plays a critical role in the livelihoods of injured workers, to my knowledge no study has extended the role of workplace racial discrimination to return to work; that is, the healing and successful reentry into the labor force after a WRII.

Finally, while addressing issues of inequalities for racialized minorities in the labor market prior literature lacks theoretical foundations to test hypotheses that will help identify the causes of said inequalities. Without a theoretical framework or foundation, racial differences cannot be rigorously investigated and solutions cannot be adequately tested.

The purpose of this study was to address some of these research gaps by combining perceptions from injured workers with detailed observable administrative data for a sample of injured workers in a state-run workers' compensation system. In addition, this dissertation employs a fundamental cause framework, hypothesizing that results found in each domain of the WC system can be explained, in part, by underlying racial discrimination. Following injured workers as they navigate the three primary areas of the WC system (health care in Chapter 2, WC agency in Chapter 3, and the workplace in 
Chapter 4) allowed for a more holistic perspective of injured workers' experiences, and a more global perspective on how fundamental cause operates within a WC system.

Conceptually, the analyses in this dissertation start with the health care provider (HCP), as they are the primary initiator of a workers' compensation claim, and then follow the worker through their interactions with the WC agency. Finally, I explore associations between workers and their employer in return-to-work outcomes.

This dissertation is organized as three studies, each examining the role of racial discrimination within a key aspect of the workers' compensation system: the healthcare setting, the workers' compensation agency, and the workplace. The rest of this chapter outlines major results from each study, provides context for results by situating them alongside prior work, and suggests both potential policy actions and areas for future research.

\section{The Health Care Setting}

The first study tested hypotheses for differences in health care outcomes for injured minorities compared to Whites in terms of timeliness, adequacy, and quality of care they receive for WRII (Chibnall, Tait, Andresen, \& Hadler, 2006; Dasinger, Krause, Thompson, Brand, \& Rudolph, 2001; Dembe et al., 2005). Specifically, I hypothesized that minorities would face longer waiting times for follow-up care, less adequate care for musculoskeletal disorders, and lower quality of care (as assessed by patient satisfaction). Evidence was found to support the association between racial discrimination and lower levels of patient satisfaction, as well as age- and gender-adjusted associations between LEP and inadequate care. Contrary to the hypothesized relationship between racial 
discrimination and timeliness of care, LEP patients were more likely to receive follow up care sooner than Whites, which is contrary to other studies that have examined timeliness of care in immigrant and general working populations (de Castro, Fujishiro, Sweitzer, \& Oliva, 2006; Parrish \& Schofield, 2005; Rousseau et al., 2008). While bivariate relationships with adequacy and quality of care and minority statuses were significant (Chapter 2, Table 1), these results did not hold when controlled for covariates. There was statistically significant mediation by household income and health-care provider communication on the association between race and patient satisfaction: over one-third of the relationship between race and satisfaction was mediated through household income and health care provider communication. Health-care providers asking about work duties is a crucial diagnostic inquiry in order to determine both work-relatedness of injury and subsequent return to work (with or without accommodations). While results did not support all of the study's hypotheses, and were contrary to what has been found in prior studies (Dasinger et al., 2001; A. Kosny et al., 2012), the results do point to areas for future research.

While racial discrimination did not appear to be a fundamental cause of disparities in timeliness of follow-up care, racialized minority status may play an important role in how protective both proactive communication and household income are for minority workers. In prior studies, income has been found to be significantly related to health outcomes (Marmot, 2004). More specifically, income can act alone (in areas with high inequality), or as an indicator of psychosocial phenomena such as social support, or anxiety and depression when income is lacking (Marmot, Bosma, Hemingway, Brunner, 
\& Stansfeld, 1997; Marmot \& Wilkinson, 2001). In addition, these psychosocial factors, along with larger social constraints, have been related to interactional effects between income and race; all of these issues are related to health in the United States (Williams, 1999; Williams \& Collins, 1995).

While I did not find race or racial discrimination to be statistically correlated with all healthcare outcomes, race and more specifically, racial discrimination, are strongly associated with levels of income, as well as psychosocial phenomena (social support, confidence, anxiety, etc.). As this study assessed both racial discrimination and income at one concurrent point in time, it is impossible to ascertain whether racial discrimination was a primary driver of household income. According to FCT, socioeconomic conditions (e.g., income) are basic causes of health disparities (Link \& Phelan, 1995) and racial discrimination is a primary determinant of income (Phelan \& Link, 2015). Therefore, it seems plausible that racial discrimination did have a role to play in the claims processes studied, but was not measured at the correct critical temporal point (e.g., childhood, or life course multiple measures).

More work is needed to understand the results of this study. Issues that may have affected the results include the potentially imprecise outcome definitions used. Case definitions for timeliness and quality of care, while supported by prior work, are not validated measures. The case definition for adequacy of care comes from both standard definitions of clinical practice (ACOEM, 2016) and expert knowledge, but it, too, has not been validated. Validating measures for these outcomes should be the next step for future research. While patient satisfaction is routinely used as an indicator of quality, it can also 
be associated with prior medical mistrust and/or HCP racial concordance with injured workers (Chen, Fryer, Phillips Jr, Wilson, \& Pathman, 2005; LaVeist, Nickerson, \& Bowie, 2000), and not necessarily related to the quality of care they receive.

Significant additional limitations may have also prevented this study from finding support for all hypotheses. It may be that the Washington State WC system is rigidly proscribed, allowing very little discretion in treatment for injured workers. It may also be that there are characteristics unique to WC health-care providers compared to the general health care community. Much of the qualitative work regarding health-care providers and WRII indicates that many physicians do not treat workers under WC systems (Agnieszka Kosny, MacEachen, Ferrier, \& Chambers, 2011; Lax \& Klein, 2008). Some studies have found that WC health-care providers lack communication skills and/or technical competence (Rudolph, Dervin, Cheadle, Maizlish, \& Wickizer, 2002). More work is needed to characterize differences between health care providers who do and do not take workers' compensation patients.

\section{Workers' Compensation Agency}

Chapter 3 details correlations between injured workers and the WC agency and how race or racial discrimination may interact with these correlations. The administrative outcomes examined included timeliness of diagnostic services, timeliness of partial-wage replacement payments, and number of independent medical exams (IMEs). I

hypothesized that racialized minorities would experience longer wait times for diagnostic services and wage-replacement payments and would also have more IMEs than Whites. In addition, this study also hypothesized that minorities would be more likely to have a 
higher count of administrative barriers and that these barriers would result in worse general health.

All hypotheses were supported in this study, with the exception of waiting longer for wage-replacement payments. This study supports the qualitative literature regarding mundane administrative barriers creating a toxic convergence of problems (MacEachen, 2000; MacEachen, Kosny, Ferrier, \& Chambers, 2010), and adds to existing literature by finding increased correlations between racialized minorities experiencing more administrative barriers, including more IMEs than Whites. The statistical nonsignificance of timeliness of wage-replacement payments finding is contrary to what was found in an earlier study that used claim data from the Washington WC agency, the same data source as this study (Bonauto et al., 2010). In the Bonauto et al. analyses, however, they compared total days to payment for low back injuries among claimants who preferred English to claimants who preferred Spanish, not whether or not the time to payment was within the state-mandated, 14-day period, as the current study does.

The current study suggests that administrative barriers appear to be more likely to occur concurrently for minority workers and to be associated with adverse self-reported health outcomes. Whether intentional or unintentional, these administrative barriers have racial implications, suggesting structural racism is at play. It appears that while "mundane" policies with no racial connotation, such as IME use and delays in adjudication, do appear disproportionately among LEP claimants. In other words, while specific deficits exist in the WC agency, they appear to target minorities, thus increasing 
barriers to receiving equitable workers' compensation services (supported by fundamental cause theory).

Further research is needed to confirm these results in a larger sample, and to follow injured workers to determine causality prospectively. While further study is needed, however, specific actions by the WC agency can and should be undertaken now. These include a review of IME utilization and the possible need for more training of WC claims managers to reduce the number of IMEs ordered. Second, improved timeliness of approval for diagnostic services must be a priority in order to ensure both improved care for injured workers and minimal costs to employers. Third, a rigorous examination of policies and procedures (e.g., timeliness of services) and how they negatively affect minorities should be conducted using health-impact reviews for all changes and subsequent new policies and procedures. Finally, as the proportion of LEP speakers in Washington State has doubled since $1980,{ }^{24}$ and the proportion of foreign-born workers in the civilian labor force has tripled since $1990,{ }^{25}$ there is clearly a need for the WC agency to direct more resources toward serving LEP speakers.

While adding to the literature regarding minority injured workers and outcomes associated with the WC agency, this study is not without limitations. The Washington State WC system is unique in the United States as a sole source of WC insurance; there may be significant differences in other state systems. In addition, firms in the state that are allowed to self-insure cover thousands of employees. Data from self-insured firms are

\footnotetext{
${ }^{24}$ Tabulation of the U.S. Census Bureau's 1990 and 2000 Decennial Censuses and 2010 and 2016 American Community Surveys. Accessed 10/10/2018. (Migration Policy Institute, 2018)

${ }^{25}$ (Migration Policy Institute, 2018)
} 
not as complete as state-fund data, so they were not included in this study. There may be significant differences between state-fund and self-insured companies and their handling of WC claims.

\section{The Workplace and Return to Work}

The workplace is the source of injury as well as an important stakeholder for injured workers in successfully returning to active employment. The literature regarding the role of the workplace in the WC systems is vast; with the majority of studies concerned with cutting costs for employers by returning injured workers back to work as quickly as possible (Boden \& Ruser, 2003; Green-McKenzie, Parkerson, \& Bernacki, 1998; Kyes et al., 1999; Wickizer et al., 2004). Workplace discrimination and subsequent labor market effects are well documented, indicating widespread racial discrimination in employment, both in the segregation of racial minorities into lower-wage, higher-hazard occupations, and difficulties in obtaining promotions for both men and women of color (Bonacich, 1972; Browne, Hewitt, Tigges, \& Green, 2001; Fryer et al., 2013). The role of workplace discrimination and how it may affect injury risk is less well documented (Shannon et al., 2009), although occupational segregation is one of the primary explanations for higher risk of injury in minority-concentrated occupations (Lipscomb, Loomis, McDonald, Argue, \& Wing, 2006; Murray, 2003). In addition, the role of workplace support in the return-to-work process has been well documented, although potential differences in how minority workers respond to workplace support are not well studied. Some research, however, has suggested it may matter more to minorities, 
although reasons for this are not explored (Arcury, Grzywacz, Chen, Mora, \& Quandt, 2014).

Each of the bodies of literature mentioned - racial differences in occupational risk, workplace discrimination, return to work, and the role of workplace support-have all been undertaken by different research sub-disciplines. In examining the role of the workplace in the return to work process for minorities, however, it appears important to combine their respective results and test for correlations among them that will help to address the role of workplace racial discrimination in the return-to-work process, as well as the potential role of workplace support to ameliorate discriminatory effects.

Chapter 4 of this dissertation examines these three aspects of occupational injury and return to work for minorities by hypothesizing that workplace racial discrimination before injury would affect an injured workers' perceptions of whether they were returning to work too early or not. The study described in Chapter 4 also tests the hypothesis of whether or not workplace support mediates the effect of discrimination on return to work; support was found for both hypotheses. Those who reported suffering workplace racial discrimination had 2.5 higher odds of feeling they returned to work too early, compared to those who did not suffer racial discrimination in the workplace (Chapter 4, Table 3). Workplace support was found to mediate the effect of workplace racial discrimination, accounting for about half of the effect of workplace discrimination on returning to work too early (Chapter 4, Table 4).

This initial study regarding the role of workplace discrimination suffered before injury and subsequent return-to-work outcomes is an important addition to the literature. 
This current study extends what little we know about reported workplace racial discrimination and its occupational health effects. In one of the few studies to assess the role of racial discrimination and injuries, Shannon et al. found those who reported discrimination were more likely to be injured on the job (Shannon et al., 2009). The current study extended prior work and found significant associations between those who suffered perceived racial discrimination at work and those who felt they returned to work too early (Chapter 4, Table 3, Model 2).

In addition, the current study found significant mediation of racial discrimination and the return-to-work-too-early outcome by having positive return-to-work support from the employer. Clearly, the workplace has an important role to play in the successful return to work of injured workers. While prior racial discrimination is associated with workers feeling they returned to work too early, this can be mediated somewhat if workplaces take the time to reach out to injured workers and be supportive in their return to work. Policies and procedures can be written by both the WC agency and individual workplaces to incentivize an increase in support.

As detailed in Chapter 4, limitations to this study include the simultaneous collection of prior workplace discrimination and return-to-work outcome. It may be that both existed after returning to work, but it is impossible to tell given the nature of crosssectional design. In addition, this study's use of a broad return-to-work support definition makes it unclear which aspects of workplace support are most effective for minorities in creating better return-to-work outcomes. Prior research, however, has found modified duties and working hours to be effective in reducing lost work-time for injured workers 
with low back pain (Anema et al., 2004). Working part-time while recovering, was also found to be effective for those with musculoskeletal disorders (Viikari-Juntura et al., 2012). Systematic reviews of the quantitative and qualitative literature, however, suggest multi-domain (health care, WC agency, and workplace) interventions to be the most likely to succeed (Cullen et al., 2018; MacEachen, Clarke, Franche, \& Irvin, 2006). Before interventions in policies and procedures can be made though, it is important to explore what types of support are the strongest indicators for successfully healing and returning to work, and to see if these vary by racial group status.

\section{Theoretical Considerations}

As noted previously, the lack of a theoretical foundation has been perhaps one of the largest gaps in prior research on the role of racial discrimination and work-related injury outcomes. Using fundamental cause theory (FCT) to frame each study in this dissertation both narrowed the scope and expanded the work of this project. FCT helped to clarify the questions asked of each domain within the WC system and helped to keep the analyses centered on the role of racial discrimination. FCT also expanded the current research and possibilities for future scholarship by placing racial discrimination center stage in a body of literature that has primarily skirted around the issue that racial discrimination has serious consequences in WC systems.

The hypothesis that racism is a fundamental cause of poor WC system outcomes was partially supported in this work, adding to the existing literature regarding racism as a fundamental cause of health inequalities. I found clear correlations between racialized policies in the WC agency and poorer outcomes for LEP workers. In addition, I found 
policies and procedures in the WC agency and the workplace had negative effects on racialized minorities. It is necessary to examine all future policy changes in the workers' compensation system through the lens of health equity for all workers; if we are to reduce inequalities in health outcomes, we must address equity in processes in the workers' compensation agency.

Racial discrimination is an enduring feature in American workplaces that has been linked to a higher risk of suffering a work-related injury. In addition, this dissertation examined multiple mechanisms by which racial discrimination affects WRII outcomes: health-care provider discrimination, structural racism in WC agency policies, and workplace discrimination. This dissertation provides support that racial discrimination works through multiple pathways in the WC system and that multiple potential mechanisms are associated with poor health, administrative and return-to-work outcomes.

\section{Limitations and Future Research}

While study limitations are detailed in each chapter and above, some general dissertation limitations should be noted. First, the lack of significant numbers for each racial, ethnic, and linguistic minority group precluded me from using detailed selfreported race, ethnicity, and language categories, which no doubt would show greater variation than what these studies were able to detect. Second, the cross-sectional nature of this study does not allow conclusions to be drawn about causation. Finally, this study was undertaken using data from a demographically distinct state (Washington) using claims data from a monopolistic state-fund WC system (only Ohio, North Dakota, 
Wyoming, and Puerto Rico have similar monopolistic WC systems) to assess the role of racial discrimination in WC system outcomes. These last limitations may limit the generalizability of my results.

\section{Conclusion}

Work-related injuries are a significant public health problem, yet relatively understudied in the medical sociology literature. While much is known about health-care providers, insurance systems, and medical outcomes for those within general (non-WRII) health-care systems, very little has been written about WRII health care. The majority of WC claimants work in low-wage, high-hazard occupations, with little if any additional safety nets to assist them (Atlas et al., 2007). Minorities are more highly concentrated in these occupations, and yet racial discrimination as a fundamental cause of worse healthcare, administrative, and subsequent return-to-work outcomes is largely missing from the literature. The three studies summarized in this chapter were designed to add racial discrimination analyses to the literature when studying these three primary stakeholders in a WC system. While not all study hypotheses were successfully supported, each study adds to the literature in significant ways.

Chapter 2, the study of racial discrimination by health-care providers, found that perceived racial discrimination was not associated with timeliness or adequacy of health services. This is good news for injured minority workers, yet a closer look at the descriptive statistics in Chapter 2, Table 1 points to a significant failure of health services to provide timely and adequate care to any WC claimant. Significant issues across the board are highlighted in this study. The role of SES proved to be significantly related to 
the effect of racial discrimination in protecting against poor quality (self-reported patient satisfaction), which may be similar to the theory of diminishing returns.

The second major domain studied in this dissertation was the WC agency detailed in Chapter 3. The 'mundane' administrative barriers that lead to 'toxic dose' of problems, as described by MacEachen (2010) were confirmed in this study with significant negative effects for racialized minorities. Worse general health outcomes were found for those with multiple administrative barriers and these barriers clearly have racial implications of disproportionately affecting minority workers.

The third domain of the workplace, detailed in Chapter 4, found significant associations with suffering racial discrimination at work and negative return-to-work outcomes. In addition, a clear policy path (improving workplace support in the RTW process) was shown to mediate the negative effects of racial discrimination on returning to work too early. More research is needed within all domains of WC systems in order to add to and extend the work discussed in this dissertation.

Finally, fundamental cause theory was a useful addition to the existing literature which has been largely conducted without a stated theoretical structure. More studies developed and carried out prospectively using the fundamental cause theory should be conducted in order to further test if racism is a fundamental cause of work-related injury and illness health inequalities. 


\section{References}

ACOEM. (2016). ACOEM's Occupational Medicine Practice Guidelines - 2016 Revision. from The Reed Group https://new.mdguidelines.com/Resources/ACOEM-Practice-Guidelines

Alonso-Villar, O., Del Rio, C., \& Gradin, C. (2012). The Extent of Occupational Segregation in the United States: Differences by Race, Ethnicity, and Gender. Industrial Relations, 51(2), 179-212.

Anema, J., Cuelenaere, B., Van Der Beek, A., Knol, D., De Vet, H., \& Van Mechelen, W. (2004). The effectiveness of ergonomic interventions on return-to-work after low back pain; a prospective two year cohort study in six countries on low back pain patients sicklisted for 3-4 months. Occup Environ Med, 61(4), 289-294.

Angelon-Gaetz, K. A., Richardson, D. B., \& Wing, S. (2010). Inequalities in the nuclear age: impact of race and gender on radiation exposure at the Savannah River Site (1951-1999). New Solut, 20(2), 195-210.

Arcury, T. A., Grzywacz, J. G., Chen, H., Mora, D. C., \& Quandt, S. A. (2014). Work Organization and Health Among Immigrant Women: Latina Manual Workers in North Carolina. American Journal of Public Health, 104(12), 2445-2452. doi:10.2105/AJPH.2013.301587

Atlas, S. J., Tosteson, T. D., Hanscom, B., Blood, E. A., Pransky, G. S., Abdu, W. A., . . . Weinstein, J. N. (2007). What is different about worker's compensation patients? Socioeconomic predictors of baseline disability status among patients with lumbar radiculopathy. Spine, 32(18), 2019-2026.

Beardwood, B. A., Kirsh, B., \& Clark, N. J. (2005). Victims twice over: perceptions and experiences of injured workers. Qual Health Res, 15(1), 30-48.

Bertrand, M., \& Mullainathan, S. (2004). Are Emily and Greg More Employable Than Lakisha and Jamal? A Field Experiment on Labor Market Discrimination. The American Economic Review, 94(4), 991-1013.

Boden, L. I., \& Ruser, J. W. (2003). Workers' compensation "reforms," choice of medical care provider, and reported workplace injuries. Review of Economics and Statistics, 85(4), 923-929.

Bonacich, E. (1972). A theory of ethnic antagonism: the split labor market. American Sociological Review, 37(5), 547-559.

Bonauto, D. K., Smith, C. K., Adams, D. A., Fan, Z. J., Silverstein, B. A., \& Foley, M. P. (2010). Language preference and non-traumatic low back disorders in washington state workers' compensation. American Journal of Industrial Medicine, 53(2), 204-215. doi:10.1002/ajim.20740

Briggs, N. C., Levine, R. S., Hall, H. I., Cosby, O., Brann, E. A., \& Hennekens, C. H. (2003). Occupational Risk Factors for Selected Cancers Among African American and White Men in the United States. American Journal of Public Health, 93(10), 1748-1752. doi:10.2105/AJPH.93.10.1748 
Browne, I., Hewitt, C., Tigges, L., \& Green, G. (2001). Why Does Job Segregation Lead To Wage Inequality among African Americans? Person, Place, Sector, or Skills? Social Science Research, 30(3), 471-495.

Buchanan, S., Vossenas, P., Krause, N., Moriarty, J., Frumin, E., Shimek, J. A. M., . . . Punnett, L. (2010). Occupational injury disparities in the US hotel industry. American Journal of Industrial Medicine, 53(2), 116-125.

Chen, F. M., Fryer, G. E., Phillips Jr, R. L., Wilson, E., \& Pathman, D. E. (2005). Patients' beliefs about racism, preferences for physician race, and satisfaction with care. Annals of Family Medicine, 3(2), 138-143.

Chibnall, J. T., Tait, R. C., Andresen, E. M., \& Hadler, N. M. (2006). Race differences in diagnosis and surgery for occupational low back injuries. Spine, 31(11), 12721275 .

Cullen, K. L., Irvin, E., Collie, A., Clay, F., Gensby, U., Jennings, P. A., . . Amick, B. C. (2018). Effectiveness of Workplace Interventions in Return-to-Work for Musculoskeletal, Pain-Related and Mental Health Conditions: An Update of the Evidence and Messages for Practitioners. J Occup Rehabil, 28(1), 1-15. doi:10.1007/s10926-016-9690-X

Dasinger, L. K., Krause, N., Thompson, P. J., Brand, R. J., \& Rudolph, L. (2001). Doctor proactive communication, return-to-work recommendation, and duration of disability after a workers' compensation low back injury. J Occup Environ Med, 43(6), 515-525.

de Castro, A. B., Fujishiro, K., Sweitzer, E., \& Oliva, J. (2006). How Immigrant Workers Experience Workplace Problems: A Qualitative Study. Archives of Environmental \& Occupational Health, 61(6), 249-258.

Dembe, A. E. (2001). Access to medical care for occupational disorders: difficulties and disparities. J Health Soc Policy, 12(4), 19-33.

Dembe, A. E., Savageau, J. A., Amick, B. C., 3rd, \& Banks, S. M. (2005). Racial and ethnic variations in office-based medical care for work-related injuries and illnesses. Journal of the National Medical Association, 97(4), 498-507.

Fryer, R. G., Pager, D., \& Spenkuch, J. L. (2013). Racial Disparities in Job Finding and Offered Wages. The Journal of Law and Economics, 56(3), 633-689.

Galizzi, M., Leombruni, R., Pacelli, L., \& Bena, A. (2016). Injured workers and their return to work: Beyond individual disability and economic incentives. Evidencebased HRM: a Global Forum for Empirical Scholarship, 4(1), 2-29. doi:doi:10.1108/EBHRM-02-2015-0002

Green-McKenzie, J., Parkerson, J., \& Bernacki, E. (1998). Comparison of workers' compensation costs for two cohorts of injured workers before and after the introduction of managed care. Journal of Occupational and Environmental Medicine, 40(6), 568-572.

Grodsky, E., \& Pager, D. (2001). The structure of disadvantage: Individual and occupational determinants of the black-white wage gap. American Sociological Review, 66(4), 542-567. doi:10.2307/3088922 
Kilgour, E., Kosny, A., McKenzie, D., \& Collie, A. (2014). Healing or Harming? Healthcare Provider Interactions with Injured Workers and Insurers in Workers' Compensation Systems. J Occup Rehabil. doi:10.1007/s10926-014-9521-x

Kilgour, E., Kosny, A., McKenzie, D., \& Collie, A. (2014). Interactions Between Injured Workers and Insurers in Workers' Compensation Systems: A Systematic Review of Qualitative Research Literature. J Occup Rehabil, 1-22. doi:10.1007/s10926014-9513-X

Kmec, J. A. (2003). Minority Job Concentration and Wages. Social Problems, 50(1), 3859.

Kosny, A., MacEachen, E., Ferrier, S., \& Chambers, L. (2011). The role of health care providers in long term and complicated workers' compensation claims. J Occup Rehabil, 21(4), 582-590. doi:10.1007/s10926-011-9307-3

Kosny, A., MacEachen, E., Lifshen, M., Smith, P., Jafri, G. J., Neilson, C., . . Shields, J. (2012). Delicate dances: immigrant workers' experiences of injury reporting and claim filing. Ethn Health, 17(3), 267-290. doi:10.1080/13557858.2011.614327

Krause, N., Dasinger, L. K., \& Neuhauser, F. (1998). Modified Work and Return to Work: A Review of the Literature. J Occup Rehabil, 8(2), 113-139. doi:10.1023/A:1023015622987

Kyes, K. B., Wickizer, T. M., Franklin, G., Cain, K., Cheadle, A., Madden, C., . . . Weaver, M. (1999). Evaluation of the Washington State Workers' Compensation Managed Care Pilot Project I: medical outcomes and patient satisfaction. Med Care, 37(10), 972-981.

LaVeist, T. A., Nickerson, K. J., \& Bowie, J. V. (2000). Attitudes about racism, medical mistrust, and satisfaction with care among African American and white cardiac patients. Medical care research and review : MCRR, 57 Suppl 1, 146-161.

Lax, M. B., \& Klein, R. (2008). More than meets the eye: social, economic and emotional impacts of work-related injury and illness. New Solutions, 18(3), 343-360.

Link, B. G., \& Phelan, J. (1995). Social Conditions as Fundamental Causes of Disease. Journal of Health and Social Behavior, 80-94.

Lipscomb, H. J., Loomis, D., McDonald, M. A., Argue, R. A., \& Wing, S. (2006). A conceptual model of work and health disparities in the United States. Int J Health Serv, 36(1), 25-50.

MacEachen, E. (2000). The mundane administration of worker bodies: from welfarism to neoliberalism. Health, Risk \& Society, 2(3), 315-327.

MacEachen, E., Clarke, J., Franche, R.-L., \& Irvin, E. (2006). Systematic review of the qualitative literature on return to work after injury. Scandinavian journal of work, environment \& health, 257-269.

MacEachen, E., Kosny, A., Ferrier, S., \& Chambers, L. (2010). The "Toxic Dose" of System Problems: Why Some Injured Workers Don't Return to Work as Expected. J Occup Rehabil, 20(3), 349-366.

Marmot, M. (2004). The status syndrome : how social standing affects our health and longevity (1st American ed.). New York, N.Y.: Times Books/Henry Holt. 
Marmot, M., Bosma, H., Hemingway, H., Brunner, E., \& Stansfeld, S. (1997). Contribution of job control and other risk factors to social variations in coronary heart disease incidence. Lancet, 350(9073), 235-239.

Marmot, M., \& Wilkinson, R. G. (2001). Psychosocial and material pathways in the relation between income and health: a response to Lynch et al. BMJ : British Medical Journal, 322(7296), 1233-1236.

Meade, M. A., Lewis, A., Jackson, M. N., \& Hess, D. W. (2004). Race, employment, and spinal cord injury. Arch Phys Med Rehabil, 85(11), 1782-1792.

Migration Policy Institute, M. (2018). Tabulation of the U.S. Census Bureau's 1990 and 2000 Decennial Censuses and 2010 and 2016 American Community Surveys. Retrieved from https://www.migrationpolicy.org/programs/data-hub/usimmigration-trends\#labor

Murray, L. R. (2003). Sick and tired of being sick and tired: scientific evidence, methods, and research implications for racial and ethnic disparities in occupational health. Am J Public Health, 93(2), 221-226.

Orrenius, P. M., \& Zavodny, M. (2009). DO IMMIGRANTS WORK IN RISKIER JOBS? Demography, 46(3), 535-551.

Parrish, M., \& Schofield, T. (2005). Injured workers' experiences of the workers' compensation claims process: institutional disrespect and the neoliberal state. Health Sociology Review, 14(1), 33-46.

Phelan, \& Link, B. G. (2015). Is Racism a Fundamental Cause of Inequalities in Health? Annual Review of Sociology, 41, 311-330.

Premji, S. (2014). Barriers to Return-to-Work for Linguistic Minorities in Ontario: An Analysis of Narratives from Appeal Decisions. J Occup Rehabil, 1-11. doi:10.1007/s10926-014-9544-3

Premji, S., \& Krause, N. (2010). Disparities by ethnicity, language, and immigrant status in occupational health experiences among Las Vegas hotel room cleaners. American Journal of Industrial Medicine, 53(10), 960-975. doi:10.1002/ajim.20860

Premji, S., Messing, K., \& Lippel, K. (2008). Broken English, Broken Bones? Mechanisms Linking Language Proficiency and Occupational Health in a Montreal Garment Factory. International Journal of Health Services, 38(1), 1-19.

Price-Glynn, K., \& Rakovski, C. (2012). Who rides the glass escalator? Gender, race and nationality in the national nursing assistant study. Work, Employment and Society, 26(5), 699-715.

Robinson, J. C. (1987). Trends in Racial Inequality and Exposure to Work-Related Hazards, 1968-1986. The Milbank Quarterly, 65(Supplement 2 (Part 2)), 404-420.

Rousseau, C., ter Kuile, S., Munoz, M., Nadeau, L., Ouimet, M. J., Kirmayer, L., \& Crepeau, F. (2008). Health care access for refugees and immigrants with precarious status: public health and human right challenges. Can J Public Health, 99(4), 290-292. 
Rudolph, L., Dervin, K., Cheadle, A., Maizlish, N., \& Wickizer, T. (2002). What Do Injured Workers Think About Their Medical Care and Outcomes After Work Injury? Journal of Occupational \& Environmental Medicine, 44(5), 425-434.

Seabury, S. A., Terp, S., \& Boden, L. I. (2017). Racial And Ethnic Differences In The Frequency Of Workplace Injuries And Prevalence Of Work-Related Disability. Health Affairs, 36(2), 266-273. doi:10.1377/hlthaff.2016.1185

Shannon, C. A., Rospenda, K. M., Richman, J. A., \& Minich, L. M. (2009). Race, Racial Discrimination, and the Risk of Work-Related Illness, Injury, or Assault: Findings From a National Study. Journal of Occupational \& Environmental Medicine, 51(4), 441-448.

Stewart, Q. T., \& Dixon, J. C. (2010). Is it race, immigrant status, or both? An analysis of wage disparities among men in the United States. International Migration Review, 44(1), 173-201.

Strong, L. L., \& Zimmerman, F. J. (2005). Occupational Injury and Absence From Work Among African American, Hispanic, and Non-Hispanic White Workers in the National Longitudinal Survey of Youth. American Journal of Public Health, 95(7), 1226-1232.

Tait, R. C., Chibnall, J. T., Andresen, E. M., \& Hadler, N. M. (2004). Management of occupational back injuries: differences among African Americans and Caucasians. Pain, 112(3), 389-396. doi:10.1016/j.pain.2004.09.027

Viikari-Juntura, E., Kausto, J., Shiri, R., Kaila-Kangas, L., Takala, E.-P., Karppinen, J., . . . Martimo, K.-P. (2012). Return to work after early part-time sick leave due to musculoskeletal disorders: a randomized controlled trial. Scandinavian journal of work, environment \& health, 134-143.

Wickizer, T. M., Franklin, G., Fulton-Kehoe, D., Turner, J. A., Mootz, R., \& SmithWeller, T. (2004). Patient Satisfaction, Treatment Experience, and Disability Outcomes in a Population-Based Cohort of Injured Workers in Washington State: Implications for Quality Improvement. Health Services Research, 39(4p1), 727748. doi:10.1111/j.1475-6773.2004.00255.x

Williams, D. R. (1999). Race, socioeconomic status and health. The added effects of racism and discrimination. Annals of the New York Academy of Sciences, 896, 173-188.

Williams, D. R., \& Collins, C. (1995). US SOCIOECONOMIC AND RACIALDIFFERENCES IN HEALTH - PATTERNS AND EXPLANATIONS. Annual Review of Sociology, 21, 349-386. 